NASA/CR-2003-212229
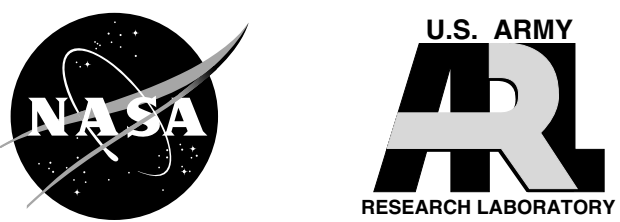

\title{
Modified Involute Helical Gears: \\ Computerized Design, Simulation of Meshing, and Stress Analysis
}

Faydor L. Litvin

University of Illinois at Chicago, Chicago, Illinois

Alfonso Fuentes

Polytehnic University of Cartagena, Cartagena, Spain

Ignacio Gonzalez-Perez, Luca Carnevali, and Kazumasa Kawasaki

University of Illinois at Chicago, Chicago, Illinois 
Since its founding, NASA has been dedicated to the advancement of aeronautics and space science. The NASA Scientific and Technical Information (STI) Program Office plays a key part in helping NASA maintain this important role.

The NASA STI Program Office is operated by Langley Research Center, the Lead Center for NASA's scientific and technical information. The NASA STI Program Office provides access to the NASA STI Database, the largest collection of aeronautical and space science STI in the world. The Program Office is also NASA's institutional mechanism for disseminating the results of its research and development activities. These results are published by NASA in the NASA STI Report Series, which includes the following report types:

- $\quad$ TECHNICAL PUBLICATION. Reports of completed research or a major significant phase of research that present the results of NASA programs and include extensive data or theoretical analysis. Includes compilations of significant scientific and technical data and information deemed to be of continuing reference value. NASA's counterpart of peerreviewed formal professional papers but has less stringent limitations on manuscript length and extent of graphic presentations.

- TECHNICAL MEMORANDUM. Scientific and technical findings that are preliminary or of specialized interest, e.g., quick release reports, working papers, and bibliographies that contain minimal annotation. Does not contain extensive analysis.

- CONTRACTOR REPORT. Scientific and technical findings by NASA-sponsored contractors and grantees.
- CONFERENCE PUBLICATION. Collected papers from scientific and technical conferences, symposia, seminars, or other meetings sponsored or cosponsored by NASA.

- SPECIAL PUBLICATION. Scientific, technical, or historical information from NASA programs, projects, and missions, often concerned with subjects having substantial public interest.

- TECHNICAL TRANSLATION. Englishlanguage translations of foreign scientific and technical material pertinent to NASA's mission.

Specialized services that complement the STI Program Office's diverse offerings include creating custom thesauri, building customized databases, organizing and publishing research results ... even providing videos.

For more information about the NASA STI Program Office, see the following:

- Access the NASA STI Program Home Page at http://www.sti.nasa.gov

- E-mail your question via the Internet to help@sti.nasa.gov

- Fax your question to the NASA Access Help Desk at 301-621-0134

- Telephone the NASA Access Help Desk at 301-621-0390

- Write to:

NASA Access Help Desk

NASA Center for AeroSpace Information 7121 Standard Drive

Hanover, MD 21076 
NASA/CR-2003-212229
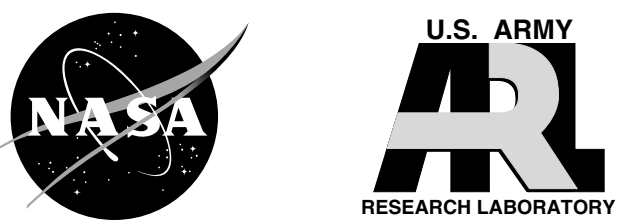

\section{Modified Involute Helical Gears: \\ Computerized Design, Simulation of Meshing, and Stress Analysis}

Faydor L. Litvin

University of Illinois at Chicago, Chicago, Illinois

Alfonso Fuentes

Polytechnic University of Cartagena, Cartagena, Spain

Ignacio Gonzalez-Perez, Luca Carnevali, and Kazumasa Kawasaki

University of Illinois at Chicago, Chicago, Illinois

Prepared under Grant NAG3-2450

National Aeronautics and

Space Administration

Glenn Research Center 


\section{Acknowledgments}

The authors express their deep gratitude to NASA Glenn Research Center, the U.S. Army Research Laboratory, Vehicle Propulsion Directorate, and the Gleason Foundation for the financial support of this research project.

The Propulsion and Power Program at NASA Glenn Research Center sponsored this work.

Available from

NASA Center for Aerospace Information 7121 Standard Drive

Hanover, MD 21076
National Technical Information Service 5285 Port Royal Road Springfield, VA 22100

Available electronically at http:/ /gltrs.grc.nasa.gov 


\title{
Modified Involute Helical Gears: Computerized Design, Simulation of Meshing, and Stress Analysis
}

\author{
Faydor L. Litvin, Ignacio Gonzalez-Perez, \\ Luca Carnevali, and Kazumasa Kawasaki \\ University of Illinois at Chicago \\ Gear Research Center, Department of Mechanical and Industrial Engineering \\ Chicago, Illinois \\ Alfonso Fuentes-Aznar* \\ Polytechnic University \\ Department of Mechanical Engineering \\ Cartagena, Spain
}

\begin{abstract}
The computerized design, methods for generation, simulation of meshing, and enhanced stress analysis of modified involute helical gears is presented. The approaches proposed for modification of conventional involute helical gears are based on conjugation of double-crowned pinion with a conventional helical involute gear. Double-crowning of the pinion means deviation of cross-profile from an involute one and deviation in longitudinal direction from a helicoid surface. Using the method developed, the pinion-gear tooth surfaces are in point-contact, the bearing contact is localized and oriented longitudinally, and edge contact is avoided. Also, the influence of errors of alignment on the shift of bearing contact, vibration, and noise are reduced substantially. The theory developed is illustrated with numerical examples that confirm the advantages of the gear drives of the modified geometry in comparison with conventional helical involute gears.
\end{abstract}

\section{Nomenclature}

$\alpha_{i}(\mathrm{i}=\mathrm{d}, \mathrm{c}) \quad$ normal pressure angle for the driving profile $(\mathrm{i}=\mathrm{d})$ or the coast profile $(\mathrm{i}=\mathrm{c})$ at the point of tangency of mismatched rack-cutters

$\beta \quad$ helix angle

$\gamma_{D p} \quad$ crossing angle between the disk and the pinion

$\gamma_{w p} \quad$ crossing angle between the worm and the pinion

$\lambda_{i}(\mathrm{i}=\mathrm{p}, \mathrm{w}) \quad$ lead angle of the pinion $(\mathrm{i}=\mathrm{p})$ or of the worm $(\mathrm{i}=\mathrm{w})$

$\rho_{D} \quad$ radius of generating disk

*Corresponding author, Universidad Politecnica de Cartagena, Departamento de Ingenieria Mecanica, Campus Universitario Muralla del Mar,

C/ Doctor Fleming, s/n - 30202 Cartagena, Spain, Tel: +34 968 326432; Fax: +34 968 326449; E-mail: alfonso.fuentes@upct.es 
$\phi_{i}(\mathrm{i}=1,2) \quad$ angle of rotation of the pinion $(\mathrm{i}=1)$ or the gear $(\mathrm{i}=2)$ in the process of meshing

$\psi_{i}(\mathrm{i}=\sigma, 1,2) \quad$ angle of rotation of the profile-crowned pinion $(\mathrm{i}=\sigma)$, the double-crowned pinion $(\mathrm{i}=1)$ or the profile-crowned gear $(\mathrm{i}=2)$ in the process of generation

$\Delta \gamma$

$\Delta \lambda$ shaft angle error

$\Delta \lambda_{i}(\mathrm{i}=1,2) \quad$ correction of lead angle of the pinion $(\mathrm{i}=1)$ or the gear $(\mathrm{i}=2)$

$\Delta \phi_{2}\left(\phi_{1}\right)$

$\Delta \psi_{p}$

$\Delta \mathbf{s}_{w}$

$\Delta E$

$\Sigma_{i}$

$a_{c}$

$a_{m r}$

$a_{p l}$

$b$

$E_{D p}$

$E_{w p}$

$l_{d}, l_{c}$

$l_{p}$

$m$

$m_{12}, m_{w p}$

$\mathbf{M}_{i j}$

$\mathbf{n}_{i}^{(j)}, \mathbf{N}_{i}^{(j)}$

$N_{i}$

$p_{1}, p_{2}$

$r_{i}$

$r_{d 1}$

$r_{i}^{*}$

$\mathbf{r}_{i}$

$s_{a}$

$s_{i}$

$S_{1}, S_{2}$

$S_{i}\left(O_{i} ; x_{i}, y_{i}, z_{i}\right)$

$\left(u_{i}, \theta_{i}\right)$

function of transmission errors

additional rotational motion of the pinion during the feed motion

translational motion of the grinding worm during the feed motion

center distance error

surfaces $(\mathrm{i}=\mathrm{c}, \mathrm{t}, \sigma, \tau, 1,2, \mathrm{w}, \mathrm{D})$

parabola coefficient of profiles of pinion rack-cutter in its normal section

parabola coefficient of the parabolic function for the modified roll of feed

motion

parabola coefficient of plunging by grinding disk or by grinding worm

parameter of relative thickness of pinion and gear rack-cutters

shortest center distance between the disk and the pinion

shortest center distance between the worm and the pinion

parameters of location of points of tangency $Q$ and $Q^{*}$, respectively

translational motion of the pinion during the generation by grinding disk

module

gear ratios between pinion and gear and between worm and pinion, respectively

matrix of coordinate transformation from system $S_{j}$ to system $S_{i}$

unit normal and normal to surface $\Sigma_{j}$ in coordinate system $S_{i}$

number of teeth of pinion $(i=1, p)$ or gear $(i=2)$ or worm $(i=w)$

screw parameters of the pinion and the gear, respectively

radius of pinion $(i=p 1, p)$, gear $(i=p 2)$ or worm $(i=w)$ pitch cylinder

dedendum radius of the pinion

radius of pinion $(i=p 1)$ or gear $(i=p 2)$ operating circle

position vector of a point in coordinate system $S_{i}$

parameter of pinion topland

displacement of pinion $(\mathrm{i}=\mathrm{c})$ or gear $(\mathrm{i}=\mathrm{t})$ rack-cutter during the generation

of profile crowned pinion or gear, respectively

dimensions of pinion and gear rack-cutter teeth, respectively

coordinate system ( $\mathrm{i}=\mathrm{a}, \mathrm{b}, \mathrm{c}, \mathrm{e}, \mathrm{k}, \mathrm{t}, \mathrm{m}, \sigma, \tau, 1,2, \mathrm{f}, \mathrm{q}, \mathrm{h}, \mathrm{D})$

parameters of surface $\Sigma_{i}$ 


\section{Basic Ideas of Proposed Approaches}

Involute gears, spur and helical ones, are widely applied in reducers, planetary gear trains, transmissions and many other industrial applications. Evolution of the design and manufacture of such gears by hobbing, shaping, and grinding has been impressive. Geometry, design and manufacture of helical gears was the subject of research represented in the works of references $[2,8,10,11,14]$ and many others.

The advantage of involute gearing in comparison with the cycloidal one is that the change of center distance does not cause transmission errors. However, the practice of design and the test of bearing contact and transmission errors show the need for modification of involute gearing, particularly, of helical gears.

The existing design and manufacture of involute helical gears provide instantaneous contact of tooth surfaces along a line. The instantaneous line of contact of conjugated tooth surfaces is a straight line $L_{0}$ that is the tangent to the helix on the base cylinder (Fig. 1). The normals to the tooth surface at any point of line $L_{0}$ are collinear and they intersect in the process of meshing the instantaneous axis of relative motion that is the tangent to the pitch cylinders. The concept of pitch cylinders is discussed in Section 2.

Involute gearing is sensitive to the following errors of assembly and manufacture: (1) the change $\Delta \gamma$ of the shaft angle, and (2) the variation of the screw parameter (of one of the mating gears). Such errors cause discontinuous linear functions of transmission errors which result in vibration and noise, and may cause as well edge-contact wherein meshing of a curve and a surface occurs instead of surface-to-surface contact.

New approaches for computerized design, generation and application of the finite element method for stress analysis of modified involute helical gears are proposed.

The basic ideas proposed in the developed approaches are as follows:

(1) Line contact of tooth surfaces is substituted by instantaneous point contact.

(2) The point contact of tooth surfaces is achieved by crowning of the pinion in profile and longitudinal directions. The tooth surface of the gear is a conventional screw involute surface.

(3) Profile crowning provides localization of bearing contact and the path of contact on the tooth surface of the pinion or the gear is oriented longitudinally.

(4) Longitudinal crowning provides a parabolic function of transmission errors of the gear drive. Such a function absorbs discontinuous linear functions caused by misalignment and therefore reduces noise and vibration. Figures 2(a) and 2(b) illustrate the profile-crowned and double-crowned pinion tooth surface.

(5) Profile crowning of pinion tooth surface is achieved by deviation of the generating tool surface in profile direction. Longitudinal crowning of pinion tooth surface can be achieved by: (a) plunging of the tool or (b) application of modified roll. 
(6) A procedure for stress analysis has been enhanced by the automatic development of the contacting model for several pairs of teeth. The derivation of the model is based on application of the equations of the tooth surfaces; computer aided design codes for building the model are not required. Figure 3 shows the contacting model of five pairs of teeth developed for stress analysis. Details of application of the proposed approaches are represented in Section 9. Figure 4 shows a modified helical gear-drive in $3 \mathrm{D}$ space.

\section{Axodes of Helical Gears and Rack-Cutters}

Introduction. The concept of generation of pinion and gear tooth surfaces is based on application of rack-cutters. The idea of the rack-cutters is the basis for design of such generating tools as disks and worms.

The concept of axodes is applied wherein meshing and generation of helical gears are considered.

Figure 5(a) shows that gears 1 and 2 perform rotation about parallel axes with angular velocities $\boldsymbol{\omega}^{(1)}$ and $\boldsymbol{\omega}^{(2)}$ with the ratio $\varpi^{(1)} / \varpi^{(2)}=m_{12}$ where $m_{12}$ is the gear ratio. The axodes of the gears are two cylinders of radii $r_{p 1}$ and $r_{p 2}$ and the line of tangency of the cylinders designated as $P_{1}-P_{2}$ is the instantaneous axis of rotation [7]. The axodes roll over each other without sliding.

The rack-cutter and the gear being generated perform related motions:

$$
\text { translational motion with velocity }
$$

$$
\mathbf{v}=\boldsymbol{\omega}^{(1)} \times \overline{O_{1} P}=\boldsymbol{\omega}^{(2)} \times \overline{O_{2} P}
$$

where $P$ belongs to $P_{1}-P_{2}$.

(2) rotation with angular velocity $\omega^{(i)}(i=1,2)$ about the axis of the gear.

The axode of the rack-cutter in meshing with gear $i$ is plane $\Pi$ that is tangent to gear axodes.

In the existing design, one rack-cutter with straight-line profile is applied for the generation of the pinion and gear tooth surfaces. Then, the tooth surfaces are in line-contact and edge-contact in a misaligned gear drive is inevitable.

Point contact in the proposed design (instead of line contact) is provided by application of two mismatched rack-cutters as shown in Fig. 5(b), one of a straight-line profile for the generation of the gear and the other one of a parabolic profile for the generation of the pinion. Such method of generation provides a profile-crowned pinion.

It will be shown later (see Sections 5 and 6) that the pinion in the proposed new design is doublecrowned (longitudinal crowning is provided in addition to profile crowning). Double-crowning of the pinion (proposed in [9]) avoids edge contact and provides a favorable function of transmission errors. 
Normal and Transverse Sections. The normal section $a-a$ of the rack-cutter is obtained by a plane that is perpendicular to plane $\Pi$ and orientated by the helix angle $\beta$ (Fig. 5(b)). The transverse section of the rack-cutter is determined as a section by a plane that has the orientation of $b-b$ (Fig. 5(b)).

Mismatched Rack-Cutters. Figure 6(a) shows the profiles of the normal sections of the mismatched rack-cutters. The profiles of the pinion and gear rack-cutters are shown in Figs. 6(b) and 6(c), respectively. Dimensions $s_{1}$ and $s_{2}$ are related by module $m$ and parameter $b$ as follows

$$
\begin{gathered}
s_{1}+s_{2}=\pi m \\
b=\frac{s_{1}}{s_{2}}
\end{gathered}
$$

Parameter $b$, that is chosen in the process of optimization, relates pinion and gear tooth thicknesses and it can be varied to modify the relative rigidity. In a conventional case of design, we choose $b=1$.

The rack-cutter for the gear generation is a conventional one and has a straight line profile in the normal section. The rack-cutter for the pinion is provided by a parabolic profile. The profiles of the rack-cutters are in tangency at points $Q$ and $Q^{*}$ (Fig. 6(a)) that belong to the normal profiles of driving and coast sides of the teeth, respectively. The common normal to the profiles passes through point $P$ that belongs to the instantaneous axis of rotation $P_{1}-P_{2}$ (Fig. 5(a)).

Pinion Parabolic Rack-Cutter. The parabolic profile of pinion rack-cutter is represented in parametric form in an auxiliary coordinate system $S_{a}\left(x_{a}, y_{a}\right)$ as follows (Fig. 7)

$$
x_{a}=a_{c} u_{c}^{2}, \quad y_{a}=u_{c}
$$

where $a_{c}$ is the parabola coefficient. The origin of $S_{a}$ coincides with $Q$.

The surface of the rack-cutter is designated by $\Sigma_{c}$ and is derived as follows:

(1) The mismatched profiles of pinion and gear rack-cutters are represented in Fig. 6(a). The pressure angles are $\alpha_{d}$ for the driving profile and $\alpha_{c}$ for the coast profile. The locations of points $Q$ and $Q^{*}$ are designated by $|\overrightarrow{Q P}|=l_{d}$ and $\left|\overrightarrow{Q^{*} P}\right|=l_{c}$ where $l_{d}$ and $l_{c}$ are defined as

$$
\begin{aligned}
& l_{d}=\frac{\pi m}{1+b} \cdot \frac{\sin \alpha_{d} \cos \alpha_{d} \cos \alpha_{c}}{\sin \left(\alpha_{d}+\alpha_{c}\right)} \\
& l_{c}=\frac{\pi m}{1+b} \cdot \frac{\sin \alpha_{c} \cos \alpha_{c} \cos \alpha_{d}}{\sin \left(\alpha_{d}+\alpha_{c}\right)}
\end{aligned}
$$


(2) Coordinate systems $S_{a}$ and $S_{b}$ are located in the plane of the normal section of the rackcutter (Fig. 6(b)). The normal profile is represented in $S_{b}$ by the matrix equation

$$
\mathbf{r}_{b}\left(u_{c}\right)=\mathbf{M}_{b a} \mathbf{r}_{a}\left(u_{c}\right)=\mathbf{M}_{b a}\left[\begin{array}{llll}
a_{c} u_{c}^{2} & u_{c} & 0 & 1
\end{array}\right]^{\mathrm{T}}
$$

(3) The rack-cutter surface $\Sigma_{c}$ is represented in coordinate system $S_{c}$ (Fig. 8) wherein the normal profile performs translational motion along $c-c$. Then we obtain that surface $\Sigma_{c}$ is determined by vector function

$$
\mathbf{r}_{c}\left(u_{c}, \theta_{c}\right)=\mathbf{M}_{c b}\left(\theta_{c}\right) \mathbf{r}_{b}\left(u_{c}\right)=\mathbf{M}_{c b}\left(\theta_{c}\right) \mathbf{M}_{b a} \mathbf{r}_{a}\left(u_{c}\right)
$$

Gear Rack-Cutter. We apply coordinate systems $S_{e}$ and $S_{k}$ (Fig. 6(c)) and coordinate system $S_{t}$ (Fig. 9(b)). The straight-line profile of gear rack-cutter is represented in parametric form in coordinate system $S_{e}\left(x_{e}, y_{e}\right)$ as:

$$
x_{e}=0, \quad y_{e}=u_{t}
$$

The coordinate transformation from $S_{k}$ to $S_{t}$ is similar to transformation from $S_{b}$ to $S_{c}$ (Fig. 8) and the gear rack-cutter surface is represented by the following matrix equation

$$
\mathbf{r}_{t}\left(u_{t}, \theta_{t}\right)=\mathbf{M}_{t k}\left(\theta_{t}\right) \mathbf{M}_{k e} \mathbf{r}_{e}\left(u_{t}\right)
$$

\section{Profile Crowned Pinion and Gear Tooth Surfaces}

The profile crowned pinion and gear tooth surfaces are designated as $\Sigma_{\sigma}$ and $\Sigma_{2}$, respectively, wherein $\Sigma_{1}$ indicates the pinion double-crowned surface.

Generation of $\Sigma_{\sigma}$. Profile crowned pinion tooth surface $\Sigma_{\sigma}$ is generated as the envelope to the pinion rack-cutter surface $\Sigma_{c}$. The derivation of $\Sigma_{\sigma}$ is based on the following considerations:

(1) Movable coordinate systems $S_{c}\left(x_{c}, y_{c}\right)$ and $S_{\sigma}\left(x_{\sigma}, y_{\sigma}\right)$ are rigidly connected to the pinion rack-cutter and the pinion, respectively (Fig. 9(a)). The fixed coordinate system $S_{m}$ is rigidly connected to the cutting machine.

(2) The rack-cutter and the pinion perform related motions, as shown in Fig. 9(a), where $s_{c}=r_{p 1} \psi_{\sigma}$ is the displacement of the rack-cutter in its translational motion, and $\psi_{\sigma}$ is the angle of rotation of the pinion.

(3) A family of rack-cutter surfaces is generated in coordinate system $S_{\sigma}$ and is determined by the matrix equation

$$
\mathbf{r}_{\sigma}\left(u_{c}, \theta_{c}, \psi_{\sigma}\right)=\mathbf{M}_{\sigma c}\left(\psi_{\sigma}\right) \mathbf{r}_{c}\left(u_{c}, \theta_{c}\right)
$$


(4) The pinion tooth surface $\Sigma_{\sigma}$ is determined as the envelope to the family of surfaces $\mathbf{r}_{\sigma}\left(u_{c}, \theta_{c}, \psi_{\sigma}\right)$ and is represented by the simultaneous consideration of vector function $\mathbf{r}_{\sigma}\left(u_{c}, \theta_{c}, \psi_{\sigma}\right)$ and the equation of meshing

$$
f_{c \sigma}\left(u_{c}, \theta_{c}, \psi_{\sigma}\right)=0
$$

Equation $f_{c \sigma}=0$ may be determined applying one of two alternative approaches:

(a) The common normal to surfaces $\Sigma_{c}$ and $\Sigma_{\sigma}$ at their line of tangency must pass through the instantaneous axis of rotation $P_{1}-P_{2}$ (Fig. 5(a)) (see [7]).

(b) The second approach is based on the representation of equation of meshing as

$$
\mathbf{N}_{c} \cdot \mathbf{v}_{c}^{(c \sigma)}=0
$$

Here: $\mathbf{N}_{c}$ is the normal to $\Sigma_{c}$ represented in $S_{c} ; \mathbf{v}_{c}^{(c \sigma)}$ is the relative velocity represented in $S_{c}$.

Generation of Gear Tooth Surface $\Sigma_{2}$. The schematic of generation of $\Sigma_{2}$ is represented in Fig. 9(b). Surface $\Sigma_{2}$ is represented by the following two equations considered simultaneously:

$$
\begin{gathered}
\mathrm{r}_{2}\left(u_{t}, \theta_{t}, \psi_{2}\right)=\mathbf{M}_{2 t}\left(\psi_{2}\right) \mathbf{r}_{t}\left(u_{t}, \theta_{t}\right) \\
f_{t 2}\left(u_{t}, \theta_{t}, \psi_{2}\right)=0
\end{gathered}
$$

Here: vector equation $\mathbf{r}_{t}\left(u_{t}, \theta_{t}\right)$ represents the gear rack-cutter surface $\Sigma_{t} ;\left(u_{t}, \theta_{t}\right)$ are the surface parameters of $\Sigma_{t}$; matrix $\mathbf{M}_{2 t}\left(\psi_{2}\right)$ represents the coordinate transformation from $S_{t}$ to $S_{2} ; \psi_{2}$ is the generalized parameter of motion. Equations (14) and (15) represent surface $\Sigma_{2}$ by three related parameters. The gear tooth surface may be represented as well in two-parameter form describing it as a ruled surface generated by a tangent to the helix on the base cylinder (see [7]).

Necessary and Sufficient Conditions of Existence of Envelope to a Parametric Family of Surfaces. Such conditions in the case of profile crowned pinion tooth surface $\Sigma_{\sigma}$ are formulated as follows (see [6], [7], and [16]):

(1) Vector function $\mathbf{r}_{\sigma}\left(u_{c}, \theta_{c}, \psi_{\sigma}\right)$ of class $C^{2}$ is considered.

(2) We designate by point $M\left(u_{c}^{(0)}, \theta_{c}^{(0)}, \psi_{c}^{(0)}\right)$ the set of parameters that satisfy the equation of meshing (12) at $M$ and satisfy as well the following conditions (see items (3) to (5)). 
(3) Generating surface $\Sigma_{c}$ of the rack-cutter is a regular one and we have at $M$ that

$$
\frac{\partial \mathbf{r}_{c}}{\partial u_{c}} \times \frac{\partial \mathbf{r}_{c}}{\partial \theta_{c}} \neq 0
$$

Vectors $\partial \mathbf{r}_{c} / \partial u_{c}$ and $\partial \mathbf{r}_{c} / \partial \theta_{c}$ represent in coordinate systems $S_{\sigma}$ tangents to coordinate lines of rack-cutter surface $\Sigma_{c}$. Inequality (16) means that normal $\mathbf{N}_{\sigma}^{(c)}$ to surface $\Sigma_{c}$ differs from zero. The designations of $\mathbf{N}_{\sigma}^{(c)}$ indicate that the normal to $\Sigma_{c}$ is represented in coordinate system $S_{\sigma}$.

(4) Partial derivatives of the equation of meshing (12) satisfy at $M$ the inequality

$$
\left|\frac{\partial f_{c \sigma}}{\partial u_{c}}\right|+\left|\frac{\partial f_{c \sigma}}{\partial \theta_{c}}\right| \neq 0
$$

(5) Singularities of surface $\Sigma_{\sigma}$ are avoided by using the procedure described in Section 8 .

By observation of conditions (1) to (5), the envelope $\Sigma_{\sigma}$ is a regular surface, it contacts the generating surface $\Sigma_{c}$ along a line and the normal to $\Sigma_{\sigma}$ is collinear to the normal of $\Sigma_{c}$. Vector function $\mathbf{r}_{\sigma}\left(u_{c}, \theta_{c}, \psi_{\sigma}\right)$ and Eq. (12) considered simultaneously represent surface $\Sigma_{\sigma}$ in three-parameter form, by three related parameters $\left(u_{c}, \theta_{c}, \psi_{\sigma}\right)$.

Representation of Envelope $\Sigma_{\sigma}$ in Two-Parameter Form. The profile-crowned surface $\Sigma_{\sigma}$ may be represented as well in two parameter form taking into account the following considerations:

(1) Assume that inequality (17) is observed, say, because

$$
\frac{\partial f_{c \sigma}}{\partial \theta_{c}} \neq 0
$$

(2) The theorem of implicit function systems existence [4] yields that due to observation of inequality (18) equation of meshing (12) may be solved in the neighborhood of point $M$ by function

$$
\theta_{c}=\theta_{c}\left(u_{c}, \psi_{\sigma}\right)
$$

(3) Then, surface $\Sigma_{\sigma}$ can be represented as

$$
\mathbf{R}_{\sigma}\left(u_{c}, \psi_{\sigma}\right)=\mathbf{r}_{\sigma}\left(u_{c}, \theta_{c}\left(u_{c}, \psi_{\sigma}\right), \psi_{\sigma}\right)
$$


Similar representations of pinion tooth surfaces may be obtained for the case wherein inequality (17) is observed if $\partial f_{c \sigma} / \partial u_{c} \neq 0$ instead of inequality (18). The pinion profile crowned tooth surface in this case may be represented as

$$
\mathbf{R}_{\sigma}\left(\theta_{c}, \psi_{\sigma}\right)=\mathbf{r}_{\sigma}\left(u_{c}\left(\theta_{c}, \psi_{\sigma}\right), \theta_{c}, \psi_{\sigma}\right)
$$

\section{Tooth Contact Analysis (TCA) of Pinion-Gear Profile-Crowned Tooth Surfaces}

Meshing of Profile-Crowned Helicoids: Conceptual Considerations. Two profilecrowned helicoids are considered. The concept of the meshing is based on the following considerations discussed in [5], [6], [7] and [13]:

(1) The helicoids transform rotation between parallel axes.

(2) The helicoid tooth surfaces are in point contact and this is achieved by the modification of the cross-profile of the pinion tooth surface.

This statement is illustrated for the example in Fig. 10 wherein an involute helicoid of the gear and pinion modified helicoid are shown. Profile crowning of the pinion is provided because the cross-profile is deviated from the involute profile. The gear and the pinion tooth surfaces are in point contact provided by mismatched crossed profiles.

(3) The formation of each of the mating helicoids may be represented as the result of screw motion of the cross-profile. Figure 11 shows the formation of a helicoid by a family of planar curves that perform a screw motion about the axis of the helicoid.

(4) The screw parameters $p_{1}$ and $p_{2}$ of the profile-crowned helicoids have to be related as

$$
\frac{p_{1}}{p_{2}}=\frac{\omega^{(2)}}{\omega^{(1)}}
$$

where $\omega^{(i)}(i=1,2)$ is the angular velocity of the helicoid.

(5) The common normal to the cross-profiles at point $M$ of tangency of profiles passes through point $I$ of tangency of the centrodes (Fig. 10).

(6) It is easy to verify that during the process of meshing, point $M$ of tangency of crossprofiles performs in the fixed coordinate system a translational motion along a straight line that passes through $M$ and is parallel to the axes of aligned gears. The motion of a contact point along line $M-M$ may be represented by two components:

(i) transfer motion with gear $i(i=1,2)$ that is performed as rotation about the gear axis. 
(ii) relative motion with respect to the helicoid surface that is a screw motion with parameter $p_{i}$.

The screw motion by its nature represents a combination of rotation about the gear axis with angular velocity designated as $\Omega^{(i)}$ and translational motion with the velocity $p_{i} \Omega^{(i)}$.

The resulting motion of the contact point in the fixed coordinate system is a translational motion with the velocity $p_{i} \Omega^{(i)}$ along line $M-M$ since rotations in transfer and relative motions are performed with $\boldsymbol{\Omega}^{(i)}=-\boldsymbol{\omega}^{(i)}$.

(7) It is easy to verify that the contact point moves over the helicoid surface along a helix that is generated by point $M$ while it performs a screw motion over the surface of the helicoid.

The path of contact on the surface of the helicoid is a helix which radius $\rho_{i}$ and the lead angle $\lambda_{i}$ are related by $p_{i}=\rho_{i} \tan \lambda_{i}(i=1,2)$.

(8) The meshing of the mating helicoids is not sensitive to the change of the center distance. Considering the drawings of Fig. 12, it is easy to verify that the change of the center distance does not cause transmission errors.

We may assume that the crossing profiles form a center distance $E^{*} \neq E$. This may affect that the point of tangency will be $M^{*}$ instead of $M$ and the pressure angle will be $\alpha^{*}$ instead of $\alpha$.

The new radii of centrodes will be $r_{p i}^{*}(i=1,2)$.

However, the line of action in the fixed coordinate system is again a straight line that is parallel to the gear axes, but passes now through point $M^{*}$ instead of $M$. The line of action is the set of points of tangency of meshing surfaces in fixed coordinate system.

(9) Considering the contact of helicoid surfaces in the 3D space, we will find out that the surfaces have a common normal and common position vectors at any point of surface tangency.

The normal during the process of meshing does not change its orientation in the fixed coordinate system.

(10) Although the profile crowned helicoids are not sensitive to the change of center distance and the surface contact is localized, such type of gearing should not be applied because the change of the shaft angle and the difference of lead angles will cause a discontinuous linear function of transmission errors (see below). Then, vibration and noise become inevitable.

This is the reason why a double-crowned pinion has to be applied instead of a profile only crowned one. Application of double-crowned pinion provides a parabolic 
function of transmission errors and the linear function of transmission errors becomes to be absorbed (see Section 7).

(11) The conceptual considerations of meshing of profile-crowned helicoids are true for all types of Novikov-Wildhaber gears, including the meshing of modified involute helical gears.

(12) The analytical investigation of profile-crowned modified helical gears is accomplished by application of TCA (see below).

Algorithm of Analytical Simulation. The algorithm is based on conditions of continuous tangency of contacting tooth surfaces of the pinion and the gear [6,7]. The meshing and contact are simulated in the paper for two cases: (1) the pinion of the gear drive is profile-crowned, and (2) the pinion is double-crowned (see Sections 5, 6, and 7). Comparison of the output for both cases (Sections 4 and 7) shows that double-crowning of the pinion reduces the transmission errors, noise, and vibration of the gear drive.

Drawings of Fig. 13 illustrate instantaneous tangency of surface $\Sigma_{\sigma}$ and $\Sigma_{2}$ in a fixed coordinate system $S_{f}$. The surfaces have to be represented in $S_{f}$ taking into account the errors of alignment (see Fig. 14).

Knowing the representation of tooth surfaces $\Sigma_{\sigma}$ and $\Sigma_{2}$ in coordinate systems $S_{\sigma}$ and $S_{2}$ that are rigidly connected to the pinion and the gear, we may represent surfaces $\Sigma_{\sigma}$ and $\Sigma_{2}$ in fixed coordinate system $S_{f}$. We use, for this purpose, the coordinate transformation from $S_{\sigma}$ and $S_{2}$ to $S_{f}$.

It is supposed that $\Sigma_{\sigma}$ and $\Sigma_{2}$ are profile crowned and therefore they are in point tangency. Tangency of $\Sigma_{\sigma}$ and $\Sigma_{2}$ at common point $M$ means that they have at $M$ the same position vector and the surface normals are collinear. Then we obtain the following system of vector equations [7]:

$$
\begin{gathered}
\mathbf{r}_{f}^{(\sigma)}\left(u_{c}, \theta_{c}, \psi_{\sigma}, \phi_{\sigma}\right)-\mathbf{r}_{f}^{(2)}\left(u_{t}, \theta_{t}, \psi_{2}, \phi_{2}\right)=\mathbf{0} \\
\mathbf{N}_{f}^{(\sigma)}\left(u_{c}, \psi_{\sigma}, \phi_{\sigma}\right)-v \mathbf{N}_{f}^{(2)}\left(u_{t}, \psi_{2}, \phi_{2}\right)=\mathbf{0} \\
f_{c \sigma}\left(u_{c}, \theta_{c}, \psi_{\sigma}\right)=0 \\
f_{t 2}\left(u_{t}, \theta_{t}, \psi_{2}\right)=0
\end{gathered}
$$

Here: $f_{c \sigma}=0, f_{t 2}=0$ are the equations of meshing of the pinion and gear with the respective generating rack-cutters $\Sigma_{c}$ and $\Sigma_{t} ; \phi_{\sigma}$ and $\phi_{2}$ are the angles of rotation of the profile crowned pinion and gear; $v \neq 0$ is a scalar factor in the equation of collinearity of surface normals.

One of the parameters, say $\phi_{\sigma}$, is chosen as the input one. The Jacobian $D$ of the system of scalar equations obtained from equations (23) - (26) has to differ from zero as the precondition of point 
tangency of surfaces $\Sigma_{\sigma}$ and $\Sigma_{2}$. In accordance to the theorem of implicit function system existence [4], observation of inequality $D \neq 0$ permits the solution of the system of equations (23) - (26) by functions

$$
\left\{u_{c}\left(\phi_{\sigma}\right), \theta_{c}\left(\phi_{\sigma}\right), \psi_{\sigma}\left(\phi_{\sigma}\right), u_{t}\left(\phi_{\sigma}\right), \theta_{t}\left(\phi_{\sigma}\right), \psi_{2}\left(\phi_{\sigma}\right), \phi_{2}\left(\phi_{\sigma}\right)\right\} \in C^{1}
$$

Solution of system of nonlinear equations (23) - (26) is accomplished using the Newton-Raphson method [15]. The computational procedure provides the paths of contact on pinion and gear tooth surfaces and the function of transmission errors.

For the simulation of meshing the following coordinate systems have been applied (Fig. 14):

(1) Movable coordinate systems $S_{\sigma}$ and $S_{2}$ that are rigidly connected to the pinion and the gear, respectively (Figs. 14(a) and 14(c)).

(2) The fixed coordinate system $S_{f}$ where the meshing of tooth surfaces $\Sigma_{\sigma}$ and $\Sigma_{2}$ of the pinion and gear is considered.

(3) All errors of assembly are referred to the gear. An additional fixed coordinate system $S_{c}$ (Figs. 14(c) and 14(b)) is applied to simulate the errors of installment $\Delta E$ and $\Delta \gamma$ as parameters of installment of coordinate system $S_{c}$ with respect to $S_{f}$. Rotation of the gear is considered as rotation of coordinate system $S_{2}$ with respect to $S_{c}$.

(4) Errors of $\Delta E$ and $\Delta \gamma$ are shown in Fig. 14(b). Parameter $L$ shown in Fig. 14(b) is applied to simulate such an error $\Delta \gamma$ of the shaft angle wherein the shortest distance between the crossed axes $z_{\sigma}$ and $z_{2}$ does not coincide with $y_{f}$.

An example of meshing of profile-crowned pinion and gear tooth surfaces has been investigated for the following data: $N_{1}=21, N_{2}=77, m=5.08 \mathrm{~mm}, b=1, \beta=30^{\circ}, \alpha_{d}=\alpha_{c}=25^{\circ}$, the parabola coefficient $a_{c}=0.002 \mathrm{~mm}^{-1}$. The following errors of alignment have been simulated: (1) change of center distance $\Delta E=1 \mathrm{~mm}$; (2) error $\Delta \lambda=3$ arc-min of the lead angle; (3) change of shaft angle $\Delta \gamma=3$ arc-min and $L=0$; and (4) change of $\Delta \gamma=15$ arc-min and $L=15 \mathrm{~mm}$.

Results of computation are as follows:

(1) Figure 15 illustrates the shift of bearing contact caused by error $\Delta E$.

(2) The path of contact is orientated indeed longitudinally (Figs. 15, 16(b) and 16(c)).

(3) Error $\Delta E$ of shortest center distance does not cause transmission errors.

The gear ratio $m_{12}$ remains constant and of the same magnitude 


$$
m_{12}=\frac{\omega^{(1)}}{\omega^{(2)}}=\frac{N_{2}}{N_{1}}
$$

However, change of $\Delta E$ is accompanied with the change of radii of operating pitch cylinders and the operating pressure angle of cross-profiles (Fig. 12).

(4) The main disadvantage of meshing of profile-crowned tooth surfaces is that $\Delta \gamma$ and $\Delta \lambda$ cause a discontinuous linear function of transmission errors as shown in Fig. 16(a). Such functions will result in vibration and noise and this is the reason why a double-crowned pinion instead of a profile-crowned one is applied.

Errors $\Delta \gamma$ and $\Delta \lambda$ cause as well the shift of the bearing contact on the pinion and gear tooth surfaces.

Our investigation shows that the main defects of the gear drive for the case wherein $L \neq 0$ and $\Delta \gamma \neq 0$ are the unfavorable functions of transmission errors, similar to the one shown in Fig. 16.

\section{Longitudinal Crowning of Pinion by Plunging Disk}

As a reminder, errors of shaft angle and lead angle cause a discontinuous linear function of transmission errors (see Section 4) and high acceleration and vibration of the gear drive become inevitable. Longitudinal crowning of the pinion tooth surface, in addition to profile crowning, is provided for transformation of the shape of the function of transmission errors and reduction of noise and vibration. The contents of this section cover longitudinal crowning of the pinion by application of a plunging, generating disk. The same goal (double-crowning) may be achieved by application of a generating worm (see Section 6).

Application of a Plunging Disk. The approach is based on the following ideas:

(1) The profile crowned surface $\Sigma_{\sigma}$ of the pinion is considered as given.

(2) A disk-shaped tool $\Sigma_{D}$ that is conjugated to $\Sigma_{\sigma}$ is determined (Fig. 17). The axes of the disk and pinion tooth surface $\Sigma_{\sigma}$ are crossed and the crossing angle $\gamma_{D p}$ is equal to the lead angle on the pinion pitch cylinder (Fig. 18(b)). The center distance $E_{D p}$ (Fig. 18(a)) is defined as

$$
E_{D p}=r_{d 1}+\rho_{D}
$$

where $r_{d 1}$ is the dedendum radius of the pinion and $\rho_{D}$ is the grinding disk outside radius.

(3) Determination of disk surface $\Sigma_{D}$ is based on the following procedure [6,7]. 
Step 1. Disk surface $\Sigma_{D}$ is a surface of revolution. Therefore, there is such a line $L_{\sigma D}$ (Fig. 18(c)) of tangency of $\Sigma_{\sigma}$ and $\Sigma_{D}$ that the common normal to $\Sigma_{\sigma}$ and $\Sigma_{D}$ at each point of $L_{\sigma D}$ passes through the axis of rotation of the disk [6,7]. Figure 18(c) shows line $L_{\sigma D}$ obtained on surface $\Sigma_{D}$. Rotation of $L_{\sigma D}$ about the axis of $\Sigma_{D}$ permits the representation of surface $\Sigma_{D}$ as the family of lines $L_{\sigma D}$.

Step 2. It is obvious that screw motion of disk $\Sigma_{D}$ about the axis of pinion tooth surface $\Sigma_{\sigma}$ provides surface $\Sigma_{\tau}$ that coincides with $\Sigma_{\sigma}$ (Fig. 18(d)).

(4) The goal to obtain a double crowned surface $\Sigma_{1}$ of the pinion is accomplished by providing of a combination of screw and plunging motions of the disk and the pinion. The generation of double-crowned pinion tooth surface is illustrated in Fig. 19 and is accomplished as follows:

(a) Figures 19(a) and 19(b) show two positions of the generated double-crowned pinion with respect to the disk. One of the two positions with center distance $E_{D p}^{(0)}$ is the initial one, the other with $E_{D p}\left(\psi_{1}\right)$ is the current position. The shortest distance $E_{D p}^{(0)}$ is defined by Eq. (29).

(b) Coordinate system $S_{D}$ is rigidly connected to the generating disk (Fig. 19(c)) and is considered as fixed.

(c) Coordinate system $S_{1}$ of the pinion performs a screw motion and is plunged with respect to the disk. Auxiliary systems $S_{h}$ and $S_{q}$ are used for a better illustration of these motions in Fig. 19(c). Such motions are described as follows:

Screw motion is accomplished by two components: (a) translational displacement $l_{p}$ that is collinear to the axis of the pinion, and (b) rotational motion $\psi_{1}$ about the axis of the pinion (Figs. 19(b) and (c)). The magnitudes $l_{p}$ and $\psi_{1}$ are related through the screw parameter $p$ of the pinion as

$$
l_{p}=p \psi_{1}
$$

Plunging motion is accomplished by a translational displacement $a_{p l} l_{p}^{2}$ along the shortest distance direction (Fig. 19(c)). Such motion allows to define the shortest distance $E_{D p}\left(\psi_{1}\right)$ (Fig. 19(b) and (c)) as a parabolic function

$$
E_{D p}\left(\psi_{1}\right)=E_{D p}^{(0)}-a_{p l} l_{p}^{2}
$$


The translational motions $l_{p}$ and $a_{p l} l_{p}^{2}$ are represented as displacement of system $S_{q}$ with respect to system $S_{h}$ The same translational motions are performed by system $S_{1}$ that performs rotational motion of angle $\psi_{1}$ with respect to system $S_{q}$.

(d) The pinion tooth surface $\Sigma_{1}$ is determined as the envelope to the family of disk surface $\Sigma_{D}$ generated in the relative motion between the disk and the pinion.

\section{Grinding of Double-Crowned Pinion by Worm}

Worm Installment. The installment of the grinding worm with respect to the pinion may be represented on the basis of meshing of two helicoids. Figure 20 illustrates the meshing of two left-hand helicoids, that represent the grinding worm and the pinion generated by the worm. Drawings of Fig. 21 yield that the crossing angle is

$$
\gamma_{w p}=\lambda_{p}+\lambda_{w}
$$

where $\lambda_{p}$ and $\lambda_{w}$ are the lead angles on the pitch cylinders of the pinion and the worm.

Figure 21 shows that the pitch cylinders of the worm and the pinion are in tangency at point $M$ that belongs to the shortest distance between the crossed axes. The velocity polygon at $M$ satisfies the relation

$$
\mathbf{v}^{(w)}-\mathbf{v}^{(p)}=\mu \mathbf{i}_{t}
$$

Here: $\mathbf{v}^{(w)}$ and $\mathbf{v}^{(p)}$ are the velocities of the worm and the pinion at $M ; \mathbf{i}_{t}$ is the unit vector directed along the common tangent to the helices; $\mu$ is the scalar factor. Equation (33) indicates that the relative velocity at point $M$ is collinear to the unit vector $\mathbf{i}_{t}$.

Determination of Worm Thread Surface $\Sigma_{w}$. In order to get the same pinion tooth surface $\Sigma_{\sigma}$ that is generated by rack-cutter surface $\Sigma_{c}$ (Section 3), the generation of $\Sigma_{w}$ can be accomplished considering that three surfaces $\Sigma_{c}, \Sigma_{\sigma}$ and $\Sigma_{w}$ are simultaneously in meshing. Figure 22 shows the axodes of these three surfaces wherein the shortest distance between pinion and worm axodes is extended. Plane $\Pi$ represents the axode of the rack-cutter. Surface $\Sigma_{w}$ is obtained using the following steps:

Step 1. Parabolic tooth surface $\Sigma_{c}$ of rack-cutter is considered as given.

Step 2. A translational motion of rack-cutter surface $\Sigma_{c}$, that is perpendicular to the axis of the pinion, and rotational motion of the pinion provide surface $\Sigma_{\sigma}$ as an envelope to the family 
of surfaces of $\Sigma_{c}$ (see Section 3). Velocity $\mathbf{v}_{1}$ (Fig. 22) is applied to rack-cutter while the pinion is rotated with angular velocity $\boldsymbol{\omega}^{(p)}$. The relation between $v_{l}$ and $\omega^{(p)}$ is defined as

$$
v_{1}=\omega^{(p)} r_{p}
$$

where $r_{p}$ is the radius of the pinion pitch cylinder.

Step 3. An additional motion of surface $\Sigma_{c}$ with velocity $\mathbf{v}_{a u x}$ along direction $t-t$ of skew rack-cutter teeth (Fig. 22) is performed and this motion does not affect surface $\Sigma_{\sigma}$. Using vector equation $\mathbf{v}_{2}=\mathbf{v}_{1}+\mathbf{v}_{\text {aux }}$, permits velocity $\mathbf{v}_{2}$ of rack-cutter $\Sigma_{c}$ in direction that is perpendicular to the axis of the worm to be obtained. Then, we may represent the generation of worm surface $\Sigma_{w}$ by rack-cutter $\Sigma_{c}$ considering that the rack-cutter performs translational motion $\mathbf{v}_{2}$ while the worm is rotated with angular velocity $\boldsymbol{\omega}^{(w)}$. The relation between $v_{2}$ and $\omega^{(w)}$ is defined as

$$
v_{2}=\omega^{(w)} r_{w}
$$

where $r_{w}$ is the radius of the worm pitch cylinder. Worm surface $\Sigma_{w}$ is generated as the envelope to the family of rack-cutter surfaces $\Sigma_{c}$.

Step 4. The discussions above permit verification of the simultaneous generation of profile crowned pinion tooth surface $\Sigma_{\sigma}$ and worm thread surface $\Sigma_{w}$ by rack-cutter surface $\Sigma_{c}$. Each of the two generated surfaces $\Sigma_{\sigma}$ and $\Sigma_{w}$ are in line contact with rack cutter surface $\Sigma_{c}$. However, the contact lines $L_{c \sigma}$ and $L_{c w}$ do not coincide, but intersect each other as shown in Fig. 23. Here, $L_{c \sigma}$ and $L_{c w}$ represent the lines of contact between $\Sigma_{c}$ and $\Sigma_{\sigma}, \Sigma_{c}$ and $\Sigma_{w}$, respectively. Lines $L_{c \sigma}$ and $L_{c w}$ are obtained for any chosen value of related parameters of motion between $\Sigma_{c}, \Sigma_{\sigma}$, and $\Sigma_{w}$. Point $N$ of intersection of lines $L_{c w}$ and $L_{c \sigma}$ (Fig. 23) is the common point of tangency of surfaces $\Sigma_{c}, \Sigma_{\sigma}$, and $\Sigma_{w}$.

Profile Crowning of Pinion. Profile crowned pinion tooth surface $\Sigma_{\sigma}$ as been obtained above by using rack-cutter surface $\Sigma_{c}$. Direct derivation of generation of $\Sigma_{\sigma}$ by the grinding worm $\Sigma_{w}$ may be accomplished as follows:

(1) Consider that worm surface $\Sigma_{w}$ and pinion tooth surface $\Sigma_{\sigma}$ perform rotation between their crossed axes with angular velocities $\boldsymbol{\omega}^{(w)}$ and $\boldsymbol{\omega}^{(p)}$. It follows from discussions above that $\Sigma_{w}$ and $\Sigma_{\sigma}$ are in point contact and $N$ is one of the instantaneous points of contact of $\Sigma_{w}$ and $\Sigma_{\sigma}$ (Fig. 23).

(2) The concept of direct derivation of $\Sigma_{\sigma}$ by $\Sigma_{w}$ is based on the two-parameter enveloping process. The process of such enveloping is based on application of two independent sets of parameters of motion [7,12]: 
(a) One set of parameters relates the angles of rotation of the worm and the pinion as

$$
m_{w p}=\frac{\omega^{(w)}}{\omega^{(p)}}=\frac{N_{p}}{N_{w}}=N_{p}
$$

wherein the number $N_{w}$ of worm threads is considered as $N_{w}=1$ and $N_{p}$ is the teeth number of the pinion.

(b) The second set of parameters of motion is provided as a combination of two components: (1) translational motion $\Delta \mathbf{s}_{w}$ of the worm that is collinear to the axis of the pinion (Fig. 24(a)); (2) small rotational motion of the pinion about the pinion axis that is determined as

$$
\Delta \psi_{p}=\frac{\Delta s_{w}}{p}
$$

where $p$ is the screw parameter of the pinion.

Analytical determination of a surface generated as the envelope to a two-parameter enveloping process is represented in [7].

The schematic of generation of $\Sigma_{\sigma}$ by $\Sigma_{w}$ is shown in Fig. 24(a) wherein the shortest center distance is shown as extended one for the purpose of better illustration.

In the process of meshing of $\Sigma_{w}$ and $\Sigma_{\sigma}$, the worm surface $\Sigma_{w}$ and the profile crowned pinion surface perform rotation about crossed axes. The shortest distance applied is

$$
E_{w p}=r_{p}+r_{w}
$$

Surfaces $\Sigma_{w}$ and $\Sigma_{\sigma}$ are in point tangency. Feed motion of the worm is provided as a screw motion with the screw parameter of the pinion. Designations in Fig. 24(a) indicate: (1) $M_{1}$ and $M_{2}$ points on pitch cylinders (these points do not coincide each with other because the shortest distance is illustrated as extended); (2) $\boldsymbol{\omega}^{(w)}$ and $\boldsymbol{\omega}^{(p)}$ are the angular velocities of the worm and profile crowned pinion in their rotation about crossed axes; (3) $\Delta \mathbf{s}_{w}$ and $\Delta \psi_{p}$ are the components of the screw motion of the feed motion; (4) $r_{w}$ and $r_{p}$ are the radii of pitch cylinders.

Double-Crowning of Pinion. Above the generation by the worm of a profile crowned surface $\Sigma_{\sigma}$ of the pinion has been presented. However, our final goal is the generation by the worm of a double crowned surface $\Sigma_{1}$ of the pinion. Two approaches are proposed for this purpose:

Worm Plunging. Additional pinion crowning (longitudinal crowning) is provided by plunging of the worm with respect to the pinion that is shown schematically in Fig. 24(b). Plunging of the worm in the process of pinion grinding is performed as variation of the shortest distance between the axes of the grinding worm and the pinion. The instantaneous shortest center distance $E_{w p}\left(\Delta s_{w}\right)$ between the grinding worm and the pinion is executed as (Fig. 24(b)) 


$$
E_{w p}\left(\Delta s_{w}\right)=E_{w p}^{(0)}-a_{p l}\left(\Delta s_{w}\right)^{2}
$$

Here: $\Delta s_{w}$ is measured along the pinion axis from the middle of the pinion; $a_{p l}$ is the parabola coefficient of the function $a_{p l}\left(\Delta s_{w}\right)^{2} ; E_{w p}^{(0)}$ is the nominal value of the shortest distance defined by Eq. (38). Plunging of the worm with observation of Eq. (39) provides a parabolic function of transmission errors in the process of meshing of the pinion and the gear of the proposed version of modified involute helical gear drive.

Modified Roll of Feed Motion. Conventionally, the feed motion of the worm is provided by observation of linear relation (37) between components $\Delta s_{w}$ and $\Delta \psi_{p}$. For the purpose of pinion longitudinal crowning, the following function $\Delta \psi_{p}\left(\Delta s_{w}\right)$ is observed

$$
\Delta \psi_{p}\left(\Delta s_{w}\right)=\frac{\Delta s_{w}}{p}+a_{m r}\left(\Delta s_{w}\right)^{2}
$$

where $a_{m r}$ is the parabola coefficient of the parabolic function (40).

Worm modified roll is provided instead of worm plunging. Application of function (40) permits the modification of the pinion tooth surface and provides a parabolic function of transmission errors of the proposed gear drive.

The derivation of double crowned surface $\Sigma_{1}$ of the pinion by application of both approaches mentioned above is based on determination of $\Sigma_{1}$ as a two-parameter enveloping process:

Step 1. We consider that surface $\Sigma_{w}$ is determined as the envelope to the rack-cutter surface $\Sigma_{c}$. The determination of $\Sigma_{w}$ is a one-parameter enveloping process.

Step 2. Double-crowned surface $\Sigma_{1}$ of the pinion is determined as an envelope of a two parameter process by application of following equations

$$
\begin{gathered}
\mathbf{r}_{1}\left(u_{w}, \theta_{w}, \psi_{w,} \Delta s_{w}\right)=\mathbf{M}_{1 w}\left(\psi_{w}, \Delta s_{w}\right) \mathbf{r}_{w}\left(u_{w}, \theta_{w}\right) \\
\mathbf{N}_{w} \cdot \mathbf{v}_{w}{ }^{\left(w 1, \psi_{w}\right)}=0 \\
\mathbf{N}_{w} \cdot \mathbf{v}_{w}{ }^{\left(w 1, \Delta s_{w}\right)}=0
\end{gathered}
$$

Here: $\left(u_{w}, \theta_{w}\right)$ are the worm surface parameters; $\left(\psi_{w}, \Delta s_{w}\right)$ are the generalized parameters of motion of two-parameter enveloping process. Vector equation (41) represents the family of surfaces $\Sigma_{w}$ of the worm in coordinate system $S_{1}$ of the pinion. Equations (42) and (43) represent two equations of meshing. Vector $\mathbf{N}_{w}$ is the normal to the worm tooth surface $\Sigma_{w}$ and is represented in system $S_{w}$. Vector $\mathbf{v}_{w}{ }^{\left({ }^{1, \psi_{w}}\right)}$ represents the relative velocity between the worm and pinion determined under the condition that parameter $\psi_{w}$ of motion is varied and the other parameter $\Delta s_{w}$ is held at rest. Vector $\mathbf{v}_{w}{ }^{\left({ }^{1} 1, \Delta s_{w}\right)}$ is determined under the condition that parameter 
$\Delta s_{w}$ is varied, and the other parameter of motion, $\psi_{w}$, is held at rest. Both vectors of relative velocity are represented in coordinate system $S_{w}$.

Vector equations (41), (42), and (43) considered simultaneously determine the double-crowned pinion tooth surface as the envelope to the two-parameter enveloping process [7].

\section{TCA of Gear Drive with Double-Crowned Pinion}

Simulation of meshing of a gear drive with double-crowned pinion is investigated by application of the same algorithm discussed in Section 4 for a gear drive with profile-crowned pinion and gear tooth surfaces. The applied design parameters are shown in Table 1. The parabolic coefficient of longitudinal crowning $a_{p l}$ is of such a magnitude that provides a maximal error of 8 arcsec of the predesigned function of transmission errors for a gear drive without errors of alignment. Figures 25(a) and 25(b) show the path of contact and the function of transmission errors, respectively. The TCA output shows that a parabolic function of transmission errors in meshing of the pinion and the gear is obtained indeed due to application of a double-crowned pinion.

The chosen approaches for TCA cover application: (1) of a disk-shaped tool (Section 5), (2) plunging worm (Section 6), and (3) modified roll of feed motion (Section 6). These approaches yield almost the same output of TCA.

The simulation of meshing is performed for the following errors of alignment: (1) change of center distance $\Delta E=140 \mu m$; (2) change of shaft angle $\Delta \gamma=3 \operatorname{arcmin}$; (3) error $\Delta \lambda=3$ arcmin; and (4) combination of errors $\Delta \gamma$ and $\Delta \lambda$ as $\Delta \gamma-\Delta \lambda=0$ arcmin.

The results of TCA are as follows:

(1) Figure 25(a) shows orientation of the path of contact of the aligned gear drive.

(2) Figures 26(a), 26(b), and 26(c) show the shift of the paths of contact caused by errors of alignment $\Delta E, \Delta \gamma$, and $\Delta \lambda$, respectively. Misalignment $\Delta E$ does not cause the shift of the bearing contact on pinion surface. The shift of paths of contact caused by $\Delta \gamma$ may be compensated by correction $\Delta \lambda_{1}$ of the pinion (or $\Delta \lambda_{2}$ of the gear). Figure 26(d) shows that the location of the path of contact can be restored by correction of $\Delta \lambda_{1}$ of the pinion taking $\Delta \gamma-\Delta \lambda_{1}=0$. This means that correction of $\Delta \lambda_{1}$ can be used for the restoration of location of the path of contact. Correction of $\Delta \lambda_{1}$ or $\Delta \lambda_{2}$ may be applied for grinding of the pinion or the gear, respectively.

It was mentioned above (see Section 4) that double crowning of the pinion provides a predesigned parabolic function. Therefore, linear functions of transmission errors caused by $\Delta \gamma$, $\Delta \lambda$ and other errors are absorbed by the predesigned parabolic function of transmission errors $\Delta \phi_{2}\left(\phi_{1}\right)$. The final function of transmission errors $\Delta \phi_{2}\left(\phi_{1}\right)$ remains a parabolic one. However, increase of the magnitude of errors $\Delta \gamma$ and $\Delta \lambda$ may result in that the final function of transmission errors $\Delta \phi_{2}\left(\phi_{1}\right)$ to become a discontinued one. In such of a case, the predesigned 
parabolic function $\Delta \phi_{2}\left(\phi_{1}\right)$ has to be of a larger magnitude or it becomes necessary to limit the range of errors $\Delta \gamma, \Delta \lambda$, and other ones.

\section{Undercutting and Pointing of Pinion}

Undercutting. Avoidance of undercutting is applied to pinion tooth surface $\Sigma_{\sigma}$ and is based on the following ideas:

(1) Appearance of singular points on generated surface $\Sigma_{\sigma}$ is the warning that the surface may be undercut in the process of generation $[6,7]$.

(2) Singular points on surface $\Sigma_{\sigma}$ are generated by regular points on the generating surface $\Sigma_{c}$ wherein the velocity of a contact point in its motion over $\Sigma_{\sigma}$ becomes equal to zero $[6,7]$ :

$$
\mathbf{v}_{r}^{(\sigma)}=\mathbf{v}_{r}^{(c)}+\mathbf{v}^{(c \sigma)}=\mathbf{0}
$$

(3) Equation (44) and differentiated equation of meshing

$$
\frac{d}{d t}\left[f\left(u_{c}, \theta_{c}, \psi_{\sigma}\right)\right]=0
$$

determine such a line $L$ on surface $\Sigma_{c}$ that generates singular points on $\Sigma_{\sigma}$. Limiting $\Sigma_{c}$ with line $L$, we may avoid the appearance of singular points on $\Sigma_{\sigma}$.

The derivation of line $L$ is based on the following considerations:

(1) Equation (44) yields

$$
\frac{\partial \mathbf{r}_{c}}{\partial u_{c}} \frac{d u_{c}}{d t}+\frac{\partial \mathbf{r}_{c}}{\partial \theta_{c}} \frac{d \theta_{c}}{d t}=-\mathbf{v}_{c}^{(c \sigma)}
$$

Here: $\partial \mathbf{r}_{c} / \partial u_{c}, \partial \mathbf{r}_{c} / \partial \theta_{c}$ and $\mathbf{v}_{c}^{(c \sigma)}$ are three dimensional vectors represented in system $S_{c}$ of pinion rack cutter.

(2) Equation (45) yields

$$
\frac{\partial f}{\partial u_{c}} \frac{d u_{c}}{d t}+\frac{\partial f}{\partial \theta_{c}} \frac{d \theta_{c}}{d t}=-\frac{\partial f}{\partial \psi_{\sigma}} \frac{d \psi_{\sigma}}{d t}
$$

(3) Equations (46) and (47) represent a system of four linear equations in two unknowns: $d u_{c} / d t$ and $d \theta_{c} / d t$. This system has a certain solution for the unknowns if matrix 


$$
\mathbf{A}=\left[\begin{array}{ccc}
\frac{\partial \mathbf{r}_{c}}{\partial u_{c}} & \frac{\partial \mathbf{r}_{c}}{\partial \theta_{c}} & -\mathbf{v}_{c}^{(c \sigma)} \\
\frac{\partial f}{\partial u_{c}} & \frac{\partial f}{\partial \theta_{c}} & -\frac{\partial f}{\partial \psi_{\sigma}} \frac{d \psi_{\sigma}}{d t}
\end{array}\right]
$$

has the rank $r=2$. This yields

$$
\begin{aligned}
& \Delta_{1}=\left|\begin{array}{ccc}
\frac{\partial x_{c}}{\partial u_{c}} & \frac{\partial x_{c}}{\partial \theta_{c}} & -v_{x c}^{(c \sigma)} \\
\frac{\partial y_{c}}{\partial u_{c}} & \frac{\partial y_{c}}{\partial \theta_{c}} & -v_{y c}^{(c \sigma)} \\
\frac{\partial f}{\partial u_{c}} & \frac{\partial f}{\partial \theta_{c}} & -\frac{\partial f}{\partial \psi_{\sigma}} \frac{d \psi_{\sigma}}{d t}
\end{array}\right|=0 \\
& \Delta_{2}=\left|\begin{array}{ccc}
\frac{\partial x_{c}}{\partial u_{c}} & \frac{\partial x_{c}}{\partial \theta_{c}} & -v_{x c}^{(c \sigma)} \\
\frac{\partial z_{c}}{\partial u_{c}} & \frac{\partial z_{c}}{\partial \theta_{c}} & -v_{z c}^{(c \sigma)} \\
\frac{\partial f}{\partial u_{c}} & \frac{\partial f}{\partial \theta_{c}} & -\frac{\partial f}{\partial \psi_{\sigma}} \frac{d \psi_{\sigma}}{d t}
\end{array}\right|=0 \\
& \Delta_{3}=\left|\begin{array}{ccc}
\frac{\partial y_{c}}{\partial u_{c}} & \frac{\partial y_{c}}{\partial \theta_{c}} & -v_{y c}^{(c \sigma)} \\
\frac{\partial z_{c}}{\partial u_{c}} & \frac{\partial z_{c}}{\partial \theta_{c}} & -v_{z c}^{(c \sigma)} \\
\frac{\partial f}{\partial u_{c}} & \frac{\partial f}{\partial \theta_{c}} & -\frac{\partial f}{\partial \psi_{\sigma}} \frac{d \psi_{\sigma}}{d t}
\end{array}\right|=0 \\
& \Delta_{4}=\left|\begin{array}{lll}
\frac{\partial x_{c}}{\partial u_{c}} & \frac{\partial x_{c}}{\partial \theta_{c}} & -v_{x c}^{(c \sigma)} \\
\frac{\partial y_{c}}{\partial u_{c}} & \frac{\partial y_{c}}{\partial \theta_{c}} & -v_{y c}^{(c \sigma)} \\
\frac{\partial z_{c}}{\partial u_{c}} & \frac{\partial z_{c}}{\partial \theta_{c}} & -v_{z c}^{(c \sigma)}
\end{array}\right|=0
\end{aligned}
$$

Equation (52) yields the equation of meshing $f\left(u_{c}, \theta_{c}, \psi_{\sigma}\right)=0$ and is not applied for investigation of singularities. The requirement that determinants $\Delta_{1}, \Delta_{2}$, and $\Delta_{3}$ must be equal to zero simultaneously may be represented as 


$$
\Delta_{1}^{2}+\Delta_{2}^{2}+\Delta_{3}^{2}=0
$$

Equation (53) enables to obtain for determination of singularities the following equation

$$
F\left(u_{c}, \theta_{c}, \psi_{\sigma}\right)=0
$$

Note: In most cases, it is sufficient for derivation of equation $F=0$ to use only one of three following equations instead of equation (53):

$$
\Delta_{1}=0, \Delta_{2}=0, \Delta_{3}=0
$$

An exception case, when application of (53) is required, is discussed in [7].

Singularities of the pinion may be avoided by limitation of the rack-cutter surface $\Sigma_{c}$ that generates the pinion by line $L$. The determination of $L$ is based on the following procedure:

(1) Using equation of meshing $f\left(u_{c}, \theta_{c}, \psi_{\sigma}\right)=0$, we may obtain in the plane of parameters $\left(u_{c}, \theta_{c}\right)$ the family of contact lines of the rack-cutter and the pinion. Each contact line is determined for a fixed parameter of motion $\psi_{\sigma}$.

(2) The sought for limiting line $L$ is determined in the space of parameters $\left(u_{c}, \theta_{c}\right)$ by simultaneous consideration of equations $f=0$ and $F=0$ (Fig. 27(a)). Then, we can obtain the limiting line $L$ on the surface of the rack-cutter (Fig. 27(b)). The limiting line $L$ on the rack-cutter surface is formed by regular points of the rack-cutter, but these points will generate singular points on the pinion tooth surface.

Limitations of the rack-cutter surface by $L$ will avoid singular points on the pinion tooth surface. Singular points on the pinion tooth surface can be obtained by coordinate transformation of line $L$ on rack-cutter surface $\Sigma_{c}$ to surface $\Sigma_{\sigma}$.

Pointing. Pointing of the pinion means that the width of the topland becomes equal to zero. Figure 28(a) shows the cross-sections of the pinion and the pinion rack-cutter. Point $A_{c}$ of the rack-cutter generates the limiting point $A_{\sigma}$ of the pinion wherein singularity of pinion is still avoided. Point $B_{c}$ of the rack-cutter generates point $B_{\sigma}$ of pinion profile. Parameter $s_{a}$ indicates the chosen width of the pinion topland. Parameter $\alpha_{t}$ indicates the pressure angle at point $Q$. Parameters $h_{1}$ and $h_{2}$ indicate the limitation of location of limiting points $A_{c}$ and $B_{c}$ of the rackcutter profiles. Figure 28(b) shows functions $h_{1}\left(N_{1}\right)$ and $h_{2}\left(N_{1}\right)$ ( $N_{l}$ is the pinion tooth number) obtained for the following data: $\alpha_{d}=25^{\circ}, \beta=30^{\circ}$, parabola coefficient of pinion rack-cutter $a_{c}=0.002 \mathrm{~mm}^{-1}, s_{a}=0.3 m$, parameter $b=1.0$ (see Eq. (3)) and module $m=1 \mathrm{~mm}$. 


\section{Stress Analysis}

This section covers stress analysis and investigation of formation of bearing contact of contacting surfaces. The performed stress analysis is based on the finite element method [17] and application of a general computer program [3].

Development of Finite Element Models. The developed approach for the finite element models is accomplished as follows [1]:

Step 1. Tooth surface equations of pinion and gear and portions of corresponding rim are considered for determination of the volumes of the designed bodies. Figure 29(a) shows the designed body for one-tooth model of the pinion of a helical gear drive.

Step 2. The designed volume of each tooth of the model is divided into six subvolumes using auxiliary intermediate surfaces 1 to 6 as shown in Fig. 29(b).

Step 3. Node coordinates are determined analytically considering the number of desired elements in longitudinal and profile directions (Fig. 29(c)).

Step 4. Discretization of the model by finite elements (using the nodes determined in previous step) is accomplished as shown in Fig. 29(d).

Step 5. Setting of boundary conditions is accomplished automatically and are shown in Fig. 30(a) and (b) for the case of a three-tooth model. The following ideas are considered:

(1) Nodes on the two sides and bottom part of the portion of the gear rim are considered as fixed (Fig. 30(a)).

(2) Nodes on the two sides and the bottom part of the pinion rim form a rigid surface (Figs. 30(a) and (b)).

(3) A reference node $N$ (Fig. 30(b)) located on the axis of the pinion is used as the reference point of the previously defined rigid surface. Reference point $N$ and the rigid surface constitute a rigid body.

(4) Only one degree of freedom is defined as free at the reference point $N$, as rotation about the pinion axis, while all other degrees of freedom are fixed. Application of a torque $T$ in rotational motion at the reference point $N$ permits the torque to be applied to the pinion model.

Step 6. The contact algorithm of the finite element analysis computer program [3] requires definition of contacting surfaces. This approach permits the automatic identification of all the elements of the model required for the formation of such surfaces.

The principal characteristics of the described approach are as follows:

(1) Finite element models of the gear drive can be automatically obtained for any position of pinion and gear obtained from TCA. Stress convergence is assured because there is at least one point of contact between the contacting surfaces. 
(2) Assumption of load distribution in the contact area is not required since the contact algorithm of the general computer program [3] is used to obtain the contact area and stresses by application of the torque to the pinion while the gear is considered at rest.

(3) Finite element models of any number of teeth can be obtained. As an example, Fig. 31 shows a whole gear drive finite element model. However, such a model is not recommended if an exact definition of the contact ellipse is required. Three or five tooth models are more adequate in such a case. Figure 3 shows the finite element model of five pairs of contacting teeth.

The use of several teeth in the models has the following advantages:

(1) Boundary conditions are far enough from the loaded areas of the teeth.

(2) Simultaneous meshing of two pairs of teeth can occur due to the elasticity of surfaces. Therefore, the load transition at the beginning and at the end of the path of contact can be studied.

Numerical Example. The finite element analysis has been performed using the design parameters shown in Table 1.

A finite element model of three pairs of contacting teeth has been applied for each chosen point of the path of contact. Elements C3D8I [3] of first order (enhanced by incompatible modes to improve their bending behavior) have been used to form the finite element mesh. The total number of elements is 45,600 with 55,818 nodes. The material is steel with the properties of Young's Modulus $E=2.068 \times 10^{5} \mathrm{MPa}$ and Poisson's ratio 0.29. A torque of $500 \mathrm{Nm}$ has been applied to the pinion. Figure 32 shows the contact and bending stresses obtained at the mean contact point for the pinion.

The variation of contact and bending stresses along the path of contact has been also studied. Figures 33 and 34 illustrate the variation of contact and bending stresses for the pinion and the gear, respectively.

The stress analysis have been performed as well for the example of a conventional helical involute drive with a shaft angle error of $\Delta \gamma=3$ arcmin (Fig. 35). We remind that the tooth surfaces of an aligned conventional helical gear drive are in line contact, but they are in point contact with error $\Delta \gamma$. The results of computation show that error $\Delta \gamma$ causes an edge contact and an area of severe contact stresses.

Figure 36 shows the results of finite element analysis for the pinion of a modified involute helical gear drive wherein an error $\Delta \gamma=3$ arcmin occurs. As shown in Fig. 36, a helical gear drive with modified geometry is free indeed of edge contact and areas of severe contact stresses. 


\section{Conclusions}

The discussions above draw the following conclusions:

(1) A new geometry of modified involute helical gears, based on the following ideas, has been proposed:

(a) The pinion of the gear drive is double-crowned and therefore the pinion tooth surface is mismatched of an involute helicoid in profile and longitudinal directions.

(b) The gear tooth surface is designed as a conventional screw involute helicoid.

(2) The pinion and gear tooth surfaces contact each other instantly at a point, the bearing contact is localized, and the function of transmission errors is a parabolic one of a low magnitude.

(3) The parabolic function of transmission errors is able to absorb discontinuous linear functions of transmission errors caused by misalignment and therefore the noise and vibration are reduced.

(4) The bearing contact is oriented longitudinally and this is in favor of the increased contact ratio. The shift of bearing contact caused by misalignment is reduced.

(5) Computerized methods for generation of a double-crowned pinion that are based on tool plunging and modified roll have been proposed.

(6) Simulation of meshing of profile-crowned and double-crowned helicoids have been developed. The output of developed TCA (Tooth Contact Analysis) has confirmed the predicted advantages of the modified geometry.

(7) Enhanced stress analysis of developed modified helical gears (based on finite element analysis) and analysis of formation of bearing contact have been performed. The contacting models are developed automatically by using equations of tooth surfaces. Comparison of stresses of developed helical gears has confirmed reduction of contact stresses and avoidance of edge contact.

\section{References}

[1] Argyris, J., Fuentes, A., Litvin, F. L., Computerized Integrated Approach for Design and Stress Analysis of Spiral Bevel Gears, Computer Methods in Applied Mechanics and Engineering, Vol. 191, pp. 1057-1095, 2002.

[2] Feng, P.-H., Litvin, F.L., Townsend, D.P., and Handschuh, R.F., Determination of Principal Curvatures and Contact Ellipses for Profile Crowned Helical Gears, ASME Journal of Mechanical Design, Vol. 121, No. 1, pp. 107-111, 1999.

[3] Hibbit, Karlsson \& Sirensen, Inc., ABAQUS/Standard User's Manual, 1800 Main Street, Pantucket, RI 20860-4847, 1998.

[4] Korn, G.A., Korn, T.M., Mathematics Handbook for Scientist and Engineers, McGraw-Hill, Inc., 2nd Ed., 1968. 
[5] Litvin, F.L., The Investigation of the Geometric Properties of a Variety of Novikov Gearing, Proc. Leningrad Mechanical Institute (in Russian), No. 24, 1962.

[6] Litvin, F.L., Theory of Gearing, NASA RP-1212 (AVSCOM 88-C-C035), Washington, DC, 1989.

[7] Litvin, F.L., Gear Geometry and Applied Theory, Prentice-Hall, Inc., Englewood Cliffs, New Jersey, 1994.

[8] Litvin, F.L., Chen, N.X., Lu, J., and Handschuh, R.F., Computerized Design and Generation of Low-Noise Helical Gears with Modified Surface Topology, ASME Journal of Mechanical Design, Vol. 117, No. 2, pp. 254-261, 1995.

[9] Litvin, F.L. et al., Helical and spur gear drive with double crowned pinion tooth surfaces and conjugated gear tooth surfaces, U.S. Patent Office, Patent No. 6,205,879, 2001.

[10] Litvin, F.L., Fan, Q., Vecchiato, D., Demenego, A., Handschuh, R.F., and Sep, T.M., Computerized Generation and Simulation of Meshing of Modified Spur and Helical Gears Manufactured by Shaving, Computer Methods in Applied Mechanics and Engineering, Vol. 190, pp. 5037-5055, 2001.

[11] Litvin, F.L., Lu, J., Townsend, D.P., and Hawkins, M., Computerized Simulation of Meshing of Conventional Helical Involute Gears and Modification of Geometry, Mechanism and Machine Theory, Vol. 34, No. 1, pp. 123-147, 1999.

[12] Litvin, F.L. and Seol, I.H., Computerized Determination of Gear Tooth Surface as Envelope to Two Parameter Family of Surfaces, Computer Methods in Applied Mechanics and Engineering, Vol. 138, No. 1-4, pp. 213-225, 1996.

[13] Litvin, F.L. and Tsay, C.B., Helical Gears with Circular Arc Teeth: Simulation of Conditions of Meshing and Bearing Contact, ASME Journal of Mechanisms, Transmissions, and Automation in Design, Vol. 107, pp. 556-564, 1985.

[14] Stosic, N., On Gearing of Helical Screw Compressor Rotors, Proc IMechE, Journal of Mechanical Engineering Science, Vol. 212, pp. 587-594, 1998.

[15] Visual Numerics, Inc., IMSL Fortran 90 MP Library, v. 3.0, info@boulder.vni.com, 1998.

[16] Zalgaller, V.A., Theory of Envelopes, Publishing House Nauka (in Russian), 1975.

[17] Zienkiewicz, O.C. and Taylor, R.L., The Finite Element Method, John Wiley \& Sons, 5th Ed., 2000.

Table 1.-Design parameters

\begin{tabular}{|l|r|}
\hline Number of teeth of the pinion, $N_{1}$ & 17 \\
Number of teeth of the gear, $N_{2}$ & 77 \\
Module, $m$ & $5.08 \mathrm{~mm}$ \\
Driving side pressure angle, $\alpha_{d}$ & $25^{\circ}$ \\
Coast side pressure angle, $\alpha_{c}$ & $25^{\circ}$ \\
Helix angle, $\beta$ & $30^{\circ}$ \\
Parameter of rack-cutter, $b$ & 1.0 \\
Face width & $70 \mathrm{~mm}$ \\
Radius of the worm pitch cylinder, $r_{w}$ & $98 \mathrm{~mm}$ \\
Parabolic coefficient of pinion rack cutter, $a_{c}$ & $0.002 \mathrm{~mm}^{-1}$ \\
Parabolic coefficient of plunging, $a_{p l}$ & $0.000085 \mathrm{~mm}^{-1}$ \\
\hline
\end{tabular}




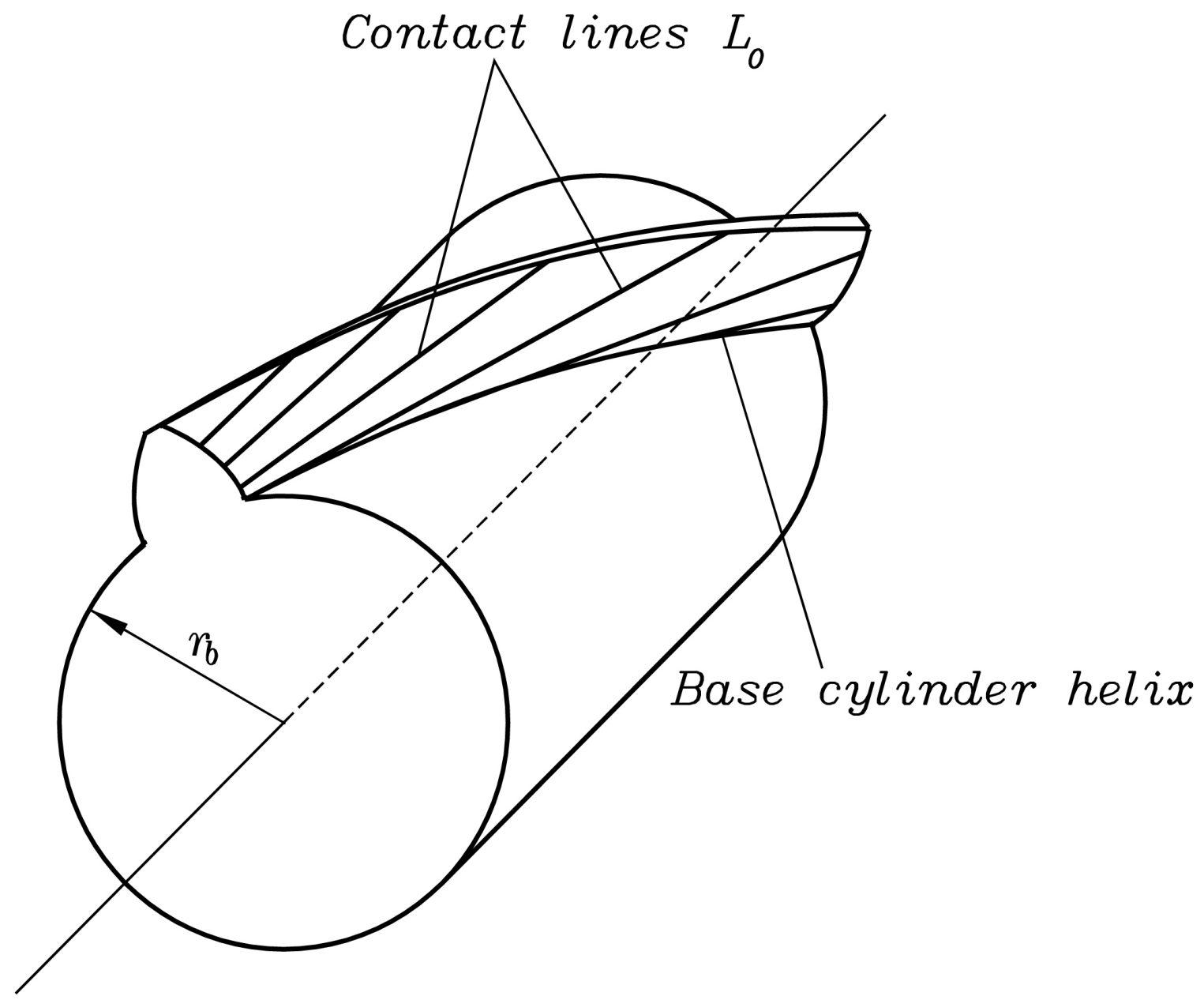

Figure 1.-Contact lines on an involute helical tooth surface. 


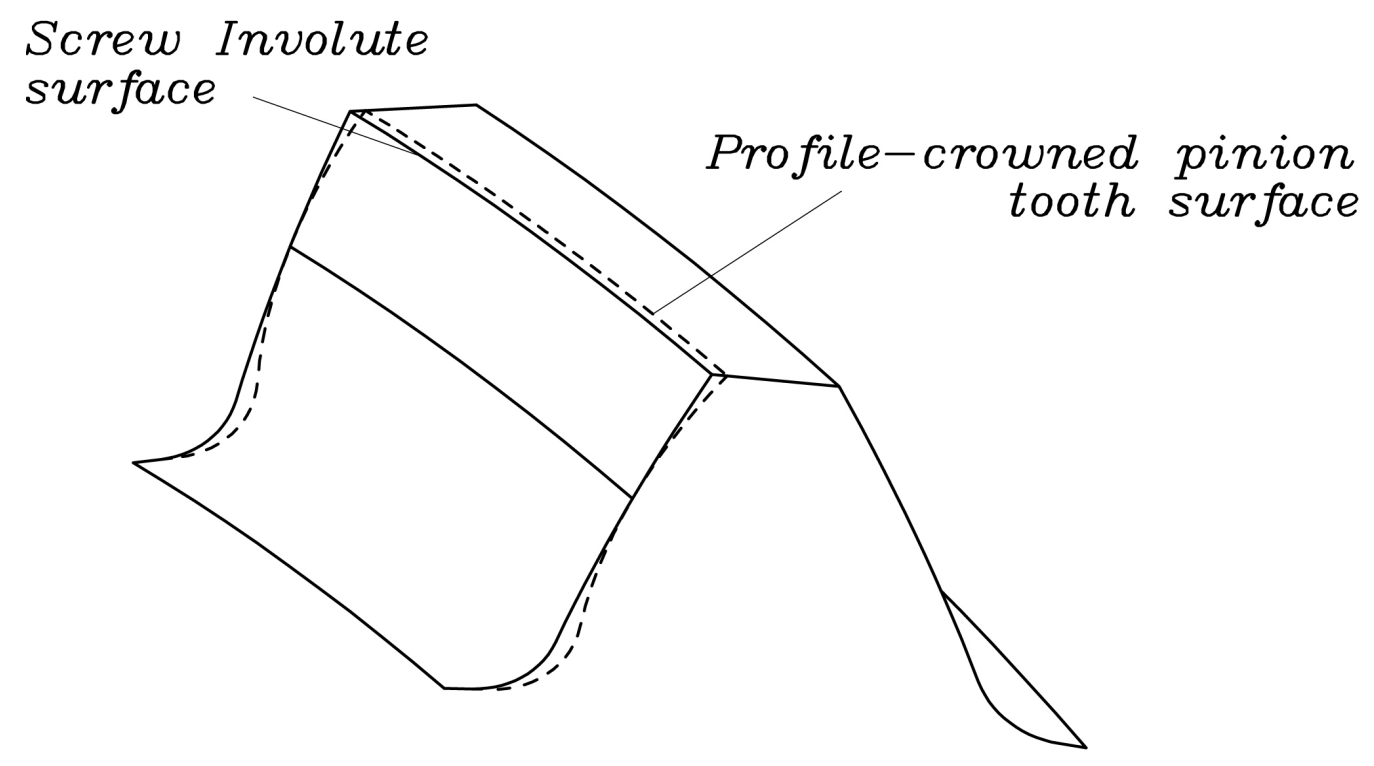

(a)

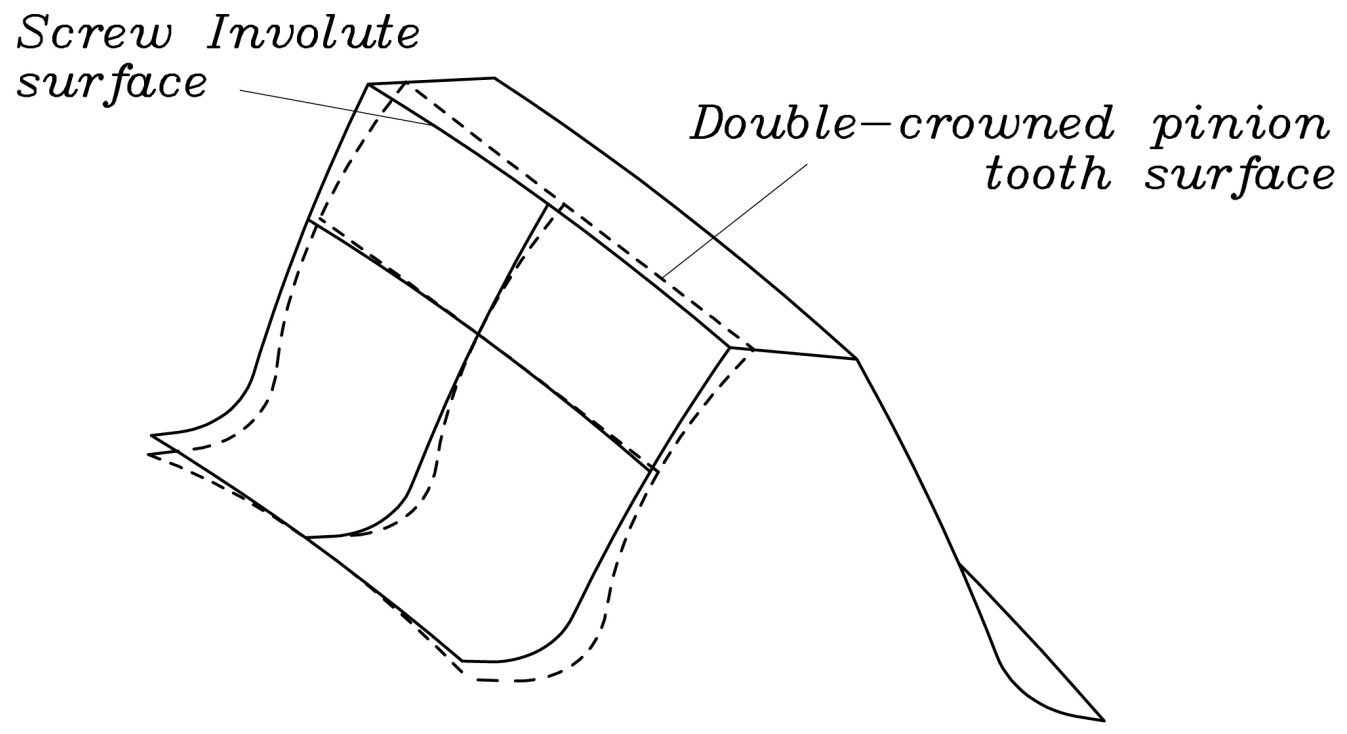

(b)

Figure 2.-Crowning of pinion tooth surface. 


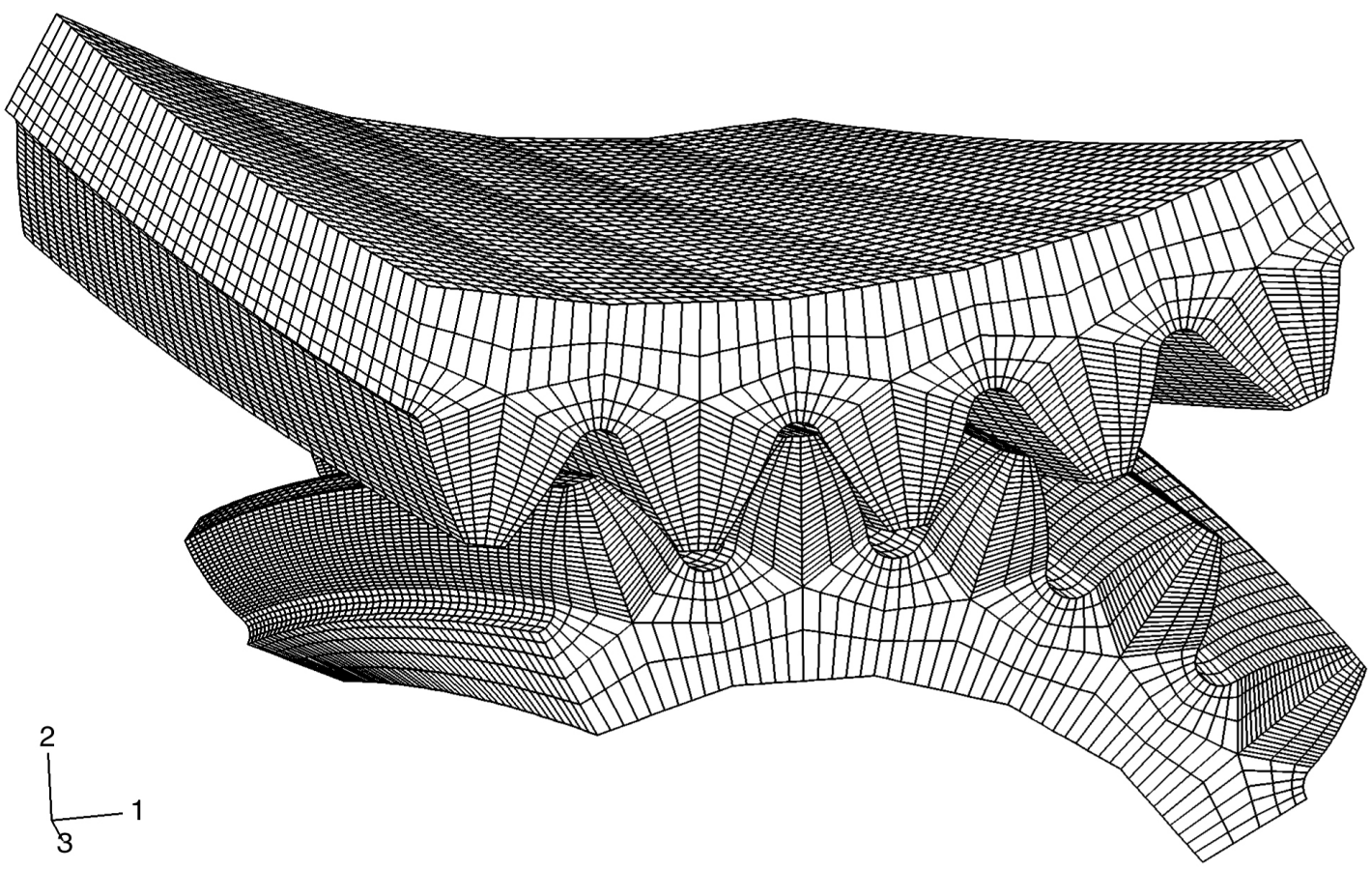

Figure 3.-Contacting model of five pairs of teeth derived for stress analysis. 


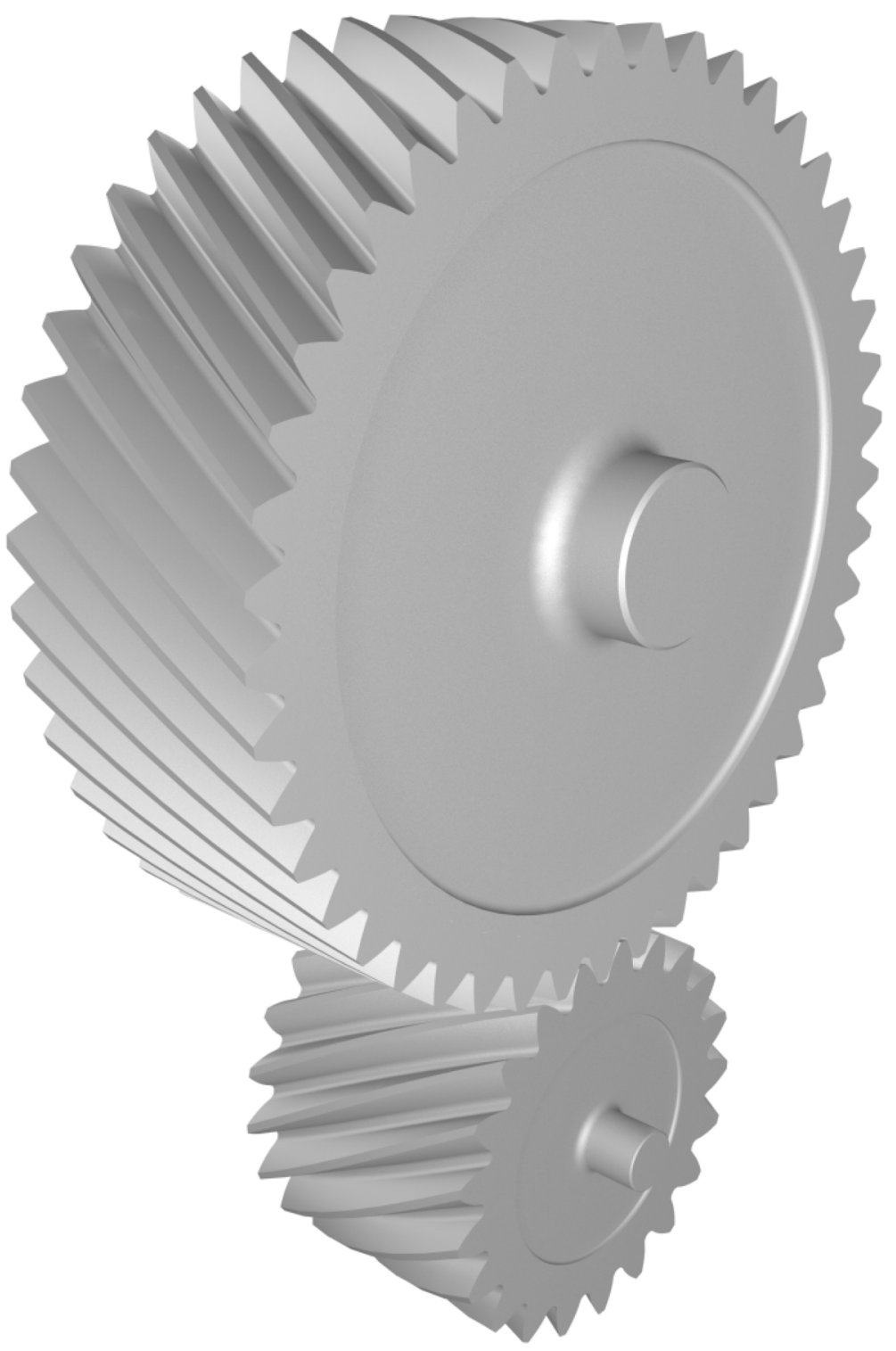

Figure 4.-Modified involute helical gear-drive. 


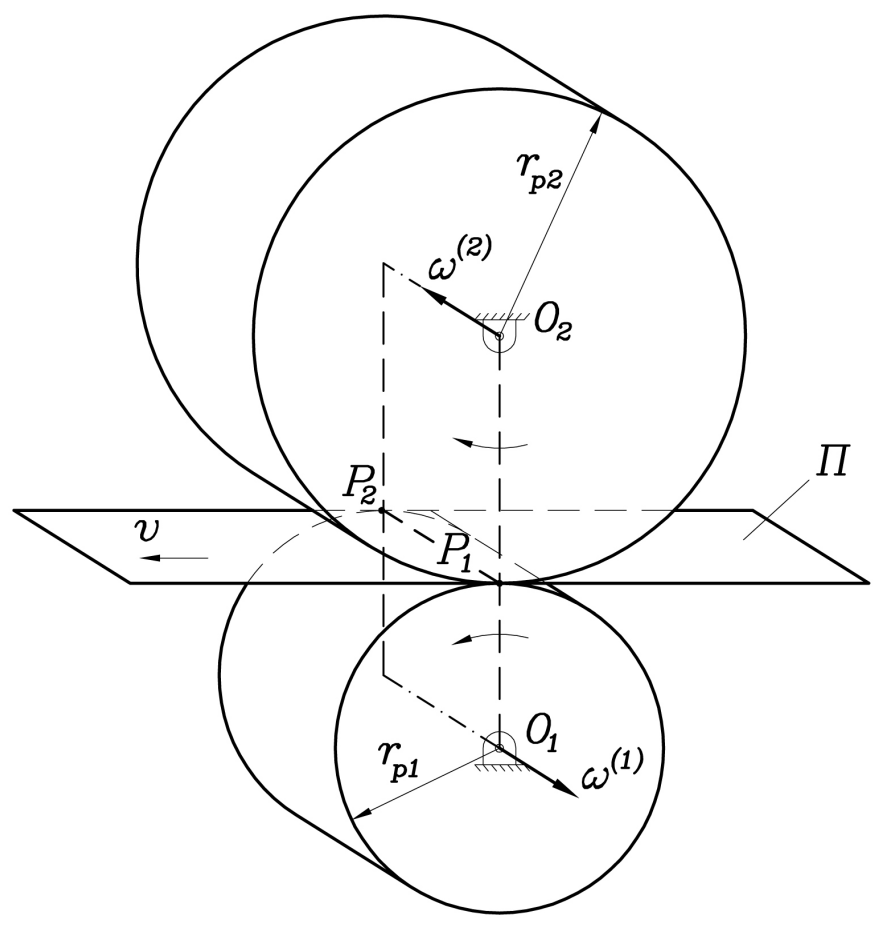

(a)

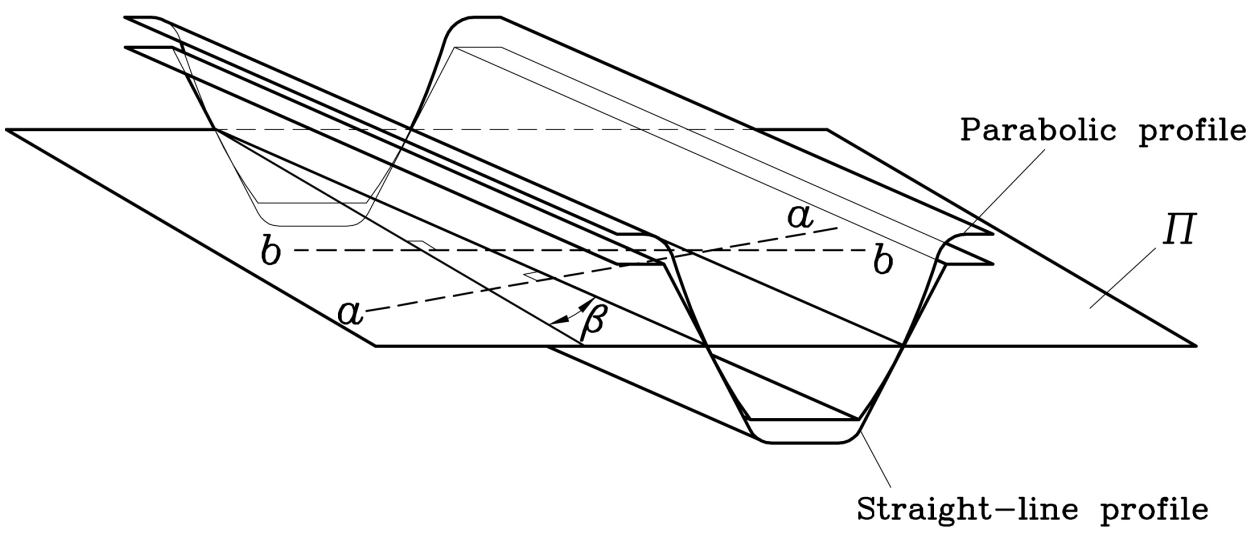

(b)

Figure 5.-Axodes of pinion, gear, and rack-cutter. (a) Axodes. (b) Tooth surfaces of two skew rack-cutters. 

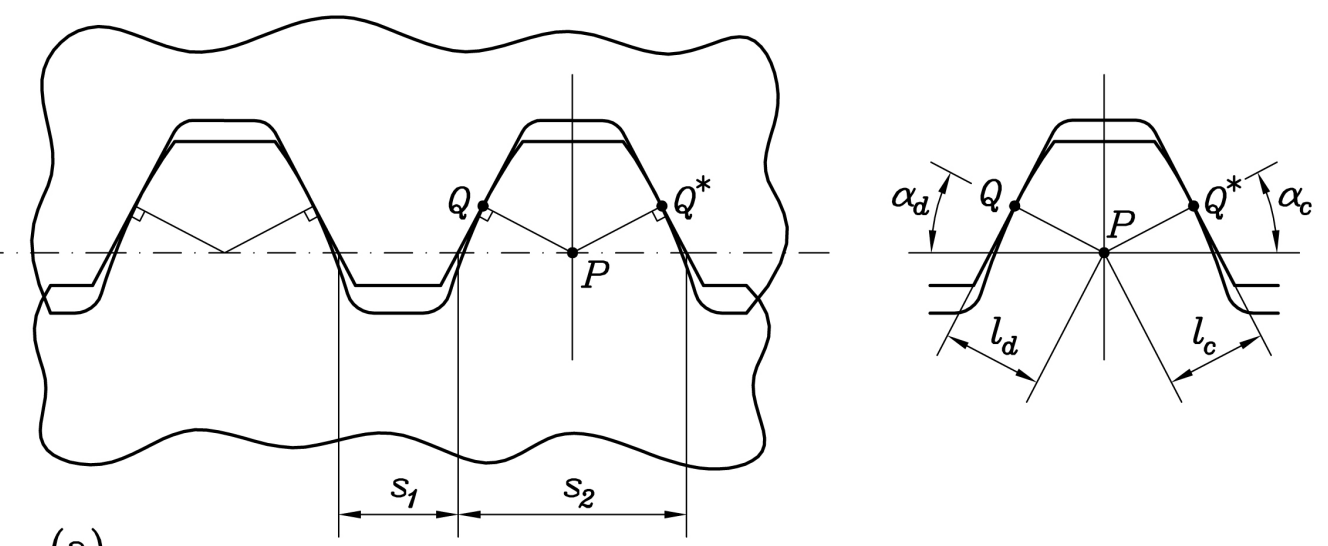

(a)

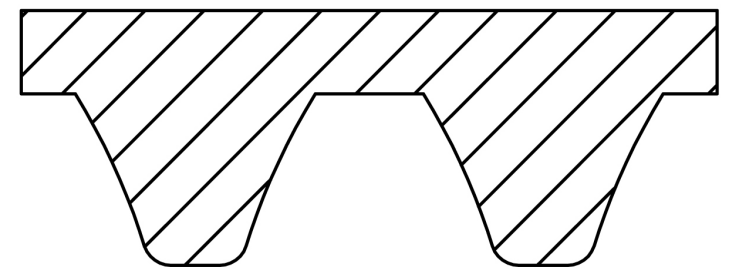

(b)
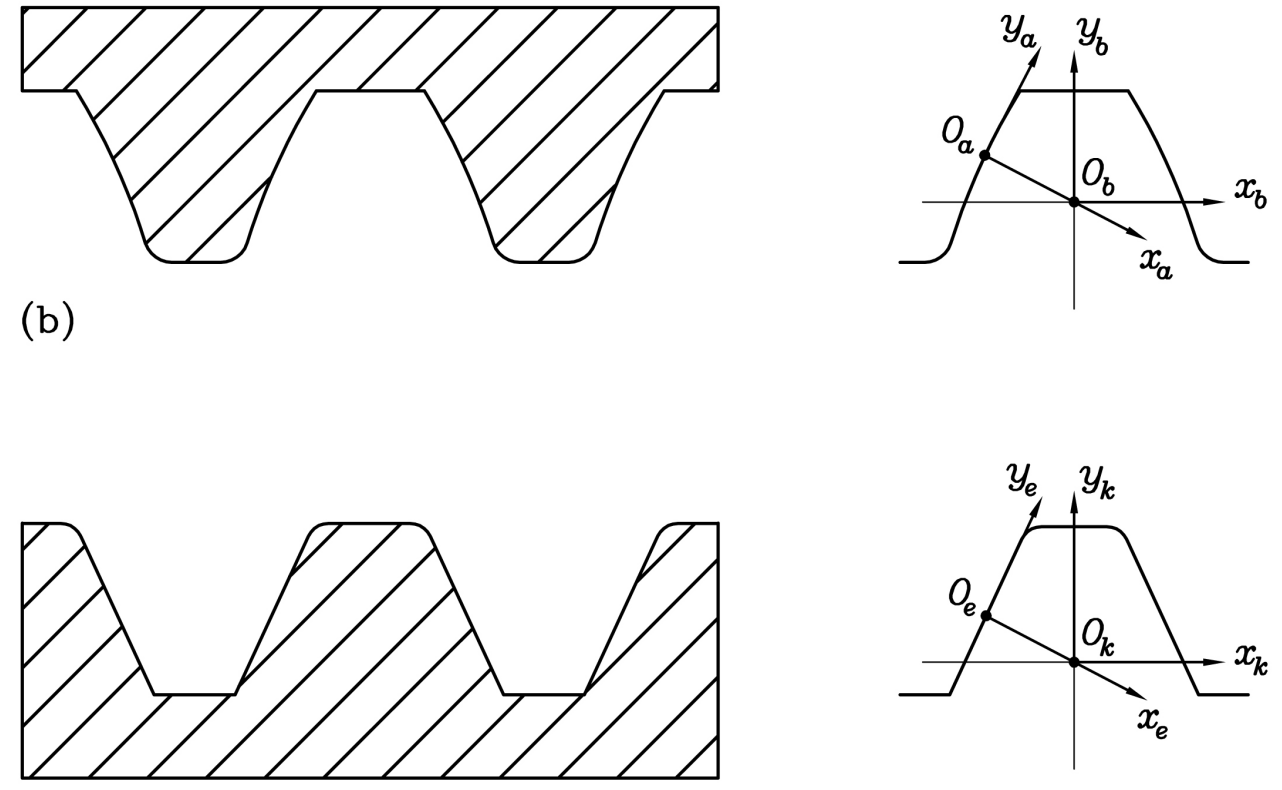

(c)

Figure 6.-Normal sections of pinion and gear rack-cutters. (a) Mismatched profiles. (b) Profiles of pinion rack-cutter in coordinate systems $S_{a}$ and $S_{b}$. (c) Profiles of gear rack-cutter in coordinate systems $S_{e}$ and $S_{k}$. 


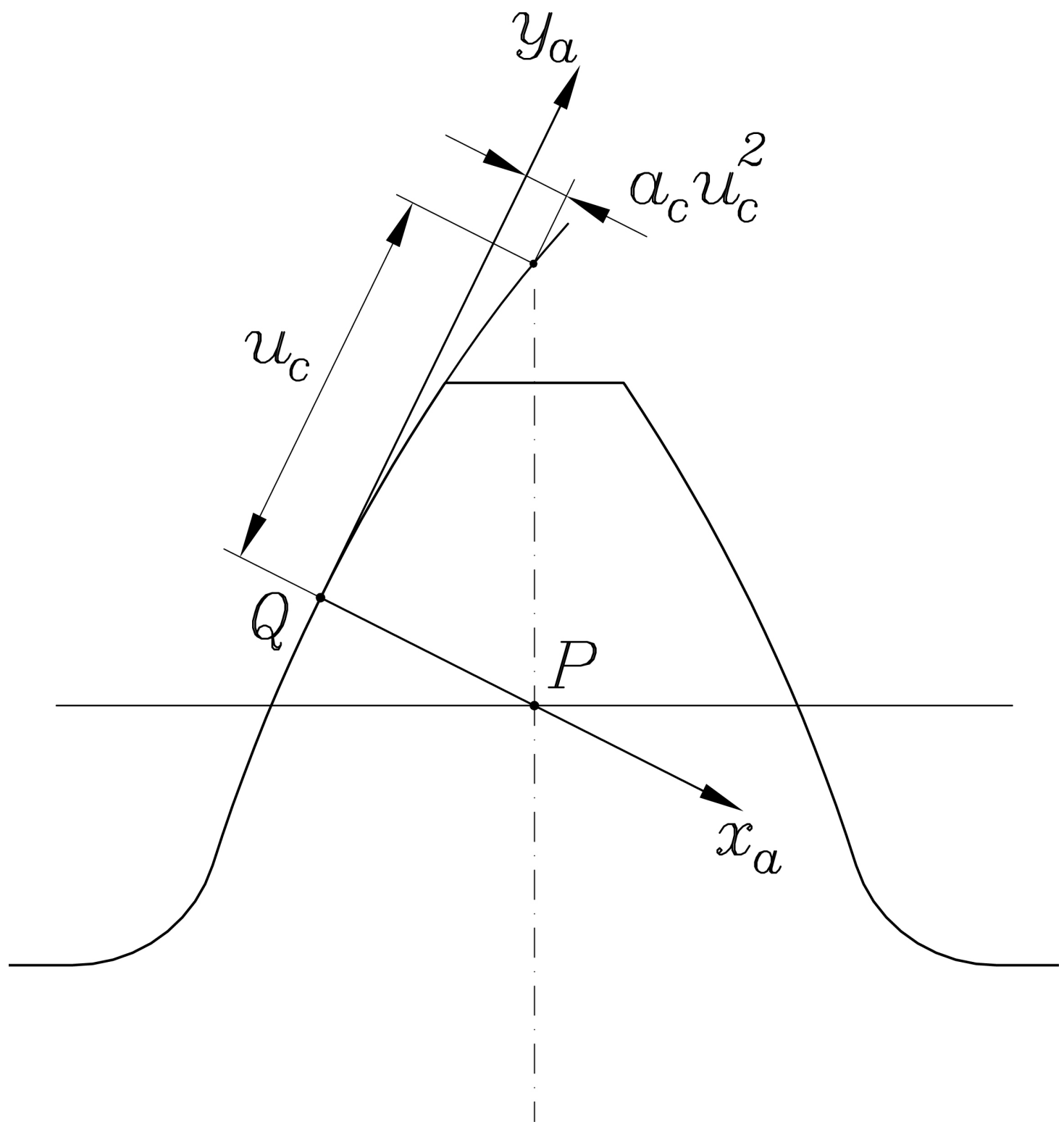

Figure 7.-Parabolic profile of pinion rack-cutter in normal section. 


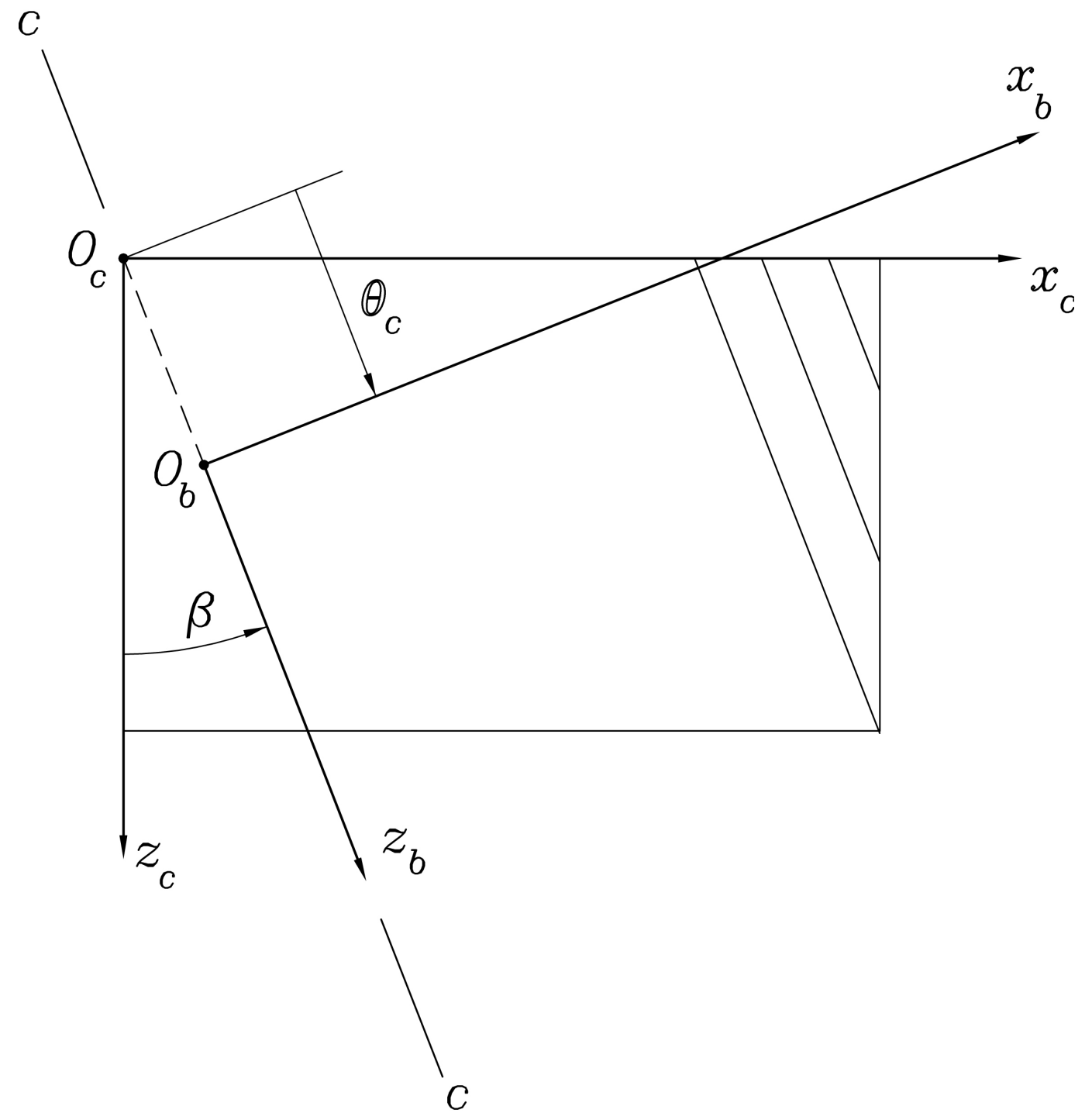

Figure 8.-For derivation of pinion rack-cutter. 


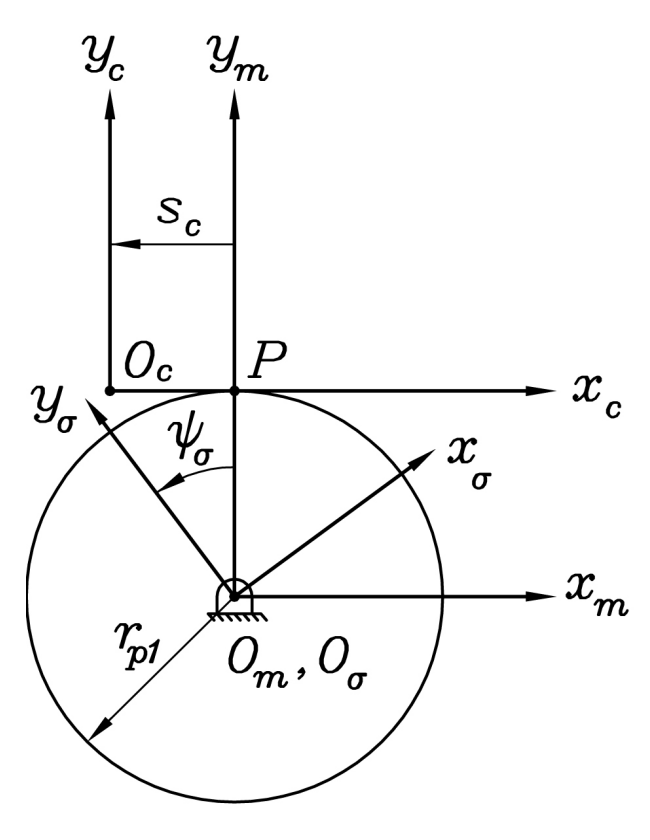

(a)

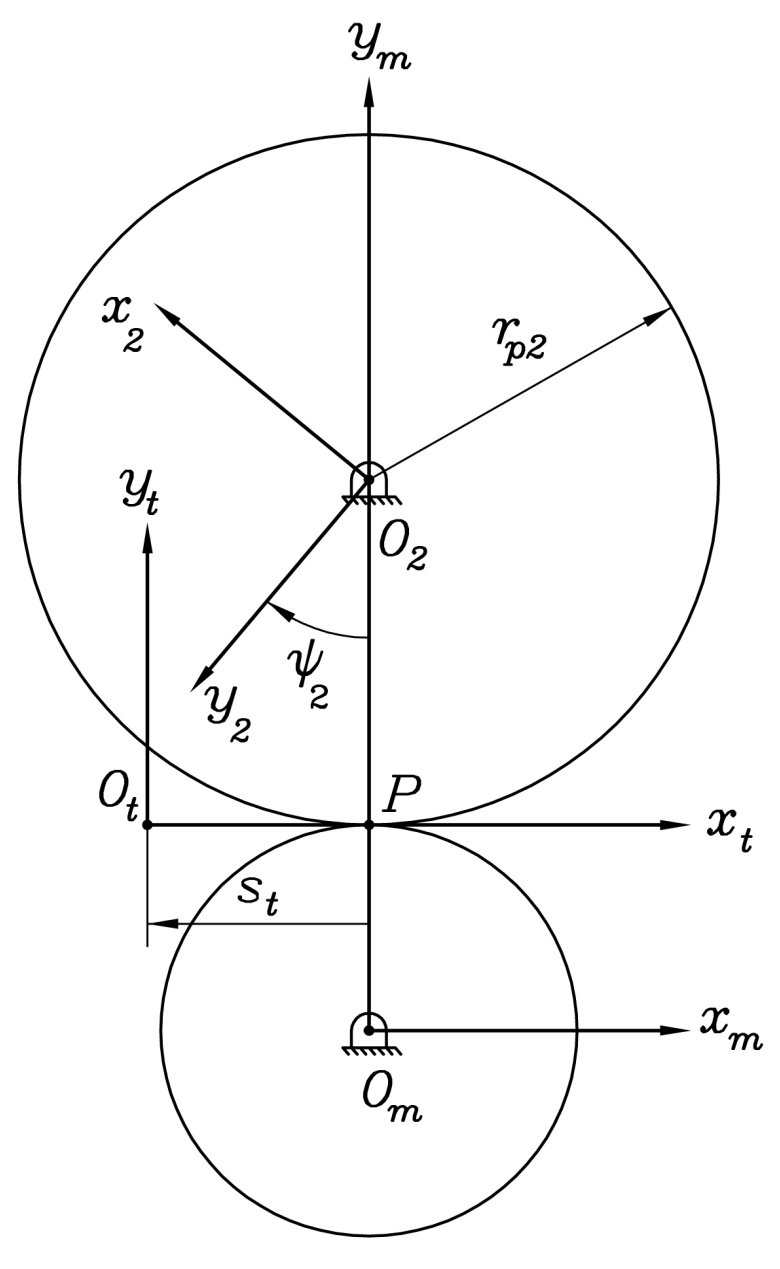

(b)

Figure 9.-Generation of profile crowned tooth surfaces by application of rack-cutters. (a) For pinion generation by rack-cutter $\Sigma_{c}$. (b) For gear generation by rack-cutter $\Sigma_{t}$. 


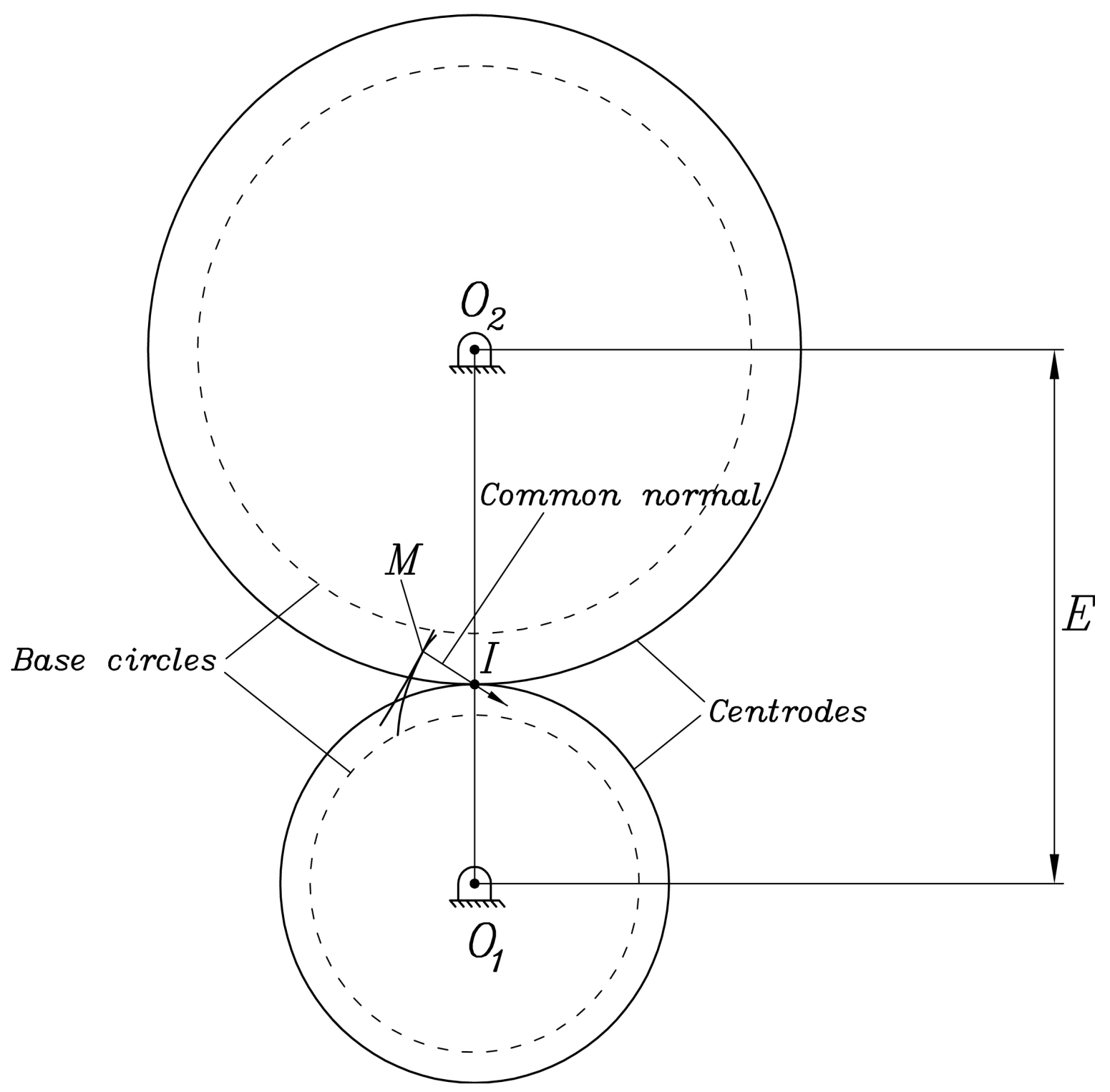

Figure 10.-Illustration of cross-profiles of profile-crowned helicoids. 


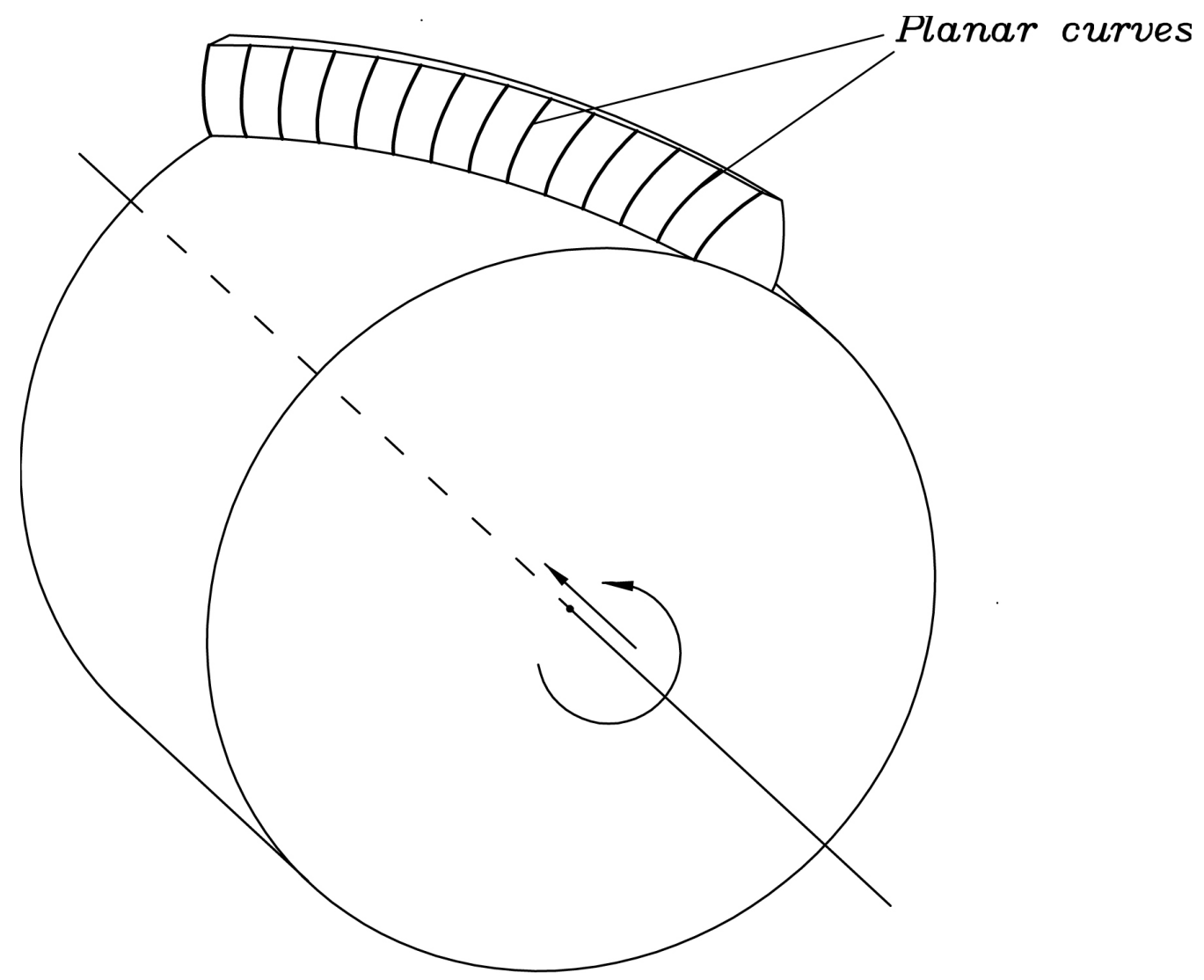

Figure 11.-Illustration of formation of helicoid surface by screw motion of a cross-profile of the helicoids. 


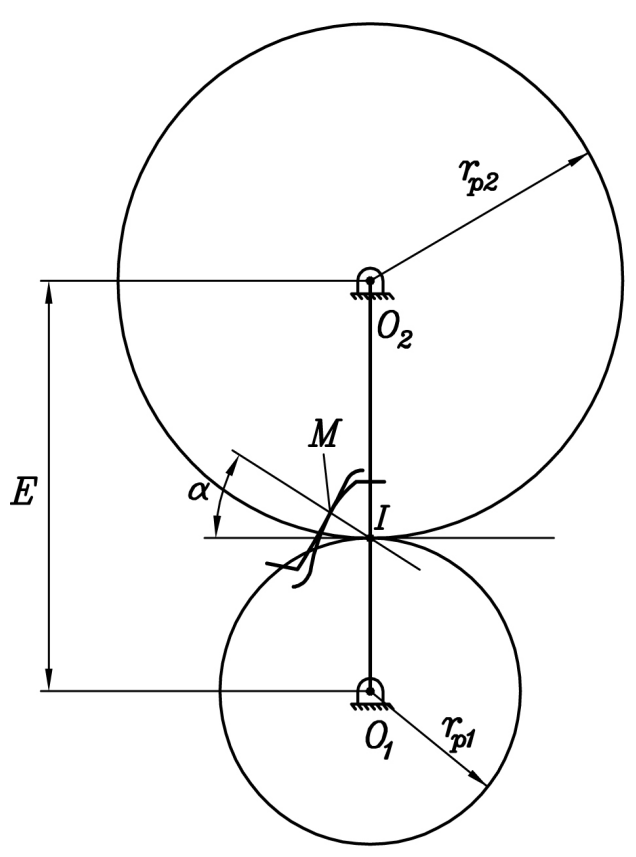

(a)

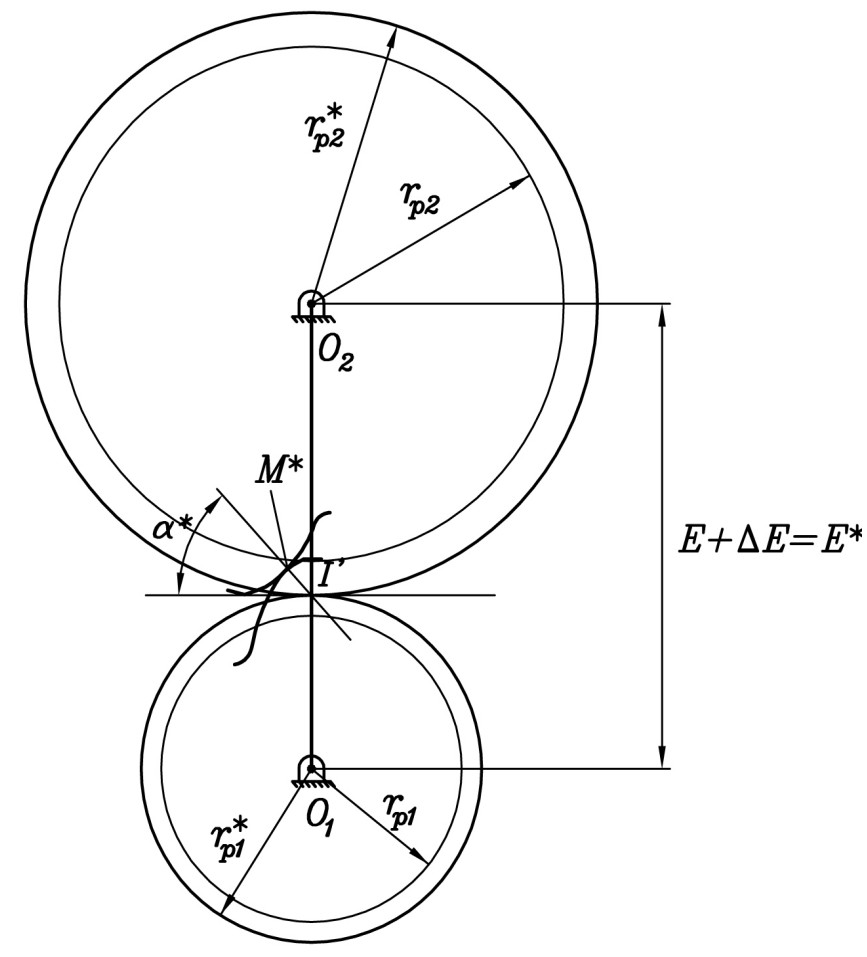

(b)

Figure 12.-Operating circles in an aligned gear drive. (a) Change of center distance $\Delta E=0$ when no errors are applied. (b) $\Delta E \neq 0$. 


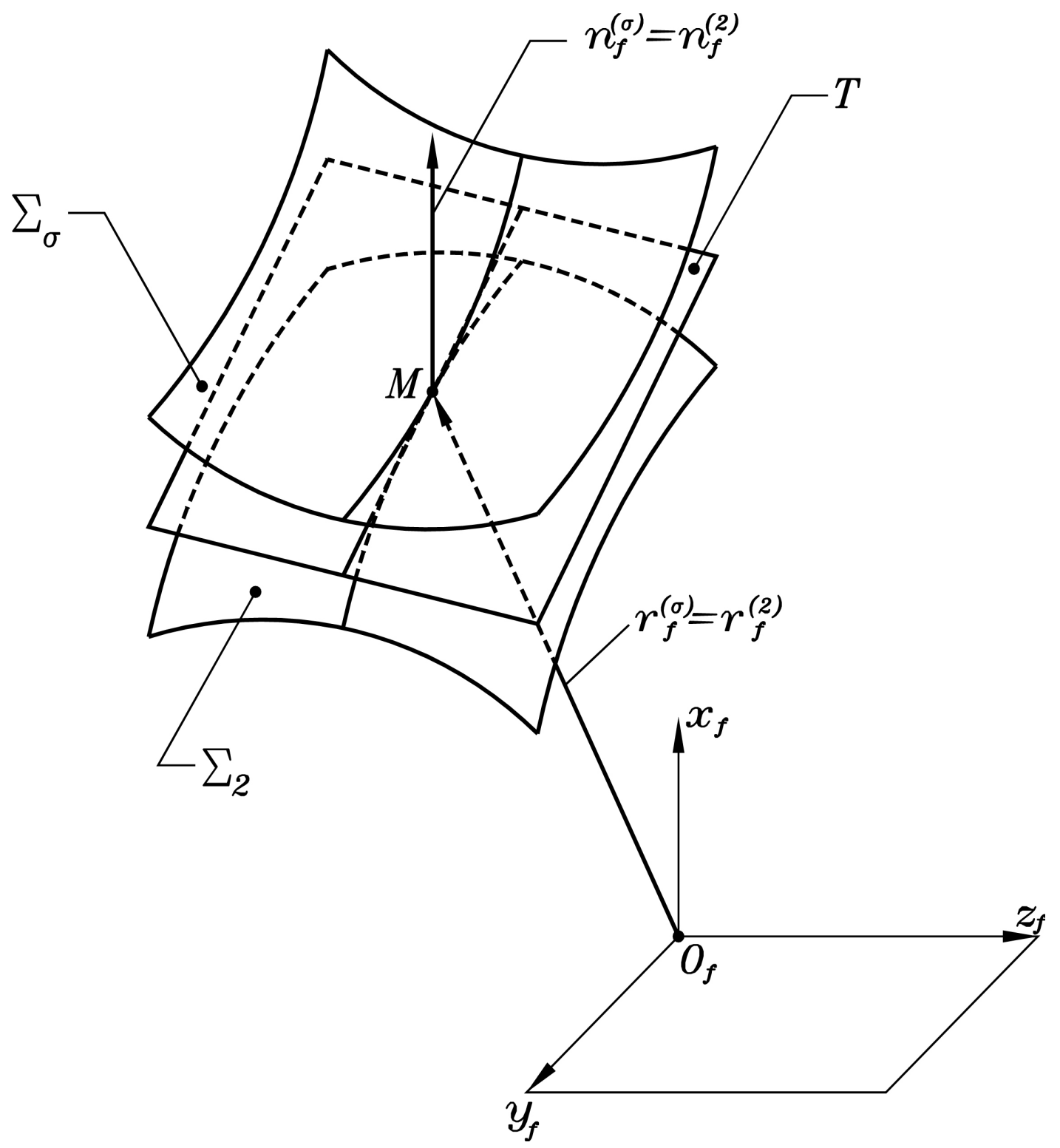

Figure 13.-Illustration of continuous tangency of contacting tooth surfaces $\Sigma_{\sigma}$ and $\Sigma_{2}$. 


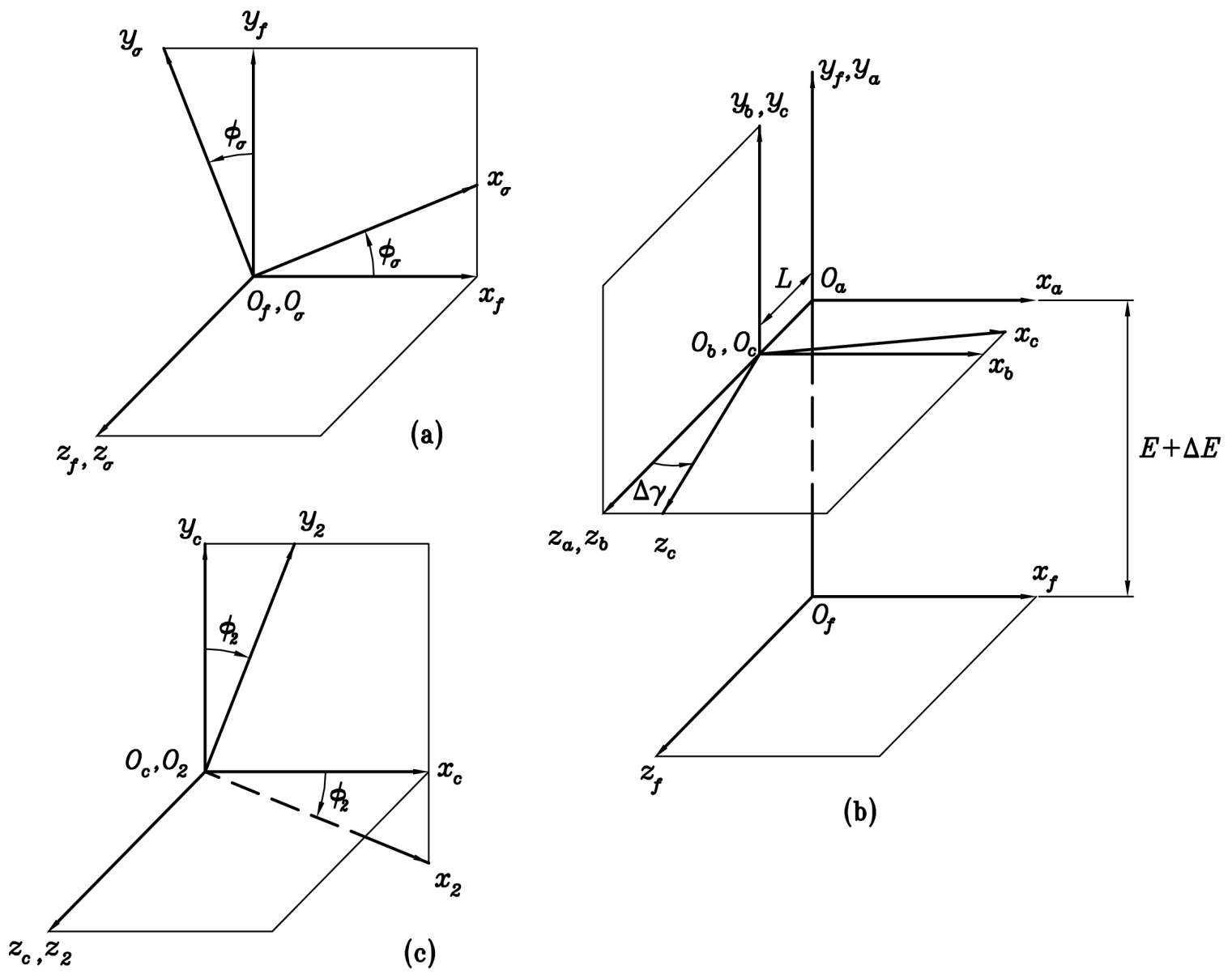

Figure 14.-IIlustration of installment of coordinate systems for simulation of misalignment. 

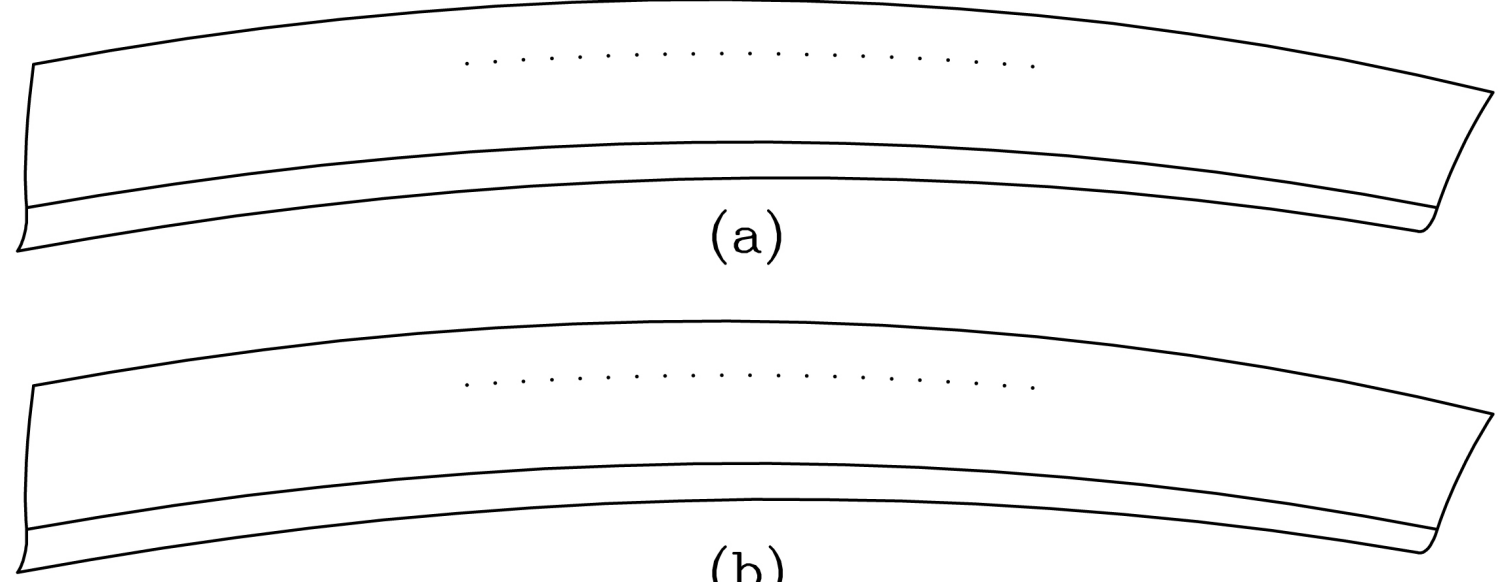

(b)

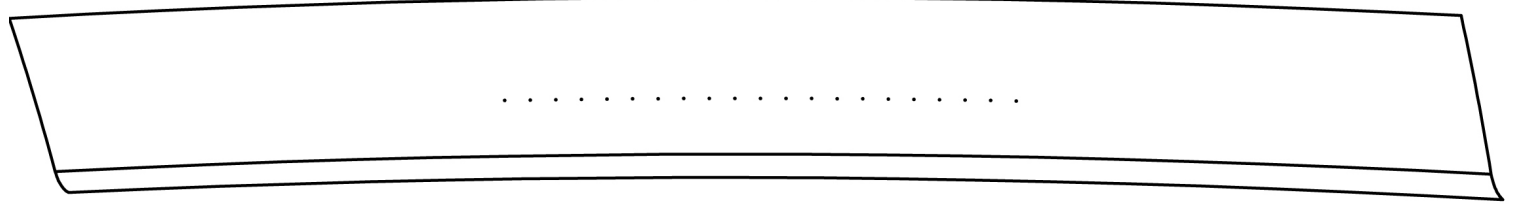

(c)

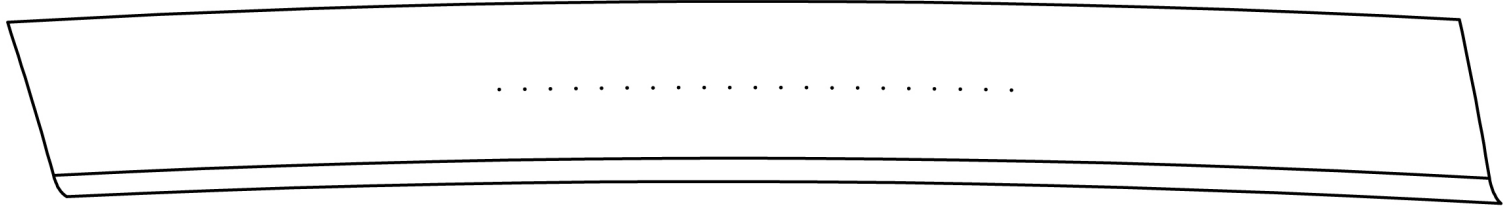

(d)

Figure 15.-Shift of bearing contact caused by $\Delta E$ for the following cases. (a) Path of contact on pinion surface when no error of center distance is applied. (b) When an error $\Delta E=1 \mathrm{~mm}$ is applied. (c) Path of contact on gear surface when no error is applied. (d) When an error $\Delta E=1 \mathrm{~mm}$ is applied. 


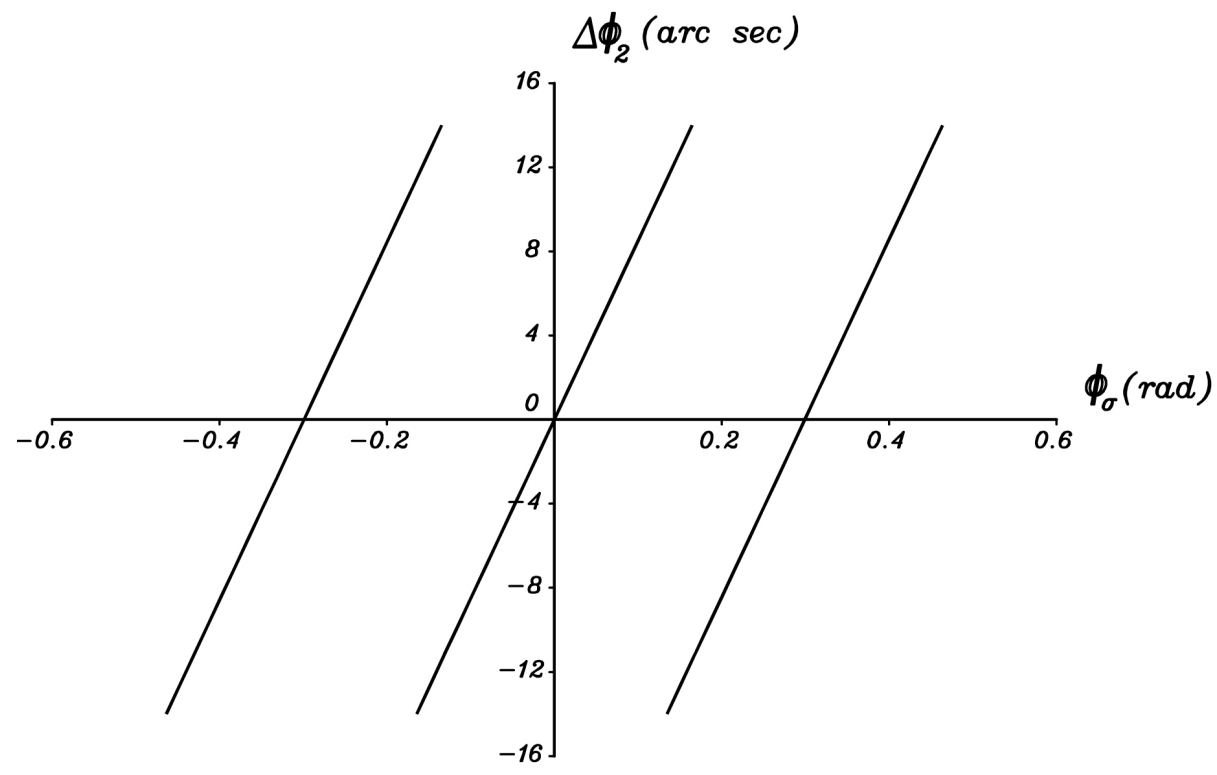

(a)

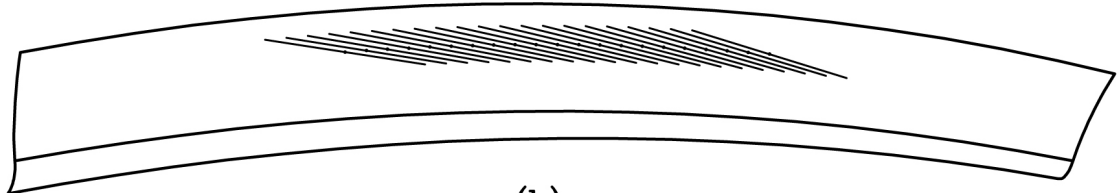

(b)

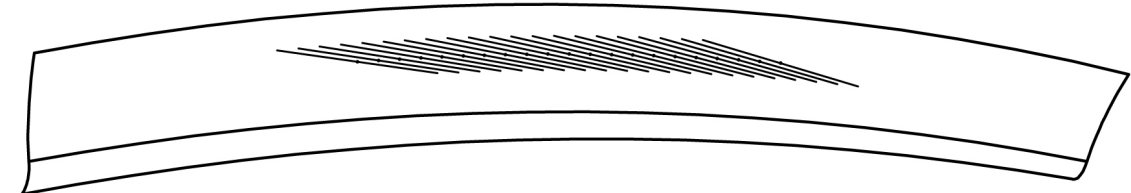

(c)

Figure 16.-lllustration of transmission errors and shift of bearing contact on the pinion tooth surface of a profile crowned gear drive caused by $\Delta \gamma$. (a) Function of transmission errors with error $\Delta \gamma=3$ arcmin. (b) Path of contact when no errors are applied. (c) Path of contact with error $\Delta \gamma=3$ arcmin. 


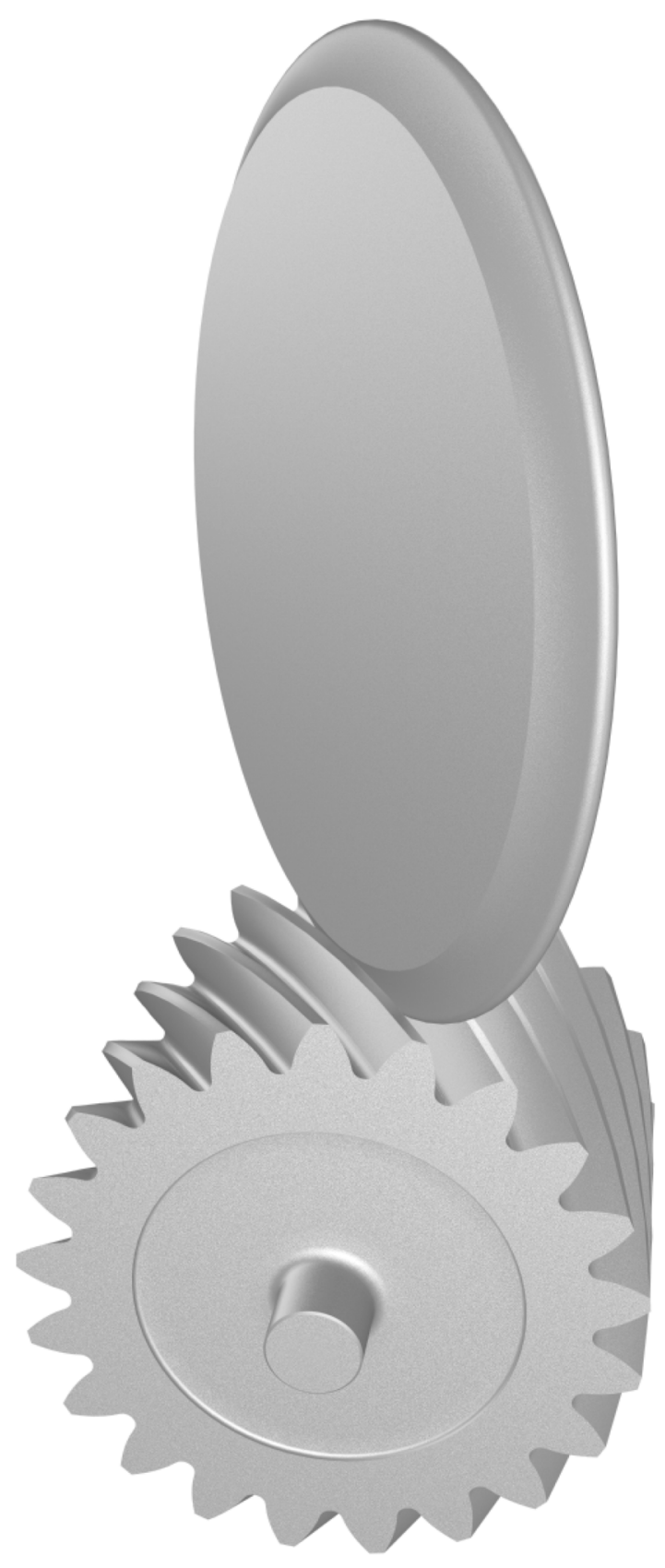

Figure 17.-Generation of pinion by grinding disk. 


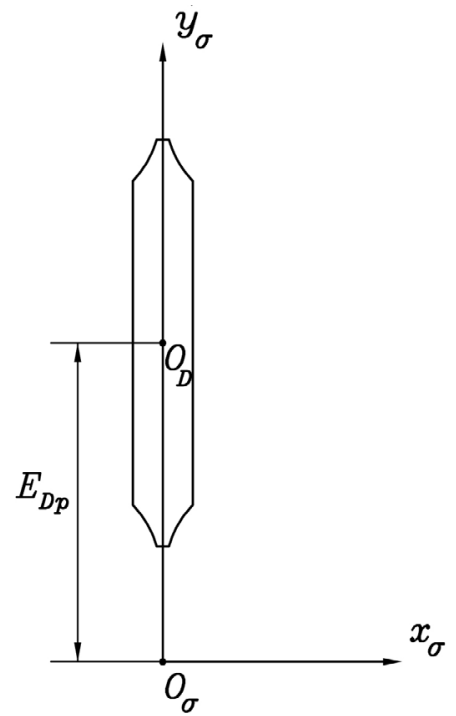

(a)

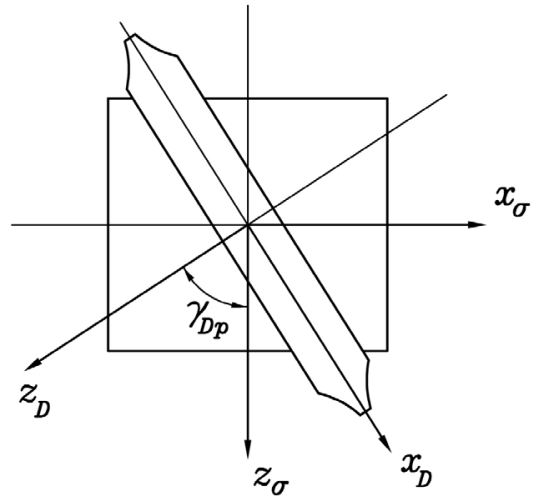

(b)

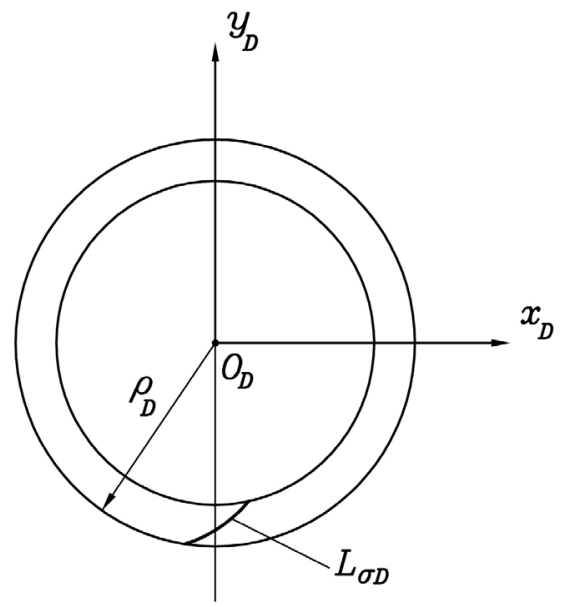

(c)

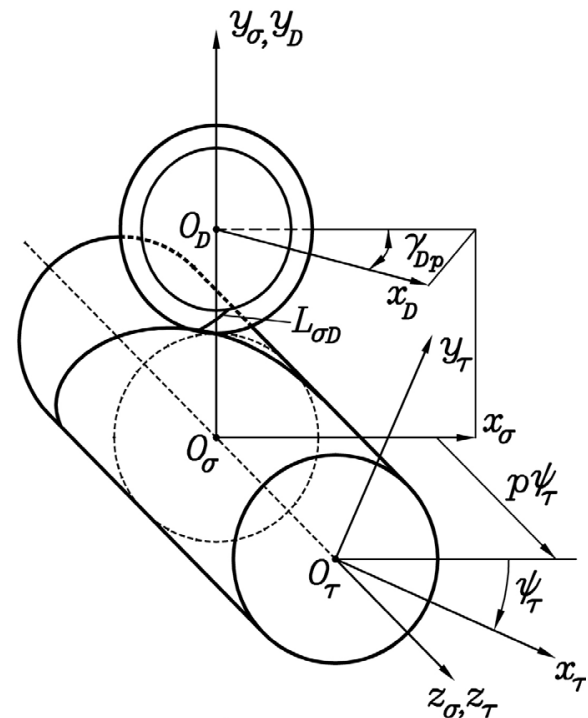

(d)

Figure 18.-Determination of disk surface $\Sigma_{D}$. (a) and (b) Installment of grinding disk. (c) Line $L_{\sigma D}$ of tangency of surfaces $\Sigma_{\sigma}$ and $\Sigma_{D}$. (d) Illustration of generation of surface $\Sigma_{\tau}$ by disk surface $\Sigma_{D}$. 

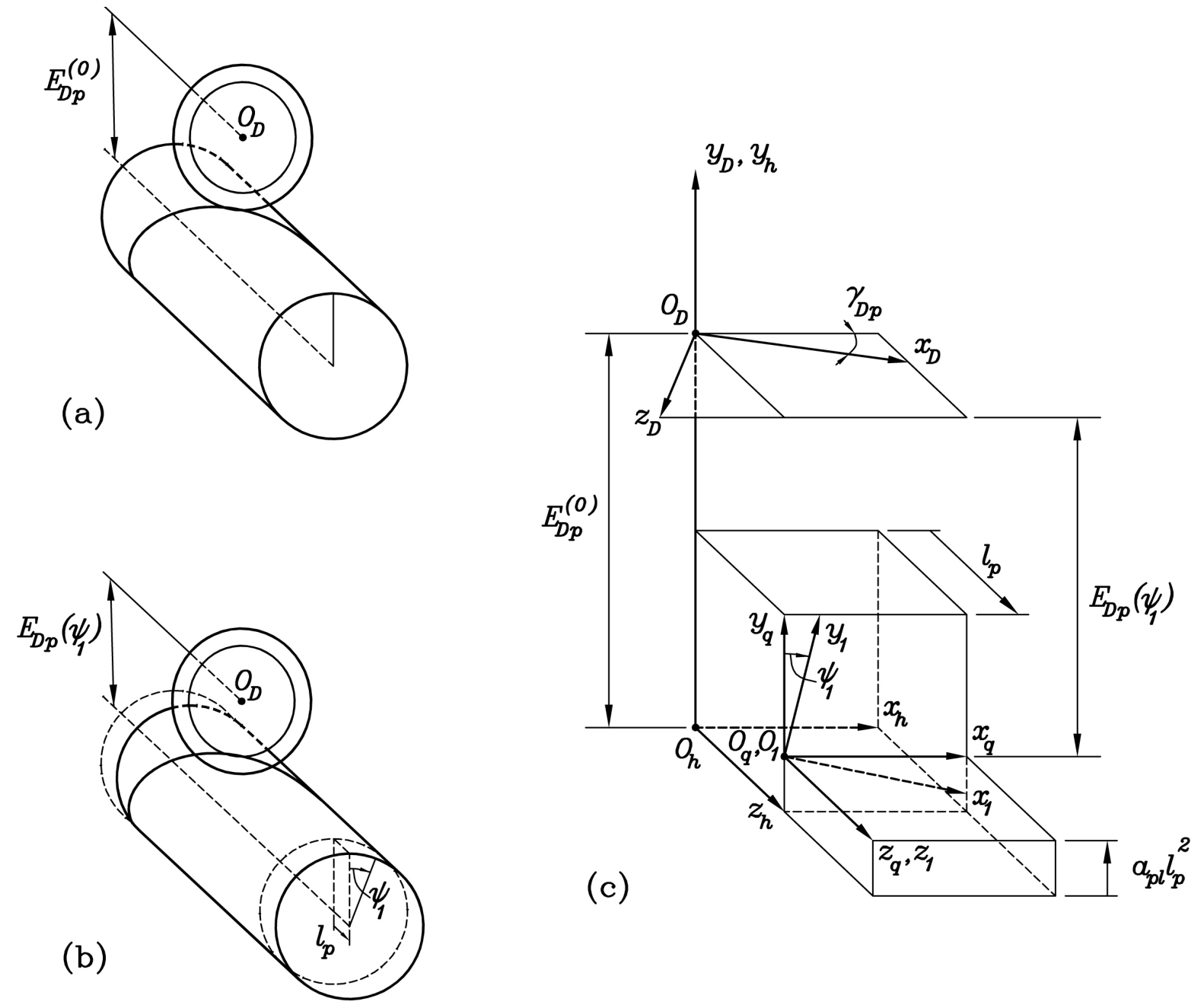

Figure 19.-Generation of double crowned pinion surface $\Sigma_{1}$ by a plunging disk. (a) Initial positions of pinion and disk. (b) Schematic of generation. (c) Applied coordinate systems. 


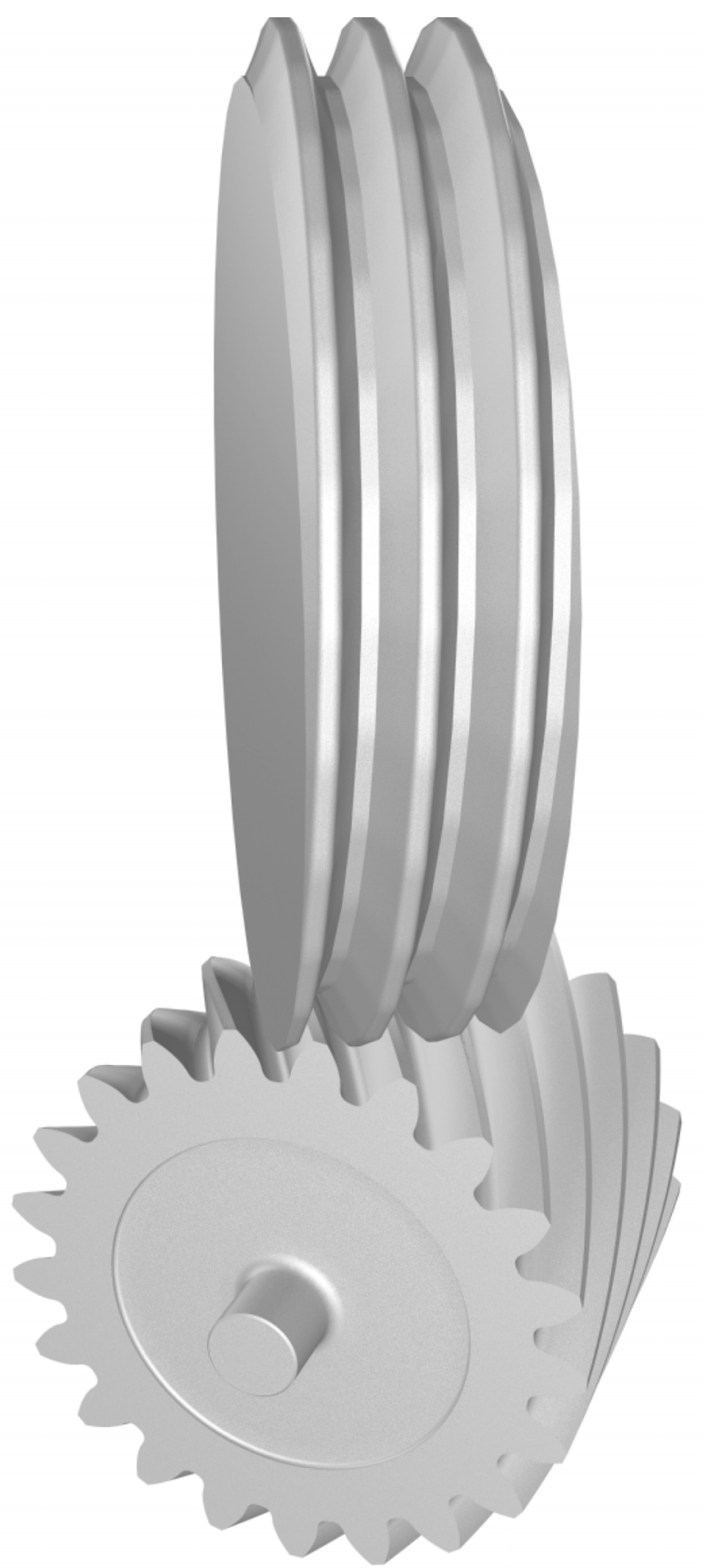

Figure 20.-Generation of pinion by grinding worm. 


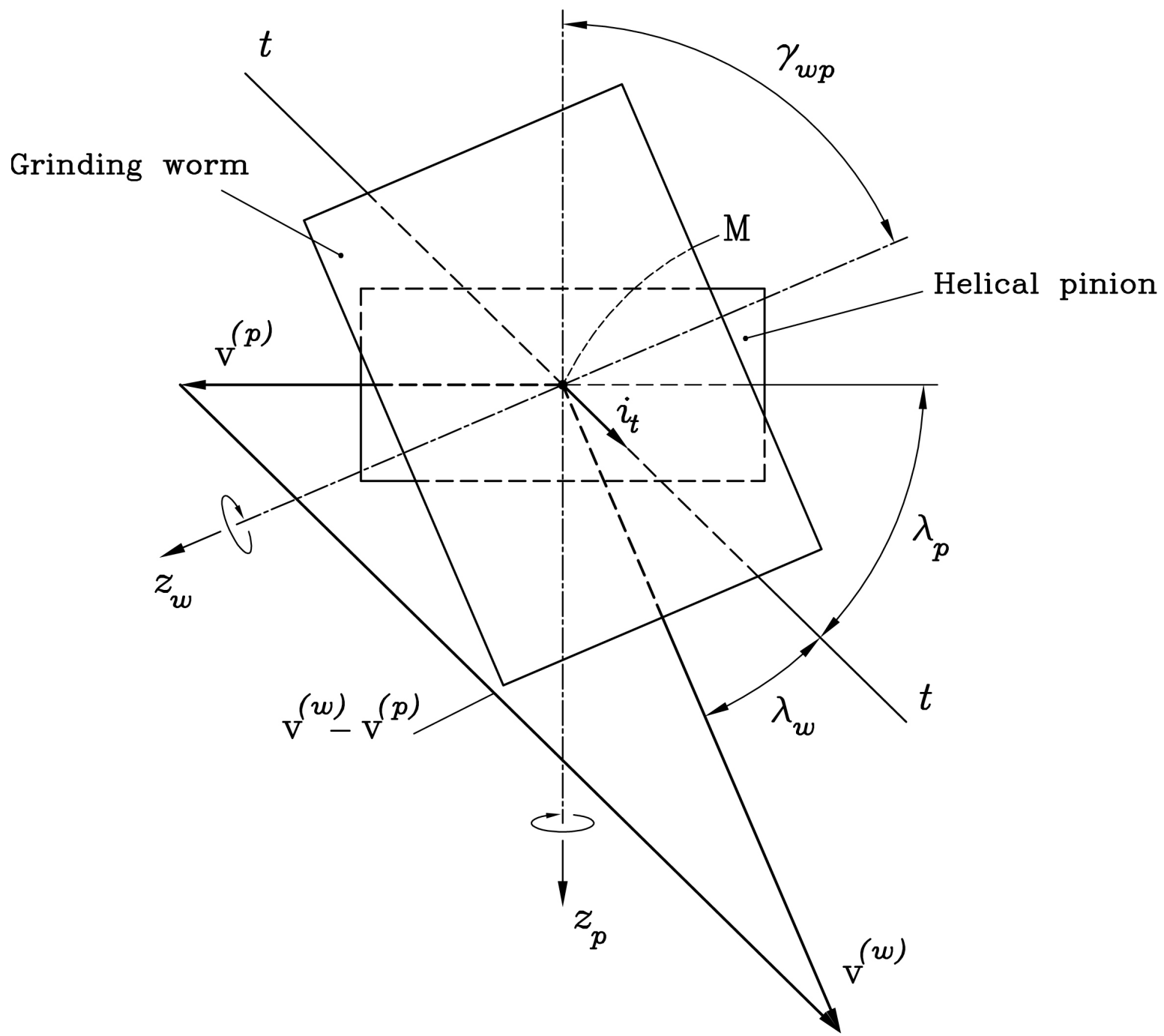

Figure 21.-Installment of grinding (cutting) worm. 


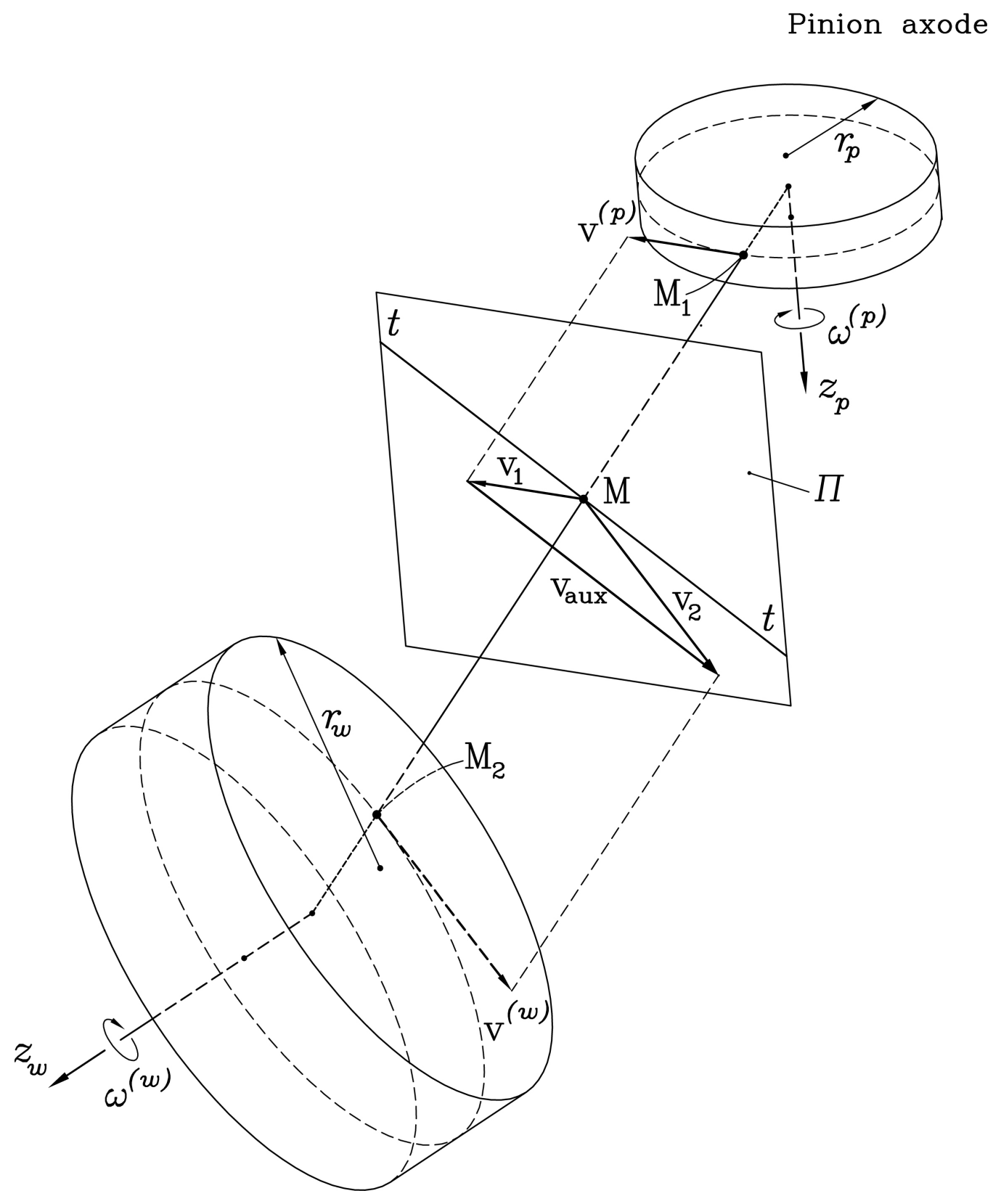

Worm axode

Figure 22.-For illustration of axodes of worm, pinion, and rack-cutter. 


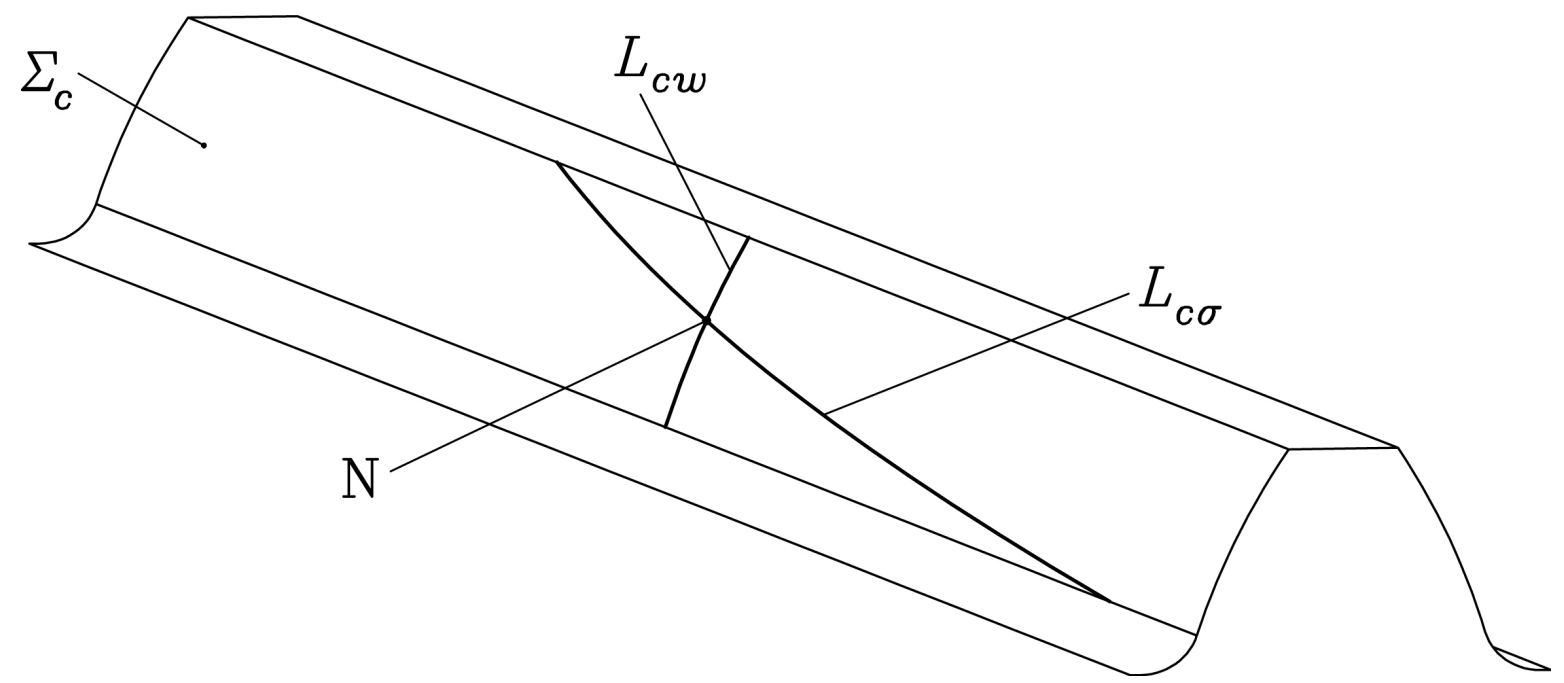

Figure 23.-Contact lines $L_{c \sigma}$ and $L_{c w}$ corresponding to meshing of rack-cutter $\Sigma_{C}$ with pinion and worm surfaces $\Sigma_{\sigma}$ and $\Sigma_{W}$, respectively.
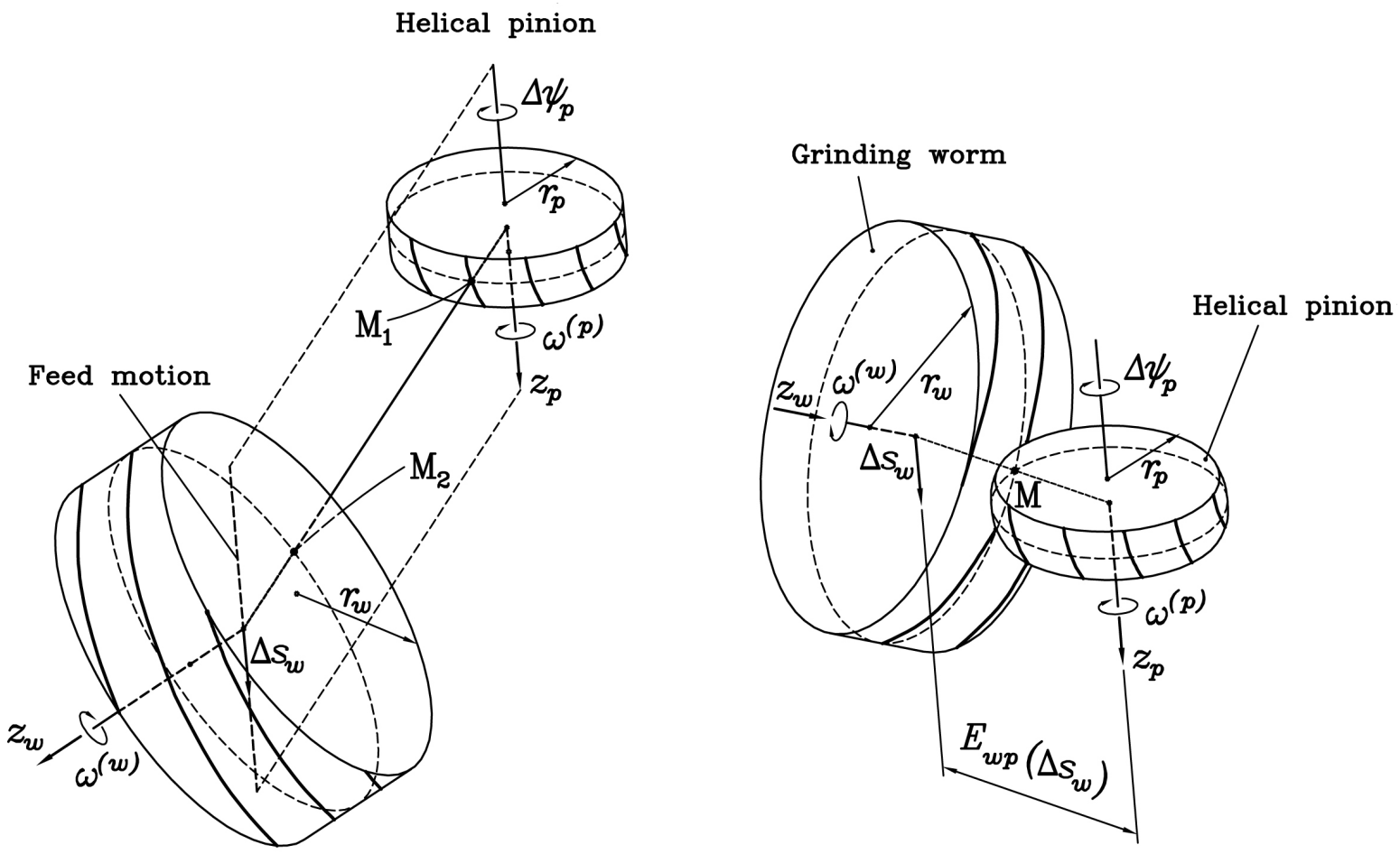

Grinding worm

(a)

(b)

Figure 24.-Schematic of generation. (a) Without worm plunging. (b) With worm plunging. 


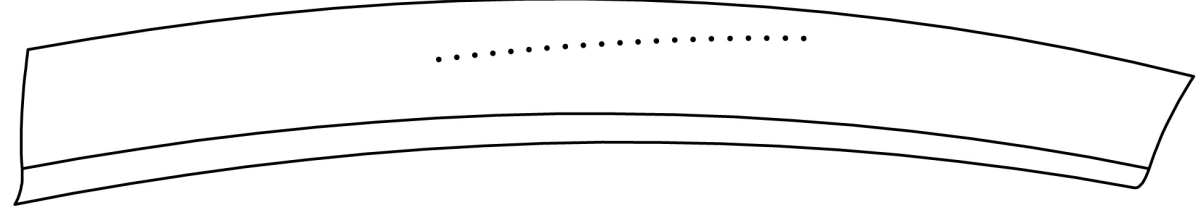

(a)

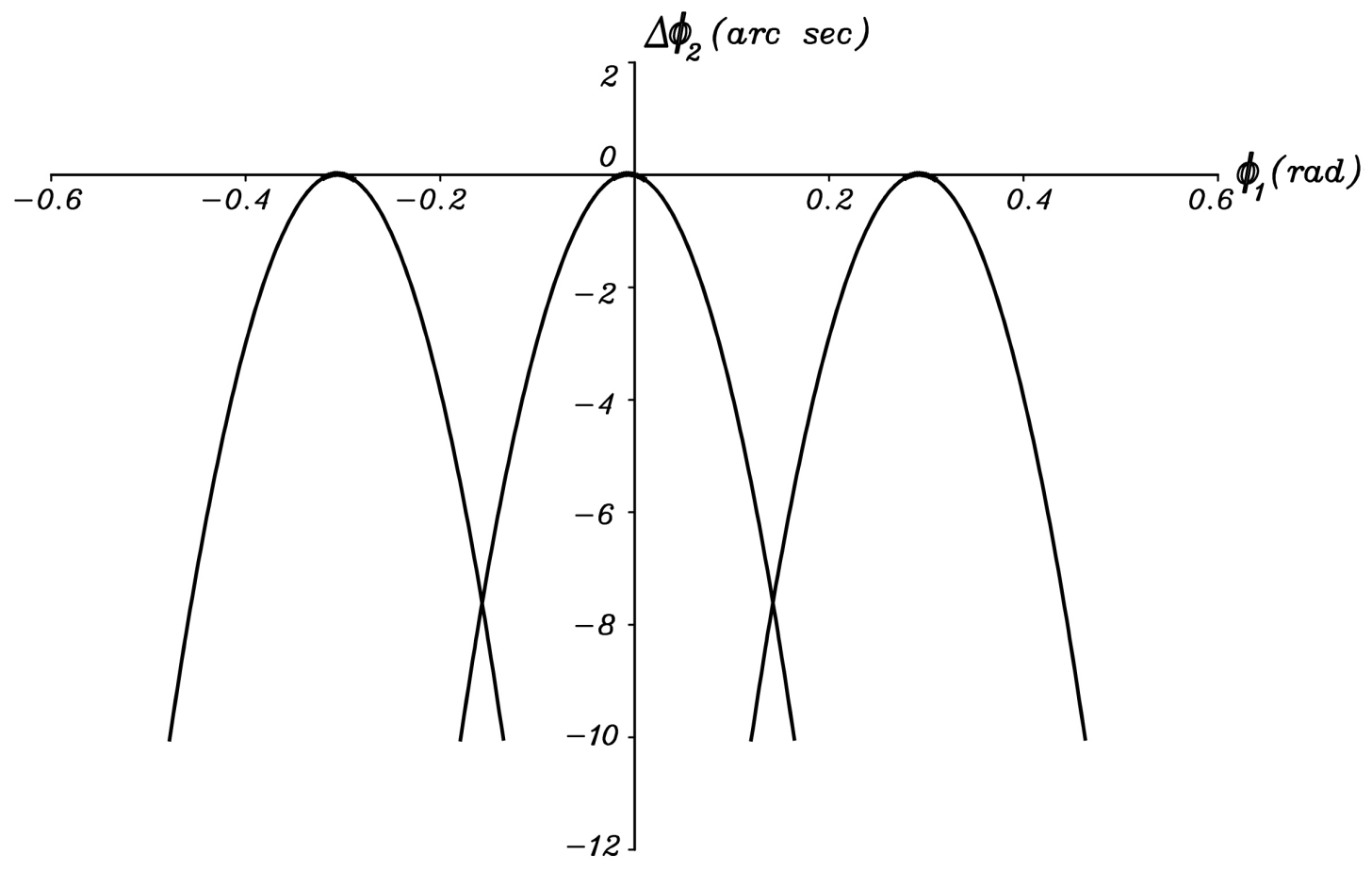

(b)

Figure 25.-Output of TCA for a gear drive wherein the pinion is generated by plunging of the grinding worm; no errors are applied. (a) Path of contact. (b) Function of transmission errors. 


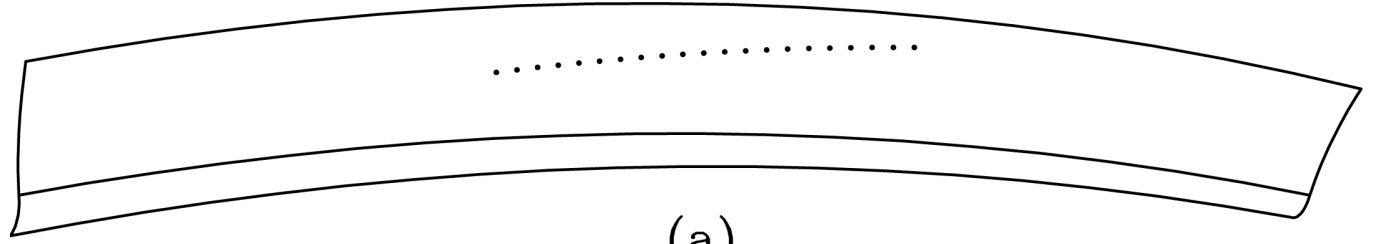

(a)

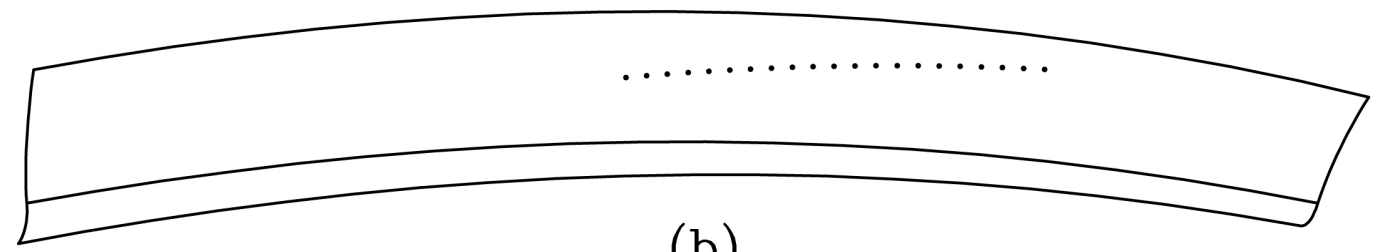

(b)
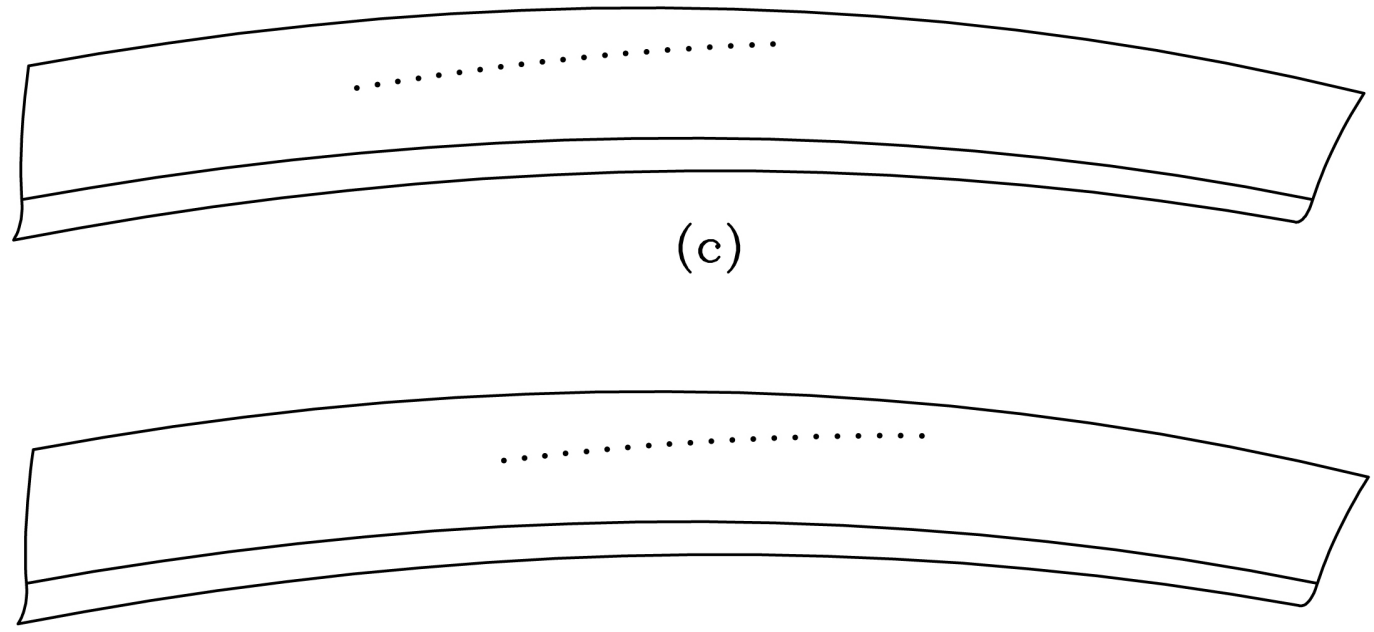

(d)

Figure 26.-Influence of errors of alignment on the shift of the path of contact for a modified involute helical gear drive wherein the pinion is generated by plunging of the grinding worm with the following errors. (a) $\Delta E=140 \mu \mathrm{m}$. (b) $\Delta \gamma=3$ arcmin. (c) $\Delta \lambda=3$ arcmin.

(d) $\Delta \gamma-\Delta \lambda_{1}=0$ arcmin. 


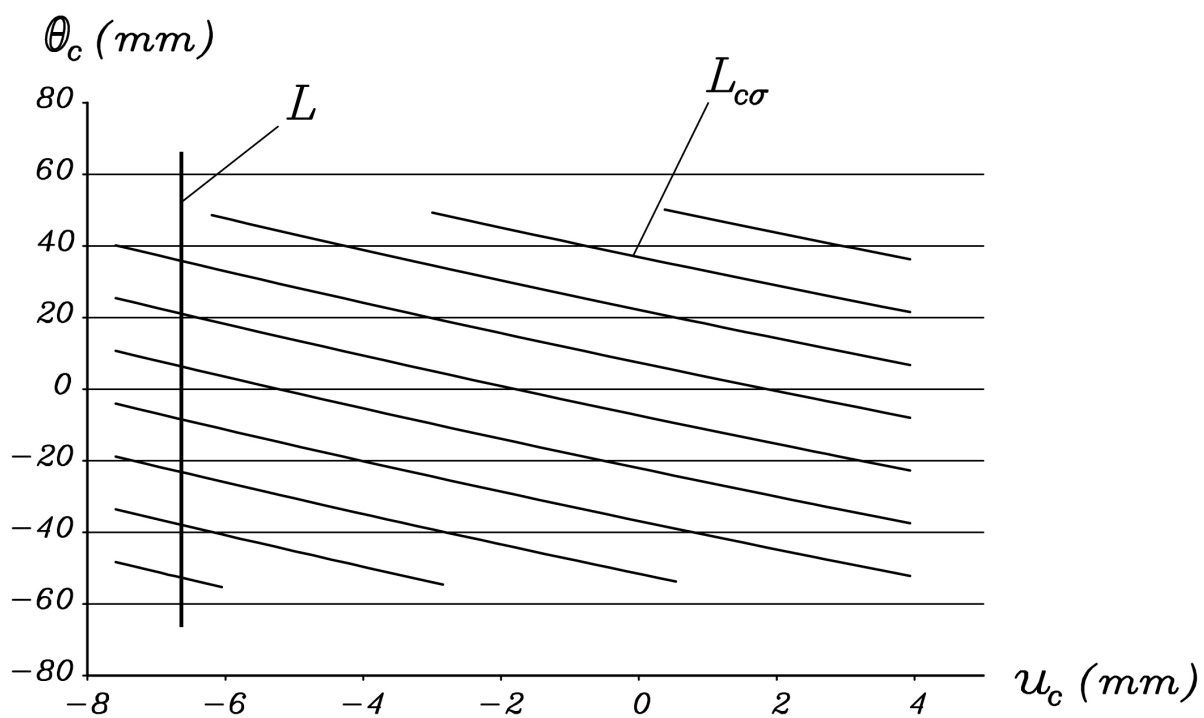

(a)

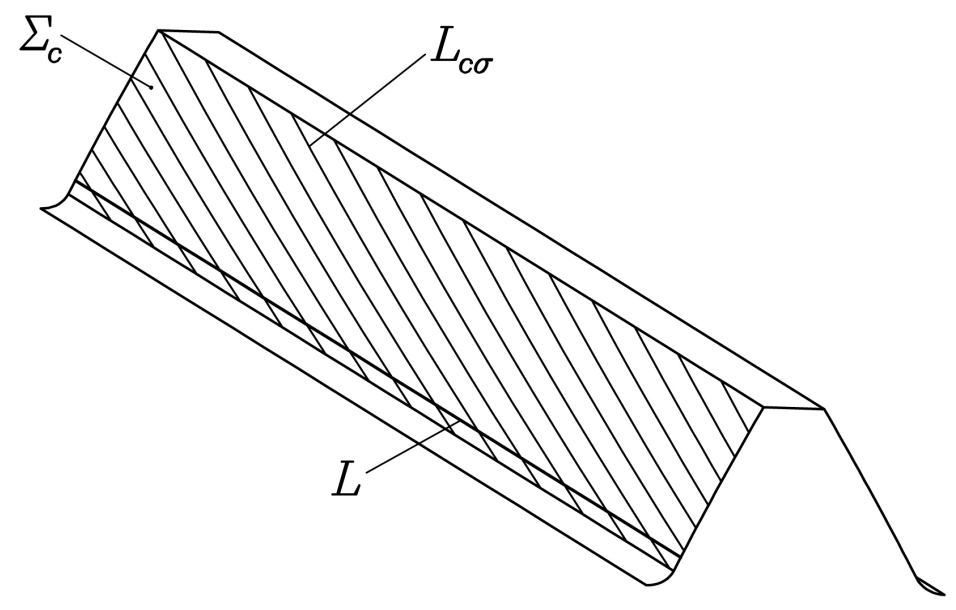

(b)

Figure 27.-Contact lines $L_{C \sigma}$ and limiting line $L$. (a) In plane $\left(u_{c}, \theta_{C}\right)$. (b) On surface $\Sigma_{C}$. 


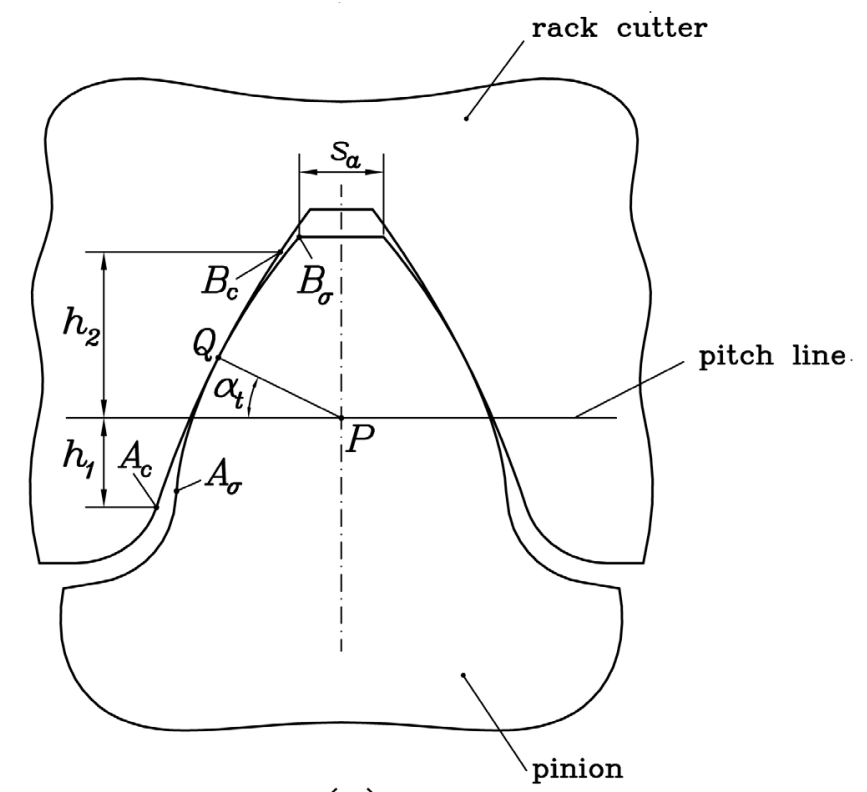

(a)

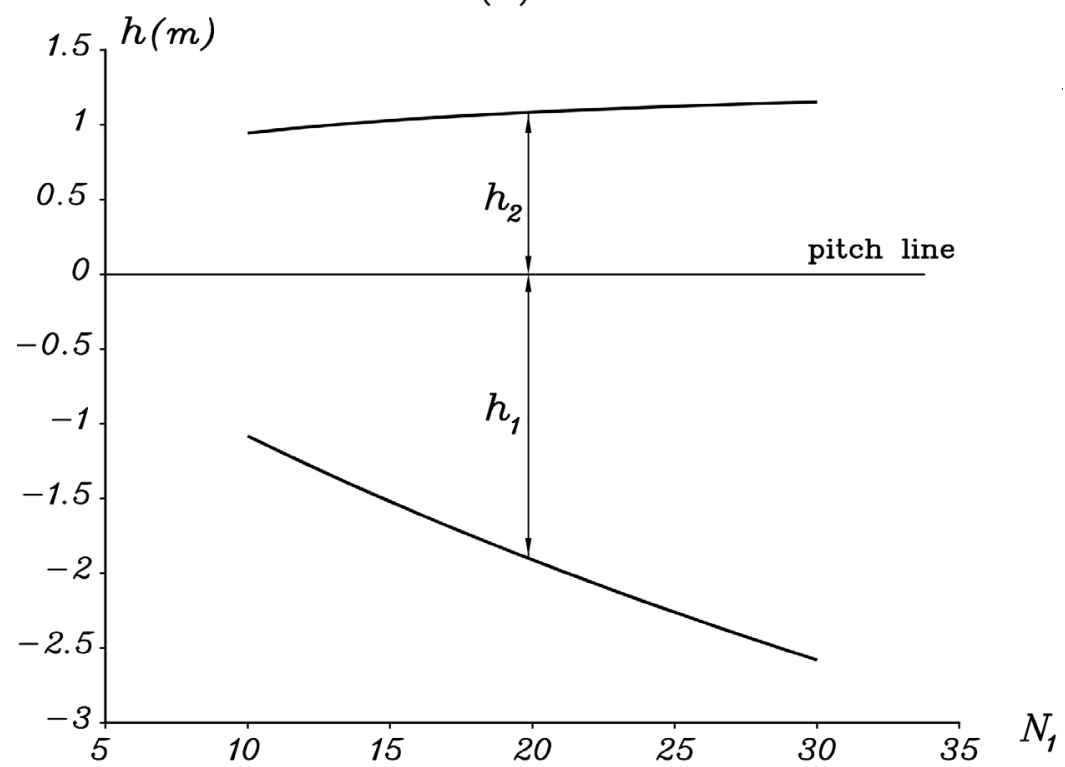

(b)

Figure 28.-Permissible dimensions $h_{1}$ and $h_{2}$ of rack-cutter. (a) Cross sections of pinion and rack-cutter. (b) Functions $h_{1}\left(N_{1}\right)$ and $h_{2}\left(N_{1}\right)$. 


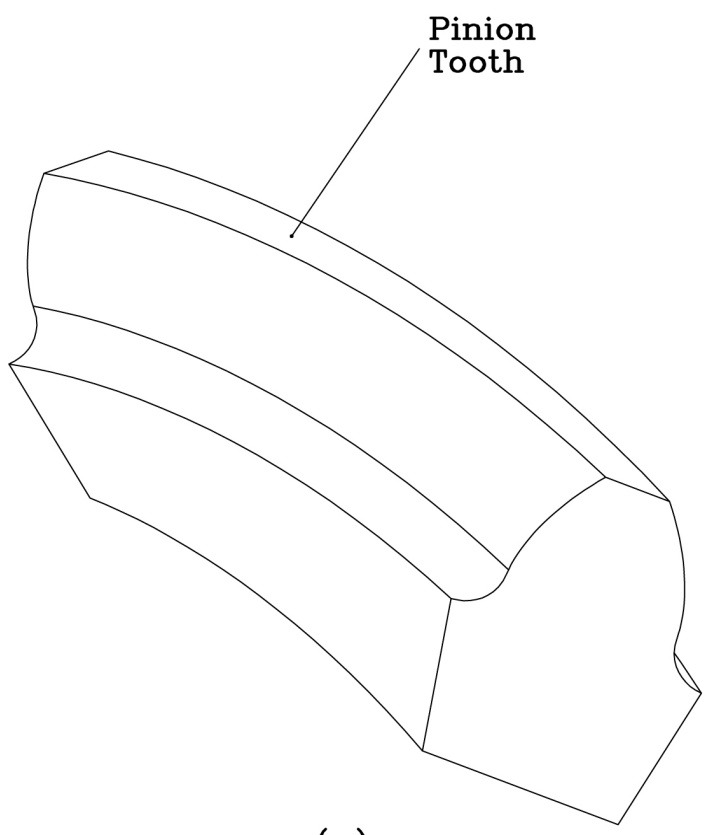

(a)

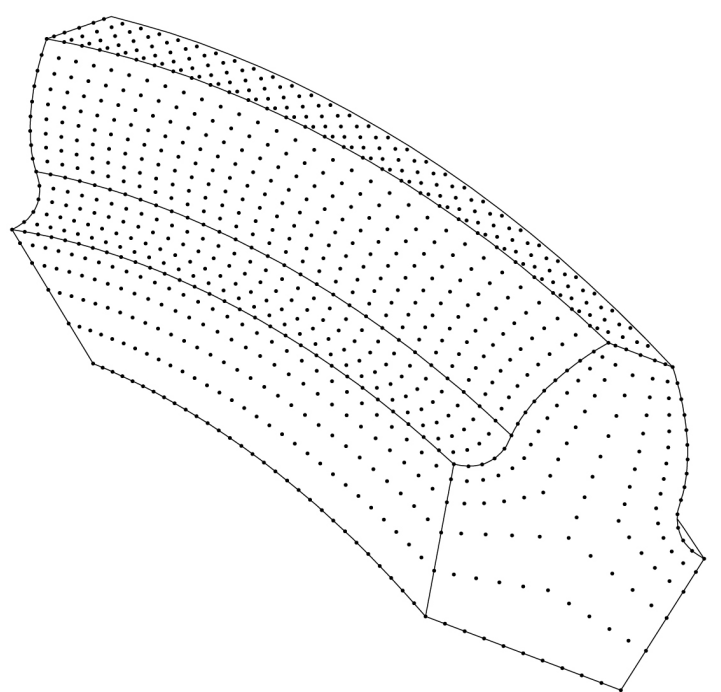

(c)

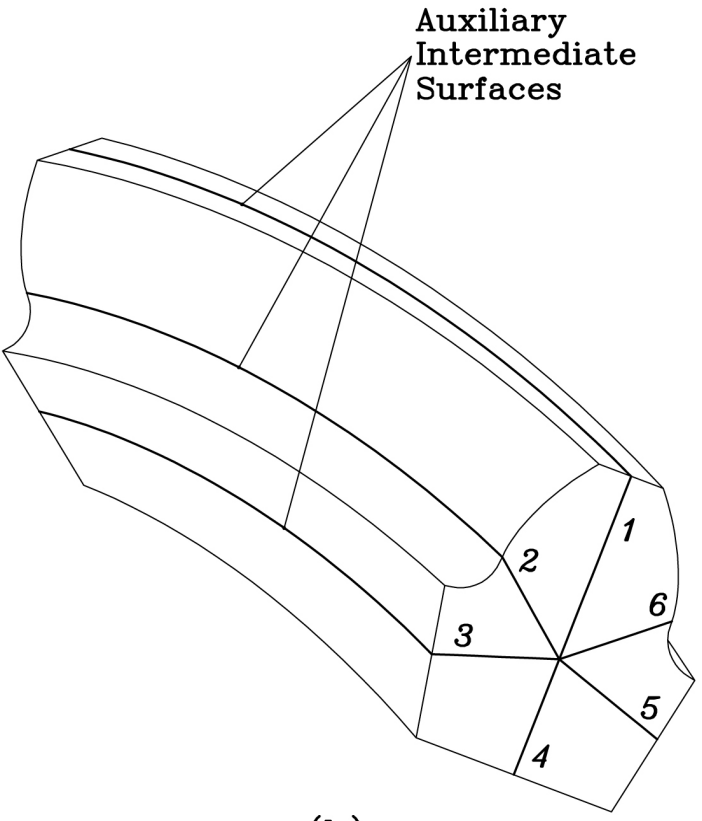

(b)

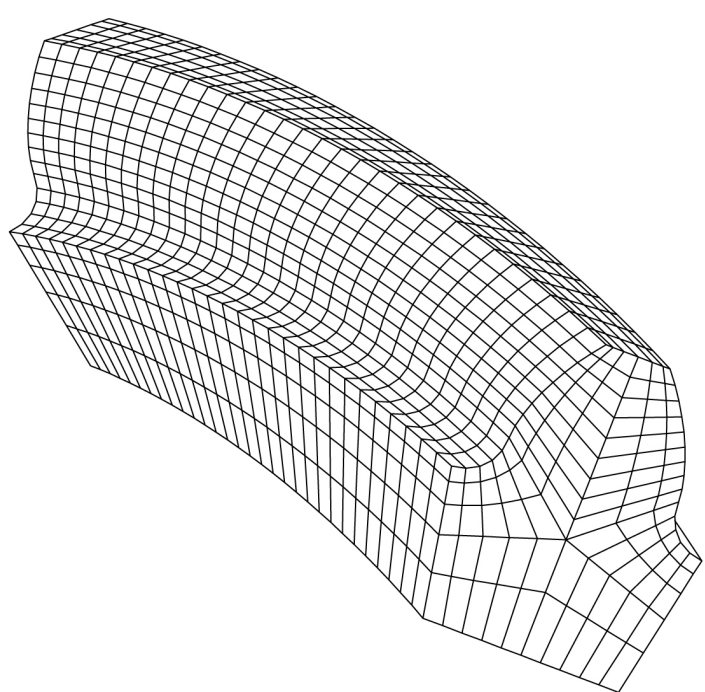

(d)

Figure 29.--Illustrations. (a) The volume of designed body. (b) Auxiliary intermediate surfaces. (c) Determination of nodes for the whole volume. (d) Discretization of the volume by finite elements. 


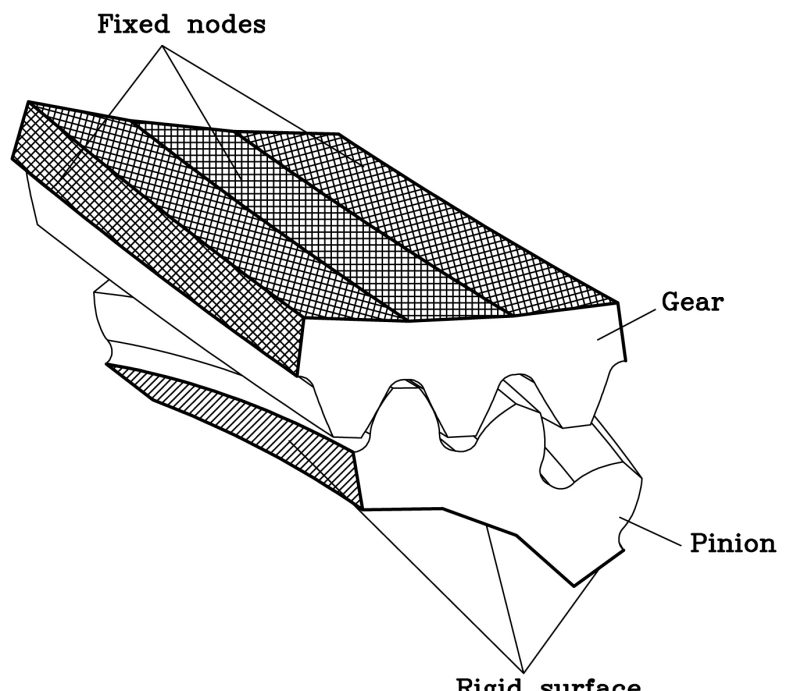

Rigid surface

(a)
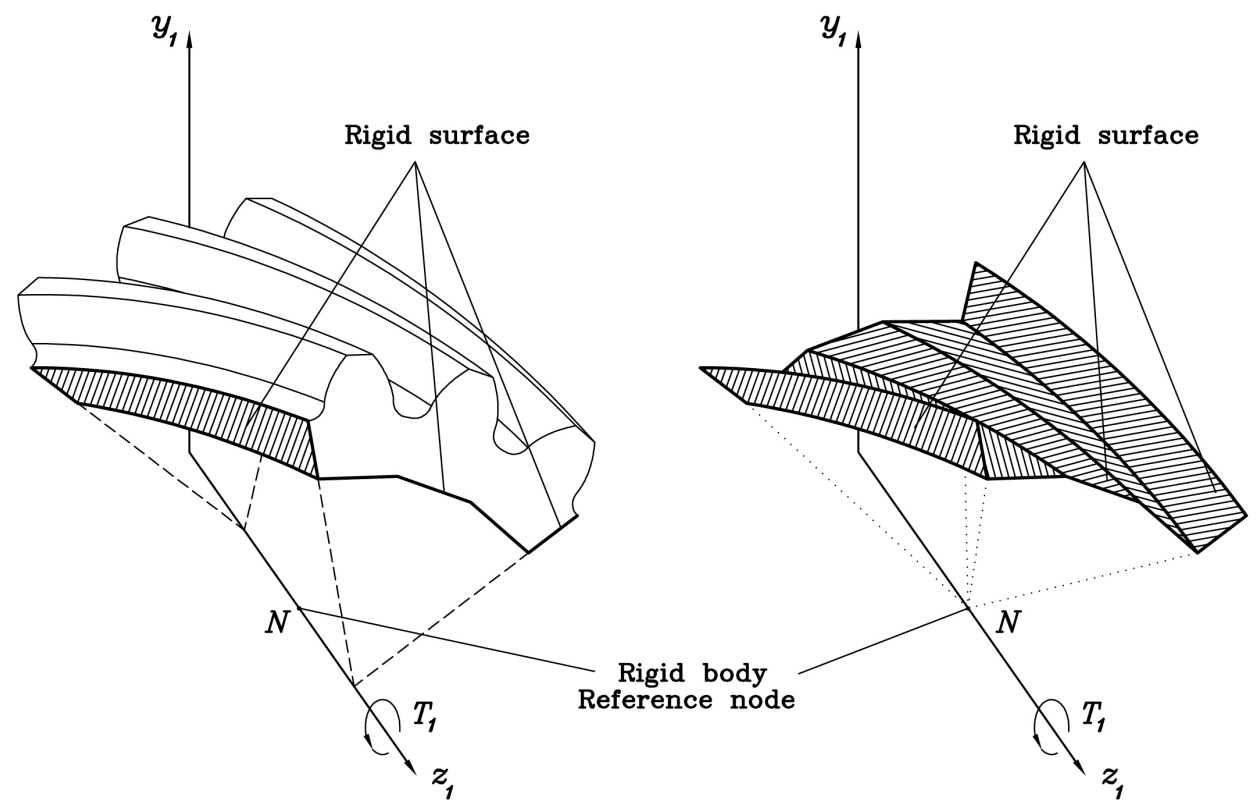

(b)

Figure 30.-Schematic illustration. (a) Boundary conditions for the pinion and the gear. (b) Rigid surfaces applied for boundary conditions of the pinion. 


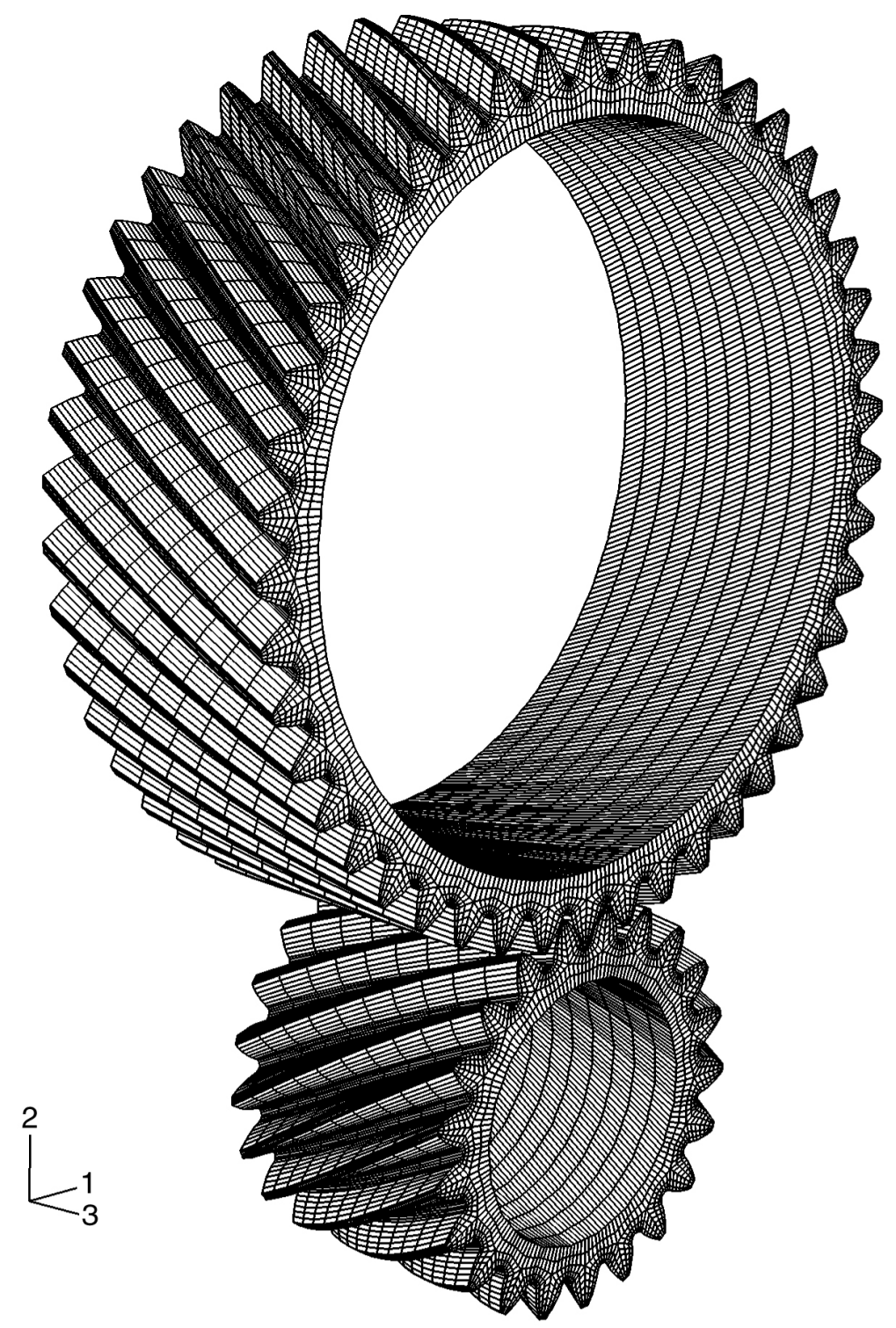

Figure 31.-Whole gear drive finite element model. 


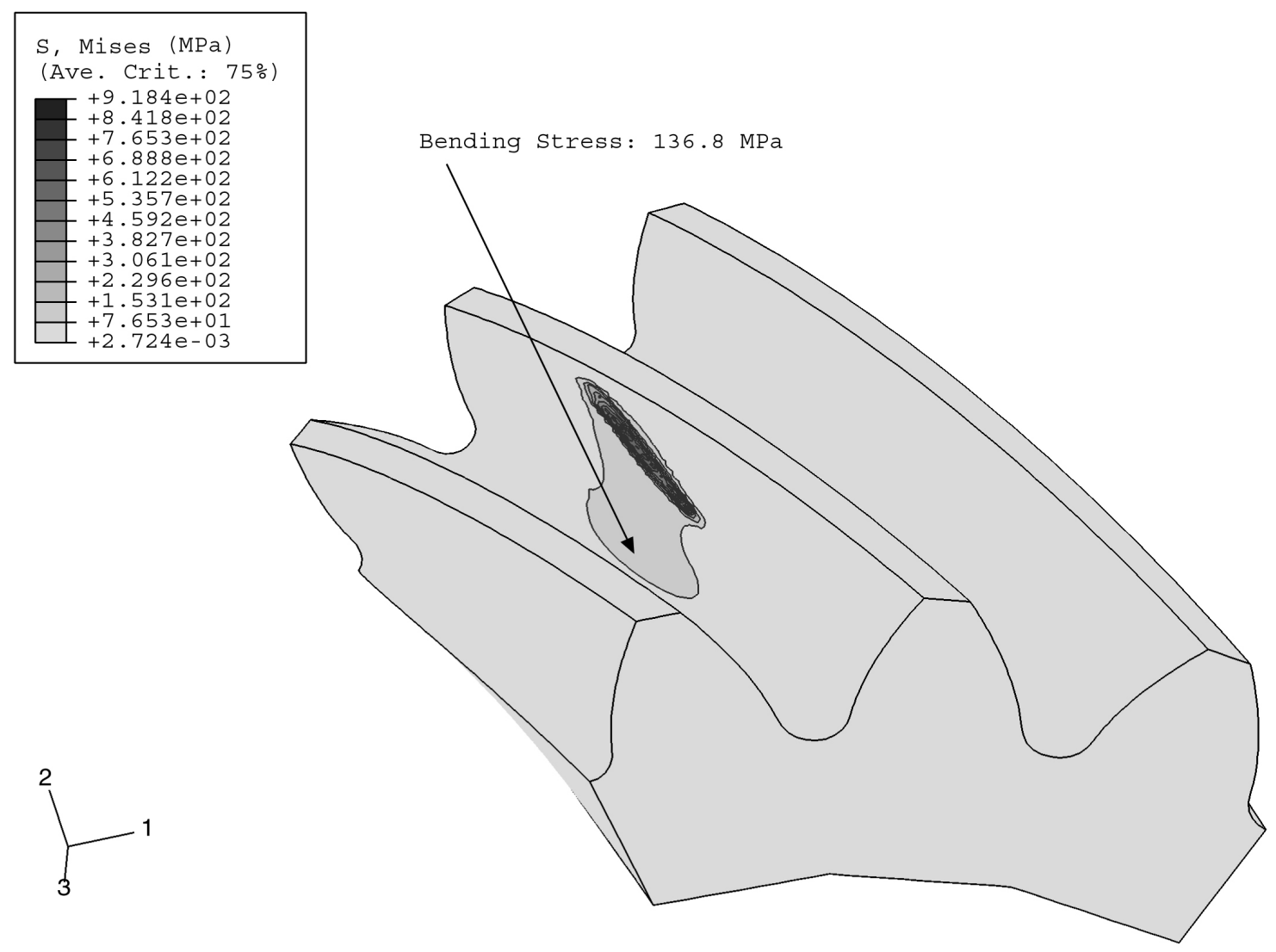

Figure 32.-Contact and bending stresses in the middle point of the path of contact on pinion tooth surface for modified involute helical gear drive wherein the generation is performed by plunging of the grinding worm. 


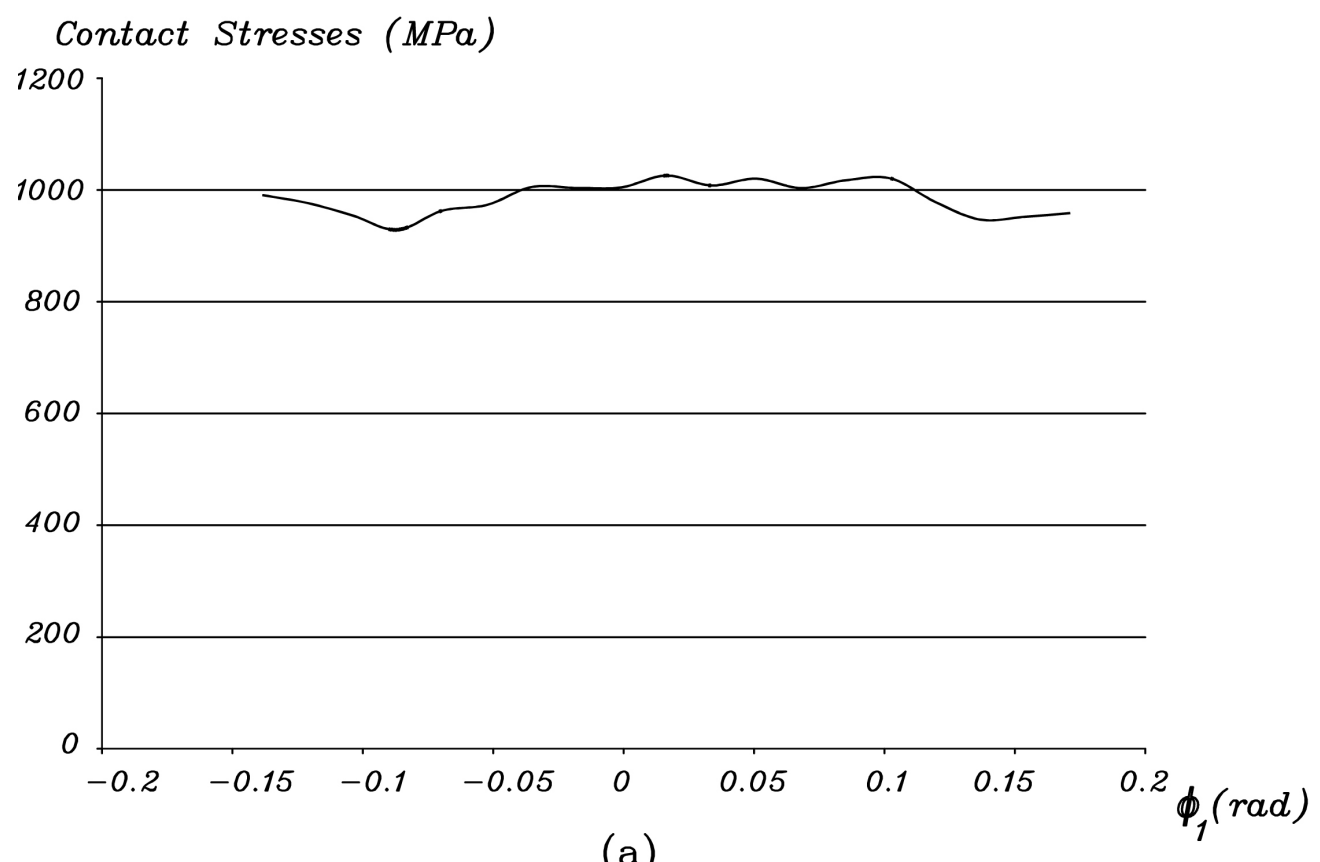

(a)

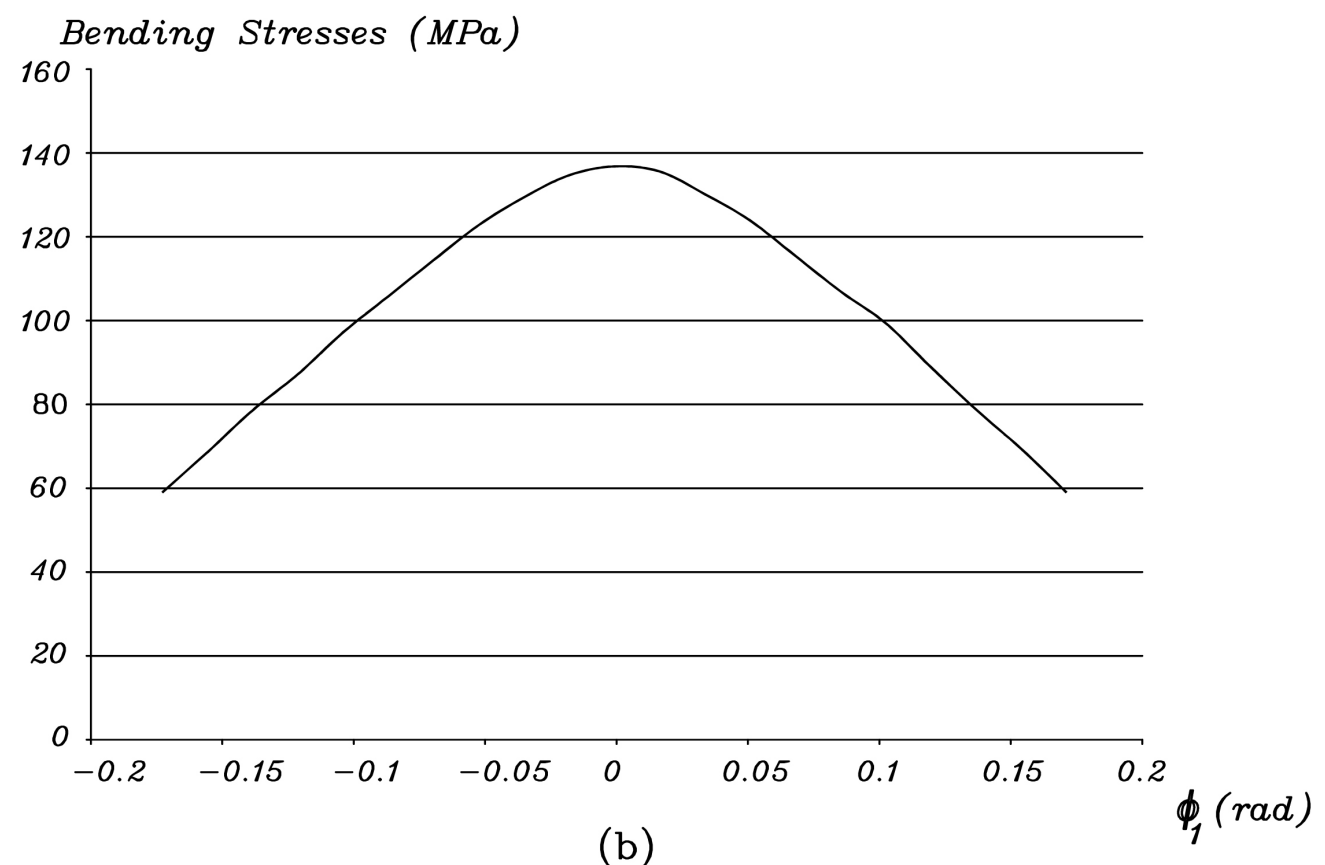

Figure 33.-Contact and bending stresses during the cycle of meshing of the pinion. 


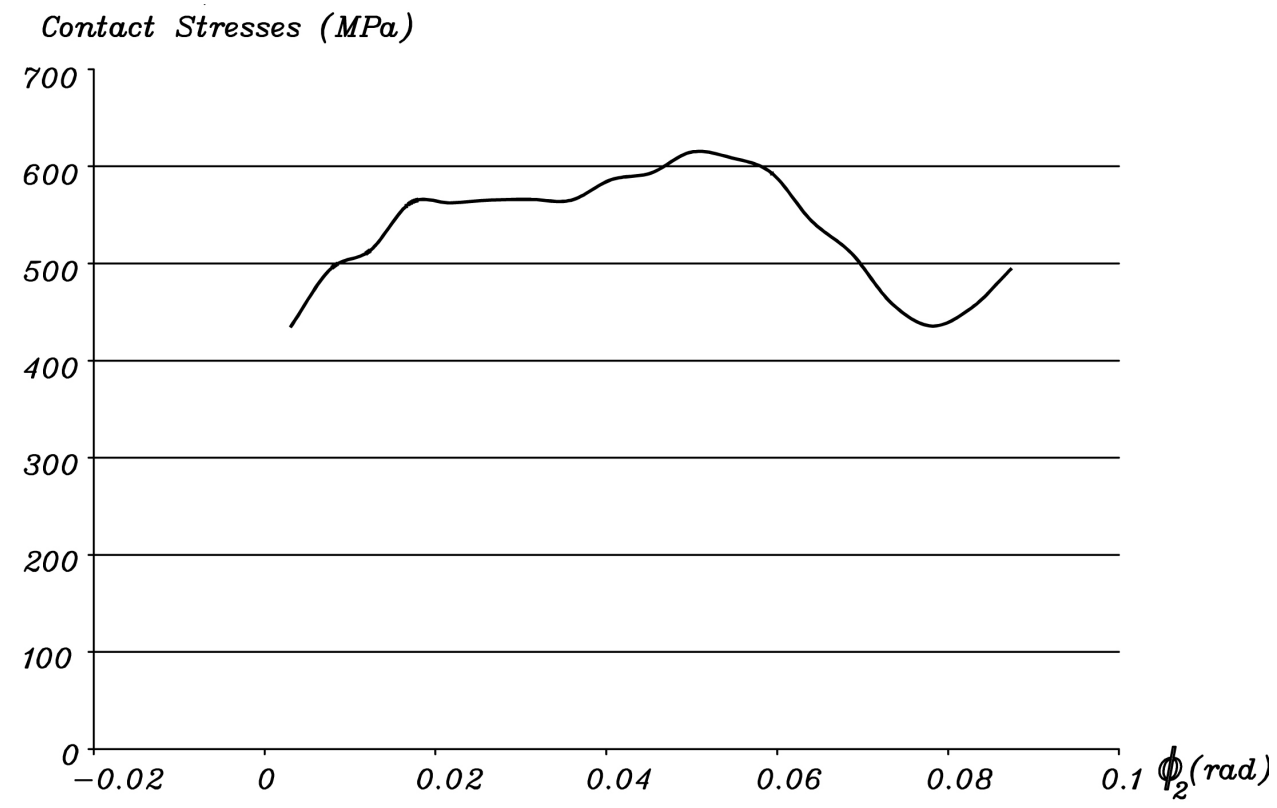

(a)

Bending Stresses (MPa)

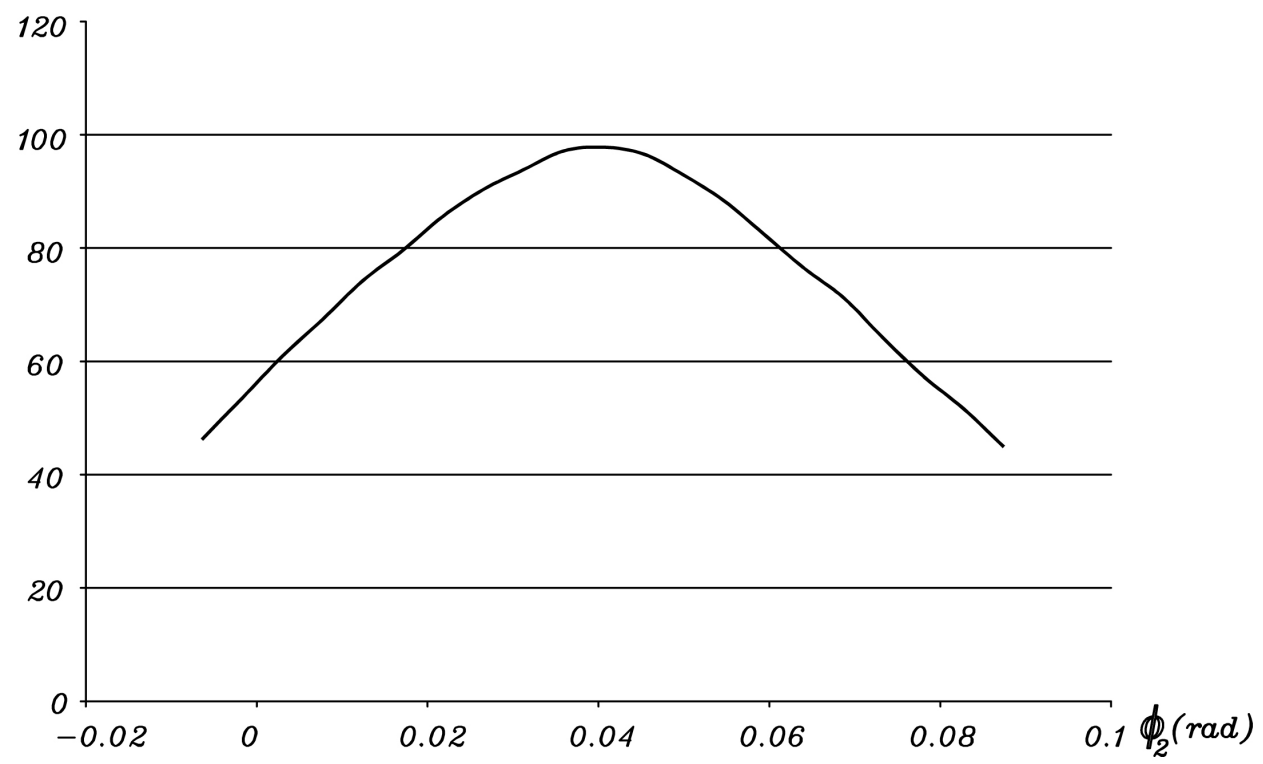

(b)

Figure 34.-Contact and bending stresses during the cycle of meshing of the gear. 


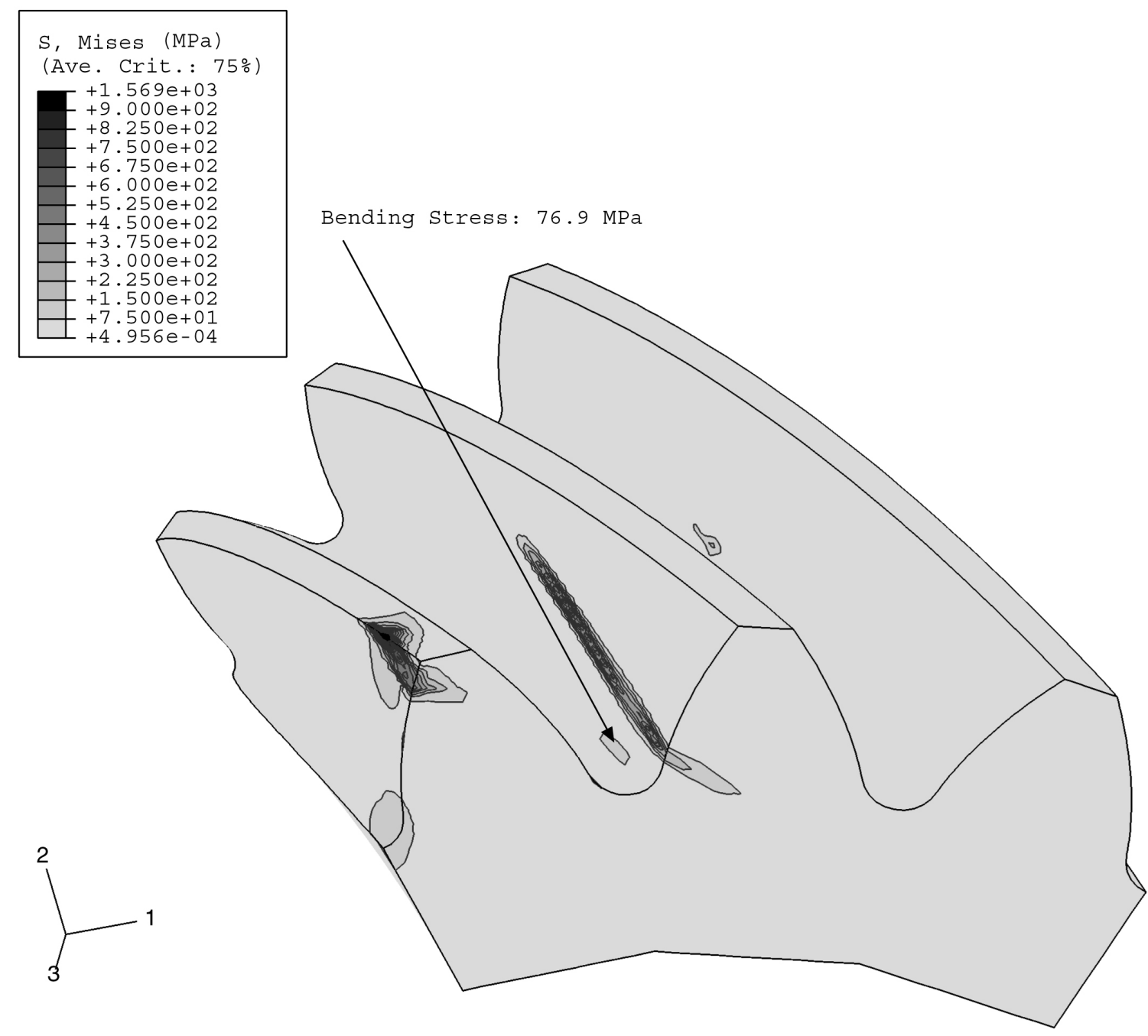

Figure 35.-Contact and bending stresses in the middle point of the path of contact on conventional involute helical pinion with error $\Delta \gamma=3$ arcmin: edge-contact with high stresses occurs. 


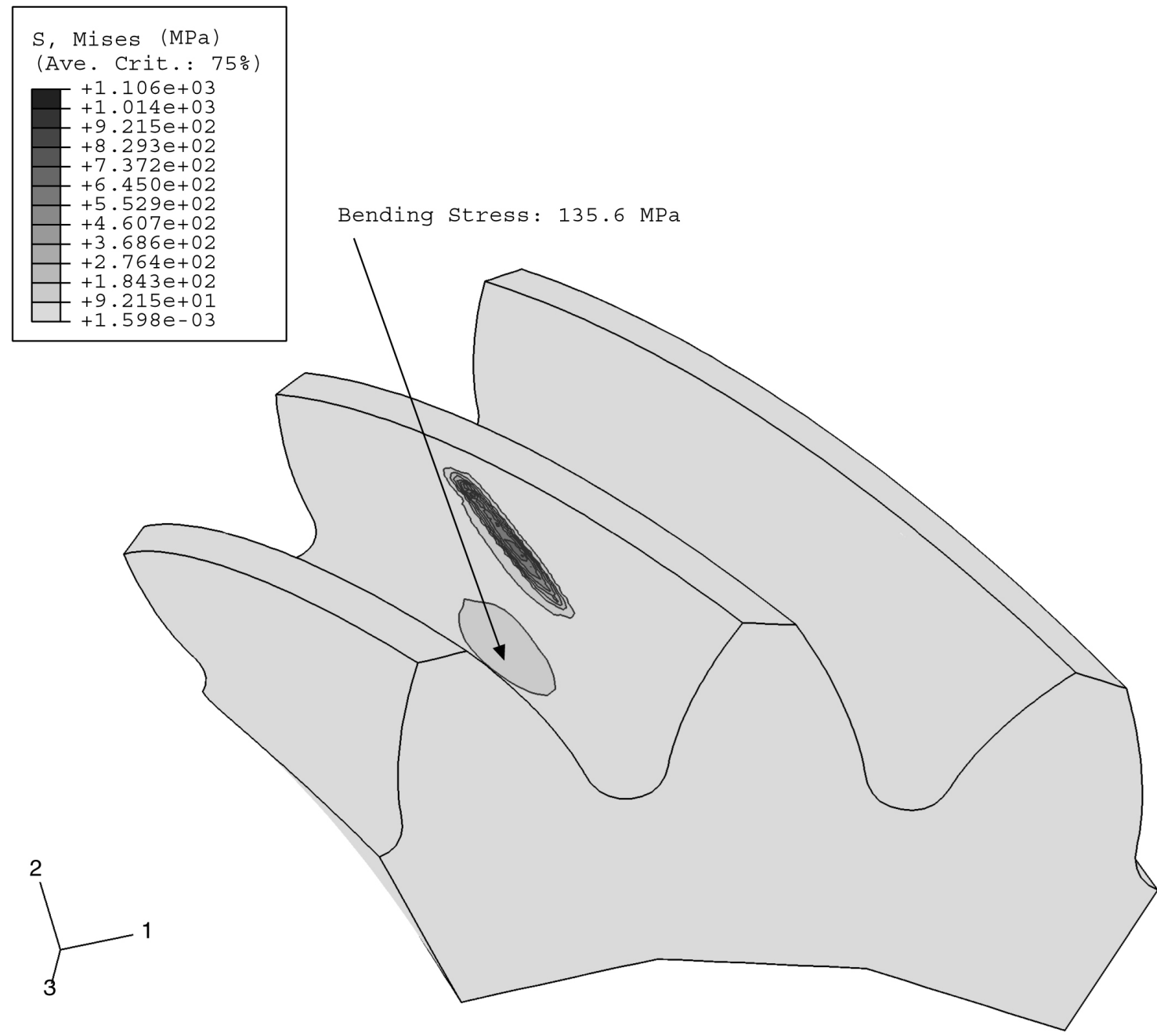

Figure 36.-Contact and bending stresses in the middle point of the path of contact on pinion tooth surface for modified involute helical gear drive wherein an error $\Delta \gamma=3$ arcmin is considered: edgecontact is avoided. 
Public reporting burden for this collection of information is estimated to average 1 hour per response, including the time for reviewing instructions, searching existing data sources, gathering and maintaining the data needed, and completing and reviewing the collection of information. Send comments regarding this burden estimate or any other aspect of this collection of information, including suggestions for reducing this burden, to Washington Headquarters Services, Directorate for Information Operations and Reports, 1215 Jefferson Davis Highway, Suite 1204, Arlington, VA 22202-4302, and to the Office of Management and Budget, Paperwork Reduction Project (0704-0188), Washington, DC 20503.

\begin{tabular}{|l|l|l}
\hline 1. AGENCY USE ONLY (Leave blank) & $\begin{array}{c}\text { 2. REPORT DATE } \\
\text { June } 2003\end{array}$ & $\begin{array}{c}\text { 3. REPORT TYPE AND DATES COVERED } \\
\text { Final Contractor Report }\end{array}$
\end{tabular}

4. TITLE AND SUBTITLE

5. FUNDING NUMBERS

Modified Involute Helical Gears: Computerized Design, Simulation of Meshing, and Stress Analysis

\section{6. $\operatorname{AUTHOR}(\mathrm{S})$}

Faydor L. Litvin, Alfonso Fuentes, Ignacio Gonzalez-Perez, Luca Carnevali, and Kazumasa Kawasaki

7. PERFORMING ORGANIZATION NAME(S) AND ADDRESS(ES)

University of Illinois at Chicago

835 South Wolcott Avenue

Chicago, Illinois 60612

WBS-22-708-28-02

NAG3-2450

1L162211A47A

8. PERFORMING ORGANIZATION REPORT NUMBER

E-13849

\section{SPONSORING/MONITORING AGENCY NAME(S) AND ADDRESS(ES)}

National Aeronautics and Space Administration

Washington, DC 20546-0001

and

U.S. Army Research Laboratory

Adelphi, Maryland 20783-1145
10. SPONSORING/MONITORING AGENCY REPORT NUMBER

NASA CR-2003-212229

ARL-CR-514

11. SUPPLEMENTARY NOTES

Faydor L. Litvin, Ignacio Gonzalez-Perez, Luca Carnevali, and Kazumasa Kawasaki, University of Illinois at Chicago, Chicago, Illinois 60612; Alfonso Fuentes, Polytechnic University of Cartagena, Cartagena, Spain. Project Manager, Robert Handschuh, U.S. Army Research Laboratory, NASA Glenn Research Center, organization code 5950, 216-433-3969.

12a. DISTRIBUTION/AVAILABILITY STATEMENT 12b. DISTRIBUTION CODE

Unclassified - Unlimited

Subject Category: 37

Distribution: Nonstandard

Available electronically at http://gltrs.grc.nasa.gov

This publication is available from the NASA Center for AeroSpace Information, 301-621-0390.

13. ABSTRACT (Maximum 200 words)

The computerized design, methods for generation, simulation of meshing, and enhanced stress analysis of modified involute helical gears is presented. The approaches proposed for modification of conventional involute helical gears are based on conjugation of double-crowned pinion with a conventional helical involute gear. Double-crowning of the pinion means deviation of cross-profile from an involute one and deviation in longitudinal direction from a helicoid surface. Using the method developed, the pinion-gear tooth surfaces are in point-contact, the bearing contact is localized and oriented longitudinally, and edge contact is avoided. Also, the influence of errors of aligment on the shift of bearing contact, vibration, and noise are reduced substantially. The theory developed is illustrated with numerical examples that confirm the advantages of the gear drives of the modified geometry in comparison with conventional helical involute gears.

\begin{tabular}{|l|l|l|}
\hline $\begin{array}{l}\text { 14. SUBJECT TERMS } \\
\text { Transmissions; Gears }\end{array}$ & $\begin{array}{c}\text { 19. SECURITY CLASSIFICATION } \\
\text { OF ABSTRACT } \\
\text { Unclassified }\end{array}$ \\
$\begin{array}{c}\text { 17. SECURITY CLASSIFICATION } \\
\text { OF REPORT } \\
\text { Unclassified }\end{array}$ & $\begin{array}{c}\text { 18. SECURITY CLASSIFICATION } \\
\text { OF THIS PAGE } \\
\text { Unclassified }\end{array}$ &
\end{tabular}

15. NUMBER OF PAGES 67

16. PRICE CODE 20. LIMITATION OF ABSTRACT 